\title{
III Congresso Brasileiro de Fisioterapia Aquática
}

Fisioterapia aquática, da clínica à evidência científica

7 a 9 de setembro de 2018, Recife/PE

Associação Brasileira de Fisioterapia Aquática (ABFA)

Presidente do III CBFA

Rogério Azevedo Antunes Pereira (PE) rogerioantunes10@hotmail.com

Presidente da ABFA

Rômulo Nolasco de Brito (SC) romulonolascobrito@gmail.com

Presidente da comissão científica

Wellington Pinheiro de Oliveira (PA) wellfisio@yahoo.com.br

\section{Comissão científica}

Flávia Gomes Martinez (RS) fla.gmartinez@gmail.com Jefferson Rosa Cardoso (PR) jeffcar@hotmail.com

Mariana Arias Ávila Vera (SP) maafisio01@gmail.com

Maurício Koprowski Garcia (SP) mauriciokg@uol.com.br Suraya Gomes Novais Shimano (MG) surayagnovais@gmail.com Valéria C. Passos de Carvalho (PE) valeriapassos@gmail.com Wellington Pinheiro de Oliveira (PA) wellfisio@yahoo.com.br

Comissão organizadora

Giovana Linhares (MG)

João Douglas Gil (SP)

Lisiane Fabris (SC)

Maurício Koprowski Garcia (SP)

Rita de Cássia Paula Souza (SC)

Rogério Azevedo Antunes Pereira (PE)

Rômulo Nolasco de Brito (SC)

\section{Avaliadores de trabalhos científicos}

Flávia Gomes Martinez (RS)

Rita de Cássia Paula Souza (SC)

Modalidade Pôster

Ana Paula de Lima Ferreira (PE)

Ediléa Monteiro de Oliveira (PA)

Fábio Jakaitis (SP)

Fernando Calixto (DF)

Laisa Liane Paineiras Domingos (RJ)

Mariana Arias Ávila Vera (SP)

Maurício Koprowski Garcia (SP)

Priscila Helena Vanin Alves de Souza Matias (AL)

Raphael Fernando Soares Gonçalves (PR)

Rômulo Nolasco de Brito (SC)

Suraya Gomes Novais Shimano (MG)

Valéria C. Passos de Carvalho (PE)

Wellington Fabiano Gomes (MG)

Wellington Pinheiro de Oliveira (PA) 
É com grande satisfação que Ihes apresentamos os Anais do III Congresso Brasileiro de Fisioterapia Aquática. Os trabalhos apresentados neste suplemento representam o esforço e dedicação dos profissionais, pesquisadores e acadêmicos empenhados no crescimento e desenvolvimento da Fisioterapia Aquática no Brasil. Estamos honrados em participar de mais esta etapa da construção e valorização do conhecimento produzidos sobre a Fisioterapia Aquática e compartilhados por todos, ao submeterem suas pesquisas e experiências. Agradecemos a todos pela participação como congressista, palestrante, organizador ou apresentador, pois sua contribuição foi fundamental para realização deste evento. Com o olhar na Fisioterapia Aquática baseada nas evidências científicas e vivenciada na clínica. Bem-vindos a Recife!

\section{Wellington Pinheiro de Oliveira \\ Presidente da Comissão Científica do III CBFA}

É com muita honra e prazer que estou como presidente do III CBFA, e como anfitrião quero dizer que não pouparemos esforços, eu e todas as comissões, para que todos os participantes tenham uma experiência maravilhosa no Recife. Iremos da máxima evidência científica à rotina de atendimentos em clínica e empreendedorismo, porém, não poderia me furtar em não falar da parte social, momento ímpar de troca de informações e estreitamento dos laços entre pessoas de todas as regiões do Brasil. O Recife é muito rico culturalmente e estaremos na belíssima praia de Boa Viagem, em um auditório panorâmico de frente para o mar. Não perca esta grande oportunidade de se atualizar numa das áreas que mais cresce na Fisioterapia. Estamos esperando vocês de braços abertos!

\section{Rogério Azevedo Antunes Pereira}

Presidente do III CBFA

Caríssimas(os) associados, profissionais, professores, alunos, pesquisadores e estudiosos em Fisioterapia Aquática, com muita alegria apresentamos neste volume especial, os resultados de toda a produção técnico-científica do III Congresso Brasileiro de Fisioterapia Aquática (III CBFA, 2018, Recife/PE). Desta maneira, temos a grande oportunidade de tornar ainda mais público e materializado neste rico material, os assuntos abordados nas palestras e mesas redondas com um único objetivo: firmar nosso compromisso com os associados e com a comunidade no intuito de fortalecer o discurso acerca da caracterização da Fisioterapia Aquática, indicações e recomendações terapêuticas do exercício aquático terapêutico, aplicações de métodos e técnicas a luz da prática clínica e evidências disponíveis, bem como de temas específicos relacionados ao ensino em Fisioterapia e em Fisioterapia Aquática, gestão e infraestrutura de serviços de Fisioterapia Aquática.

Estamos juntos neste crescente e fantástico movimento da Fisioterapia Aquática e graças a sua participação, estamos evoluindo e proporcionando à população e comunidade acadêmica, publicações científicas e avanços significativos nesta especialidade reconhecida pelo Conselho Federal de Fisioterapia Aquática desde 2014 (Res. COFFITO n. 443/2014).

Aproveite o material!!! Foi todo pensado e organizado para você!

E se ainda não é associado(a) da ABFA, não deixe para depois. Acesse o site www.abfaquatica.com.br, associe-se e comece a fazer parte desta associação, dos benefícios, descontos em cursos de extensão, cursos de pós-graduações e eventos apoiados pela ABFA. Quer mais? Além disto, sendo associado(a), terá a segurança e apoio representativo da ABFA para todos assuntos e demandas relacionadas a especialidade e exercício profissional. Continue contando conosco. Fraterno abraço!

\section{Rômulo Nolasco De Brito}

Presidente da ABFA

Associação Brasileira de Fisioterapia Aquática 


\section{Sumário}

Palestras.

Exercícios aquáticos na dor neuropática: evidências científicas .....................................4

Exercícios em água funda: evidências científicas e prática clínica ....................................4

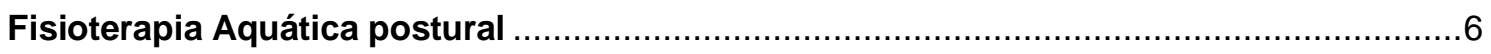

Fisioterapia Aquática em crianças com síndrome de Down ..........................................

Um mergulho na escuridão: fisioterapia aquática para deficientes visuais ...................... 8

Conceito Halliwick: inclusão e participação através das atividades aquáticas funcionais. 8

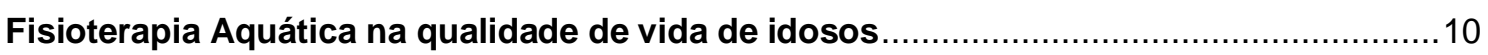

Benefícios da Fisioterapia Aquática no período gestacional: evidências científicas ........10

Efeitos do método Watsu sobre o nível de estresse pós-traumático (TEPT) em vítimas de

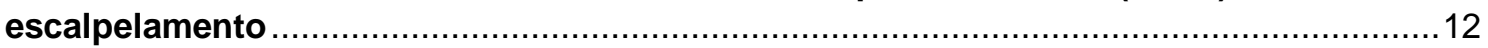

Fisioterapia Aquática aplicada ao paciente crítico/alta complexidade .............................12

Desafios e contribuições da reabilitação aquática na recuperação funcional de militares

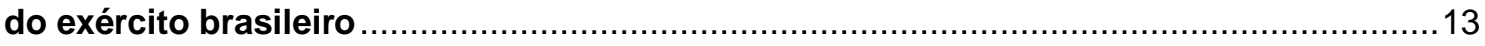

Eletromiografia e acelerometria para análise da marcha aquática no Parkinson ...............14

Fisioterapia Aquática em lesões complexas de membros inferiores ..............................15

Panorama da Fisioterapia Aquática em Pernambuco na assistência às crianças com

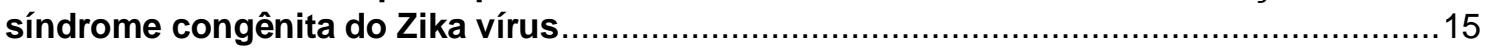

Uso da acelerometria na quantificação de carga durante o exercício aquático .................16

Atuação da Fisioterapia Aquática na vertigem postural paroxística benigna....................17

Fisioterapia Aquática na prevenção e recovery de atletas paralímpicos .........................18

Fisioterapia Aquática nos diversos tipos de encefalopatia crônica não progressiva ........18

Nada melhor: estimulação aquática para bebês ........................................................19

A Fisioterapia Aquática aplicada ao atleta de alto rendimento......................................20

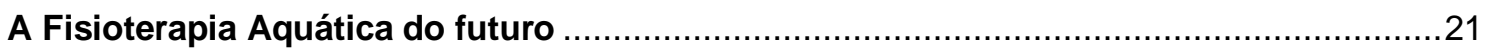

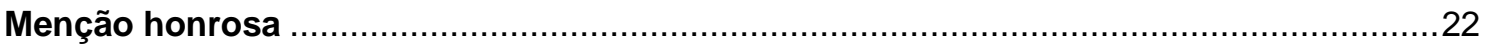

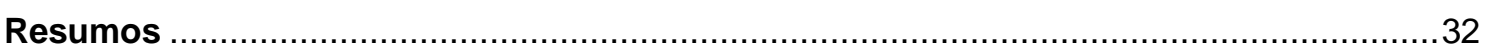


Palestras

\title{
Exercícios aquáticos na dor neuropática: evidências científicas
}

\author{
Rômulo Nolasco de Brito
}

\author{
Universidade do Sul de Santa Catarina - UNISUL
}

A fisioterapia aquática como especialidade tem sido reconhecida há décadas pelos seus resultados científicos e clínicos. Pode-se se destacar 3 pilares: um relacionados aos efeitos das propriedades físicas e respostas fisiológicas e terapêuticas; outro pelos benefícios dos métodos e técnicas como Bad Ragaz, Watsu® e Halliwick, por exemplo; e, por fim, aos resultados obtidos e relatados pela literatura quanto a recuperação funcional, equilíbrio, mobilidade, marcha, força e no manejo da dor (analgesia). Considerando este último resultado, tratamento da dor, e em especial a dor crônica / neuropática, o objetivo desta palestra foi apontar as evidências da intervenção fisioterapêutica em ambiente aquático, do exercício aquático terapêutico a partir de estudos pré-clínicos e clínicos. Destaca-se aqui o efeito térmico, que é o resultado do calor, atua de quatro maneiras, vasodilatação, mecanismo de controle / comporta da dor, elevação dos níveis de beta-endorfina e relaxamento muscular. $\mathrm{O}$ efeito mecânico pode ser descrito como estímulos hidromecânicos da água adaptados às partes do corpo e à pressão hidrostática da água na pele. $\mathrm{Na}$ imersão em água aquecida, o seu efeito anti-hiperalgésico é mediado, pelo menos em parte, através dos receptores opióides periféricos, adenosina (A1) e canabinoide (CB2). Em relação ao exercício na água, libera opioides endógenos como encefalina, endorfina e outros que são responsáveis pela hiponocicepção. Exercício resulta em um aumento na ativação de neurotransmissores (dopamina, noradrenalina e serotonina) que tipicamente são reduzidos nos pacientes com depressão. Exercício aquático de alta intensidade evita a nocicepção e a hiperalgesia induzida por Glu e que os receptores CB1, opióides e A1 da coluna vertebral têm participação nesse efeito. Os receptores periféricos $A 1$ e opióide, mas não CB1, também estão envolvidos no efeito hiponociceptivo do exercício. O exercício físico pode ativar várias vias através que compartilham o mesmo mecanismo endógeno (inibição da fosforilação da PKA). Identifica-se ainda, efeitos positivos do exercício terapêutico aquático no tratamento da sintomatologia dolorosa nos pacientes com fibromialgia, osteoartrite, hérnia de disco e dor lombar e síndromes dolorosas pós afecções do SNP e SNC.

\section{Exercícios em água funda: evidências científicas e prática clínica}

\section{Flávia Gomes Martinez}

\section{Universidade Federal do Rio Grande do Sul - UFRGS}

A profundidade das piscinas influencia a prescrição e execução de procedimentos em fisioterapia aquática. Exercícios em água funda podem ser excelentes alternativas para a fisioterapia aquática. A expansão do mercado de trabalho, a necessidade de trabalhar com pacientes em grupos e o manejo de custos estimulam a utilização de técnicas de caminhada e corrida em água funda (deep water) para pacientes em tratamento com fisioterapia aquática, bem como em sessões das modalidades conhecidas como Jogging Aquático e Hidropostural. O Jogging Aquático ou Deep Water Running é uma modalidade que foi utilizada inicialmente para indivíduos com problemas de coluna e membros inferiores. Desenvolvida e divulgada na América do Norte na década de 90 por Mary Sanders, ela vem sendo muito utilizada no Sul do Brasil como programa de atividade física em grupos para idosos, pessoas com afecções musculoesqueléticas, bem como problemas metabólicos crônicos, onde muitas pesquisas fisiológicas, biomecânicas e funcionais são realizadas (Kruel, GPAT, UFRGS, década de 90). Recentemente pesquisas com pacientes neurológicos e sujeitos com Parkinson foram iniciadas com essa modalidade. Pesquisas demonstram que a água funda pode ser utilizada com êxito em treinamento desportivo de alto rendimento, com menores frequências cardíacas para gasto 
energético semelhante a atividades em ambiente seco. Um aspecto importante para a execução de exercícios em água funda é a adaptação dos pacientes ao meio líquido e a utilização de implementos seguros para flutuação. Em geral são utilizados cinturões pélvicos flutuantes e/ou tubos de etaflon, mas sua instabilidade ou mal posicionamento estimularam o desenvolvimento de vestes flutuantes que garantem mais estabilidade estática e dinâmica do corpo. Muitas evidências científicas têm auxiliado na compreensão de efeitos biomecânicos, fisiológicos e terapêuticos dos exercícios em água funda, sobretudo a corrida e a caminhada com as técnicas conhecidas como high knee e cross country. Investigações biomecânicas: variáveis cinemáticas e neuromusculares (cinemetria e EMG), com uso de variáveis fisiológicas $\left(\mathrm{VO}_{2}, \mathrm{FC}, \mathrm{FR}, \mathrm{PAS}\right.$, marcadores bioquímicos), além de ensaios clínicos randomizados. $s$ grupos de pesquisadores mais frequentes em publicações na área são do: Japão, Brasil, EUA, Espanha, UK, Itália e Portugal. Estudos dos anos 90 e 2000 buscavam entender as respostas fisiológicas de atividades aquáticas em água funda e as possibilidades de utilização como treinamento de alta performance. Já na última década, além de pesquisas com marcadores bioquímicos e variáveis fisiológicas, biomecânicas e neuromusculares, muitos ensaios clínicos foram realizados, demonstrando a efetividade da caminhada ou corrida em água funda para a melhoria de qualidade de vida, dor e funcionalidade de pacientes com fibromialgia, câncer, osteoartrite, lombalgia e dor crônica. Dentre os achados agudos e crônicos da corrida em água funda destacam-se: menores níveis de $\mathrm{FC}, \mathrm{VO}_{2}$, lactato e $\mathrm{CK} /$ menor resposta S. simpático, menores níveis de adrenalina, cortisol e marcadores anti-fibrinogênicos, alterações em respostas cinemáticas e neuromusculares, redução da PAS e melhora dos níveis de marcadores imunoendócrinos: adiponectina sérica, IL10, TNF- CD8 e células T. Já as pesquisas que investigam efeitos crônicos, citamos redução de dor, fadiga e risco de quedas e ganhos funcionais (lombalgia, AVC, fibromialgia, câncer, hipertensão, síndrome metabólica, diabetes, obesidade, osteoartrite), ganho de força, flexibilidade, equilíbrio e qualidade de vida, bem como regulação da FC e PAS. As pesquisas com uso da eletromiografia também têm tido destaque, sobretudo comparando técnicas de caminhada e corrida em água funda, com resultados mostrando variação de comportamento emg conforme técnica de DWR (HK ou CC) e diferenças cinemáticas em tronco, pelve, quadris e joelhos entre elas. e maior atividade de reto femoral, bíceps femoral, glúteo máximo, glúteo médio, paravertebrais, conforme a técnica e velocidade. Menor atividade de sóleo e gastrocnêmios (menor demanda de propulsão vertical) em relação à locomoção em ambiente seco também foi encontrado. Embora existam perspectivas promissoras quanto á aplicação de exercícios terapêuticos em água funda, ainda há problemas a serem superados. Dentre eles, a execução de exercícios em água funda pode ser muito variada e encontramos barreiras para a correção, há problemas com estabilidade do corpo, o cinturão nem sempre fica bem posicionado, podendo haver diferentes posições do corpo e cinemática articular de Msls que pode diferir muito de sujeito a sujeito, o que leva a diferentes ativações musculares e diferentes estratégias de propulsão. Conforme o caso, a adequação dessas variáveis deve ser realizada. Estratégias de correção devem ser melhor desenvolvidas, enquanto a Escala de Borg segue sendo um bom instrumento para obtenção do esforço subjetivo dos pacientes. As alternativas de exercícios em água funda envolvem exercícios posturais, treinamento em circuitos, treinamento intervalado, exercícios localizados compensatórios, exercícios tônico-posturais e de estabilização, flexibilidade. Mais estudos são necessários e a UFRGS tem desenvolvido estudos com cinemetria, ergoespirometria, acelerometria, termografia, US e EMG, além de Pesquisa multicêntrica para pacientes com Parkinson, com diferentes intervenções: Caminhada nórdica, dança e jogging aquático. Para essas pesquisas tem sido utilizadas variáveis dependentes funcionais, qualitativas, biomecânicas e neuromusculares. Como perspectivas futuras, mais ensaios clínicos, com diferentes populações, diferentes tipos de exercícios, diferentes dispositivos de suporte e novos implementos são necessários. Para modelos de periodização, pesquisas com modelos animais e pesquisas básicas com marcadores bioquímicos, investigações robustas com variáveis biomecânicas e neuromusculares são necessárias. 


\title{
Fisioterapia aquática postural
}

\author{
Lisiane Fabris
}

\section{ProAcqua Fisioterapia Aquática, Método Inteligência Postural "Agradecimento ao CREFITO-10 pelo apoio e incentivo ao crescimento científico"}

Segundo o American Posture Institute (2018), a postura é a forma como o corpo se orienta e se estabiliza no espaço, independentemente se está estático ou realizando algum movimento dinamicamente. Em suma, é como o corpo se equilibra. Assim, ao se analisar a postura, é fundamental identificar como o corpo se sustenta em relação à força gravitacional e como a musculatura antigravitacional realiza a sustentação das estruturas ósseas, sobretudo, da coluna vertebral, pois o controle neuromuscular é essencial à estabilidade de tronco e, consequentemente, à produção de movimentos. Portanto, uma avaliação fisioterapêutica prévia à Fisioterapia Aquática, deve abordar: o estado das estruturas ósseas, a marcha, a palpação para identificação de disestesia, pele e tecidos subcutâneos, dor, amplitudes de movimentos, capacidades funcionais e exames diagnósticos por imagem. A boa postura ocorre quando há harmonia entre as estruturas ósseas e musculares para que, em conjunto, suportem e protejam o corpo contra lesões/ou deformidades que podem progredir ao longo do tempo, causando complicações graves. Dentre as principais causas de alterações posturais, estão: movimentos repetitivos ocupacionais, sedentarismo, períodos prolongados na posição sentada, postura flexora dominante, carregamento incorreto de pesos, sentar-se sobre a carteira e cruzar as pernas, traumas físicos, sapatos inadequados, postura inadequada para dormir e as patologias congênitas ou adquiridas. Todos esses fatores podem acarretar um desequilíbrio entre as cadeias musculares anterior e posterior, as quais são conjuntos de músculos de mesma direção e sentido, comportando-se como um músculo único. Como complicações relevantes das alterações posturais encontram-se: sobrecarga articular, enrijecimento das articulações vertebrais, retrações miofasciais, encurtamento musculares, alterações, disfunções ou incapacidades funcionais. As fibras musculares responsáveis pela manutenção postural são as vermelhas, S (slow), ou do tipo I. Como tais fibras são curtas e de contração lenta, necessitam constantemente de relaxamento, alongamento e fortalecimento, a fim de favorecer o equilíbrio entre as cadeias musculares. Dessa forma, o ambiente aquático torna-se excelente para a promoção da saúde postural, pois o empuxo alivia o peso corporal, o relaxamento da cadeia muscular antigravitacional e a liberação miofascial quando na posição horizontal do corpo. Já com o corpo na posição vertical, tem-se um recrutamento das fibras tônicas, visto que a flutuação oportuniza instabilidade, de acordo com o nível de profundidade, a qual recruta, para a manutenção do equilíbrio do corpo ao "lutar" contra a flutuação, as fibras motoras tônicas antigravitacionais, promovendo o fortalecimento muscular, sobretudo pela ativação do "core", o qual também pode ser obtido pela resistência ao movimento proporcionada pela viscosidade da água. Dentre os preceitos, métodos e técnicas fisioterápicas relevantes para o tratamento hidrocinesioterapêutico das disfunções posturais estão: Bad Ragaz, as rotações do método Halliwick, Water Pilates, a Hidroativação, a tração vertebral horizontal com lastros, Watsu, os alongamentos e as liberações miofasciais. 


\title{
Fisioterapia aquática em crianças com síndrome de Down
}

\author{
Priscila Helena Vanin Alves de Souza Matias
}

\author{
Mestre em Saúde da Criança e do Adolescente - UNICAMP \\ Especialista em Fisioterapia Neurofuncional na Criança e no Adolescente - ABRAFIN
}

Introdução: As condições genéticas da Síndrome de Down (SD) podem influenciar a estrutura e a função cerebral interferindo no desenvolvimento de habilidades intelectuais e motoras da criança. Basicamente, existem 3 aspectos na criança com SD que comprometem o sistema nervoso central (SNC) ocasionando disfunções psicomotoras: alterações na forma e volume cerebral, distúrbios na maturação e processos fisiopatológicos do SNC. Estudos sobre a imagem do SNC de crianças com SD revelam que os lobos frontais, temporais e cerebelo com menores tamanhos; apresentando também, um menor volume no hipocampo, corpo caloso e tronco encefálico com giro temporal superior diminuído. Consequentemente, conforme o acometimento de cada área, a criança com SD pode apresentar déficits cognitivos, distúrbios na fala, hipotonia, déficits de equilíbrio postural e coordenação dos movimentos. Essas características dificultam a variabilidade de experiências motoras e a exploração do ambiente, prejudicando 0 desenvolvimento neuropsicomotor (DNPM) e, consequentemente, podendo interferir na funcionalidade dessas crianças. Devido à importância e ao impacto dos atrasos do DNPM, em relação às atividades funcionais da criança com $S D$, é fundamental que se possa, o mais precocemente, direcionar uma possível intervenção. As intervenções propostas para criança com SD devem enfatizar a abordagem sensório-motora; buscando gerar movimento através da percepção, cognição e ação. A Fisioterapia possui diversas formas de abordagens e recursos utilizados como intervenção para as crianças com SD, no entanto, essas crianças solicitam uma abordagem global que pode ser efetivada com a Fisioterapia Aquática. Descrição da experiência e Impactos: Dentro deste contexto, conciliando o entendimento das diversas disfunções da criança com SD, a compreensão das propriedades físicas da água, dos efeitos fisiológicos no corpo em imersão, da análise do movimento humano no ambiente aquático é possível obter os subsídios necessários para elaboração de um plano de tratamento baseado na utilização da água como meio de facilitação do movimento. O fisioterapeuta, através da conduta proposta, pode direcionar o paciente a utilização da água como suporte, assistência e resistência proporcionando o recrutamento muscular, treinamento do equilíbrio e da marcha. Considerando as propriedades específicas da água como pressão hidrostática, força de flutuação, viscosidade e fluxo turbulento a fisioterapia aquática promove o estímulo do sistema sensório-motor, através do feedback sensorial adequando o controle neuromuscular e, consequentemente o equilíbrio postural. Portanto, buscando explorar os benefícios dos exercícios terapêuticos na água, foi formada a Liga Acadêmica de Fisioterapia Aquática (LAFA) do Centro Universitário Tiradentes, a fim de proporcionar a abordagem no meio aquático em diversas disfunções, em especial, para as crianças com SD. A cada semestre as crianças são avaliadas em relação ao DNPM e funcionalidade, sendo gerado relatório para os pais estarem cientes do desenvolvimento infantil. A abordagem terapêutica é baseada no Conceito Halliwick almejando a promoção de estratégias diversas para o controle motor, independência funcional, aprendizado sensorial e cognitivo utilizando atividades lúdicas. Conclusão: As atividades da LAFA possibilitam o atendimento em piscina terapêutica para pacientes da comunidade de Maceió que necessitavam desse tipo de intervenção; sendo possível favorecer o DNPM e funcional das crianças com SD do Instituto Amor 21. Em relação à vivência do acadêmico possibilita a prática clínica, acesso à conteúdos que agregam na sua formação profissional e a produção de estudos científicos. 


\title{
Um mergulho na escuridão: fisioterapia aquática para deficientes visuais
}

\author{
Suraya Gomes Novais Shimano \\ Universidade Federal do Triângulo Mineiro, ABFA. \\ "Agradecimento ao Crefito-4 pelo apoio, patrocínio e incentivo ao crescimento científico"
}

Introdução: É considerado portador de cegueira, o indivíduo com acuidade visual igual ou menor que 3/60 $(0,05)$ no olho de melhor visão, com a melhor correção óptica, até ausência de percepção de luz, já a visão subnormal ou baixa visão corresponde à acuidade visual igual ou menor que $6 / 18(0,3)$ e igual ou maior do que $3 / 60(0,05)$. Estes têm mais propensão a apresentar alterações de postura e equilíbrio, o que pode aumentar o risco de queda. Em um mundo visual, estas disfunções provocam um comportamento de reclusão e sedentarismo que irão culminar em diminuição de impulsos provenientes da ação muscular e posição articular, com um quadro clínico de perda de força e flexibilidade musculares, falta de condicionamento cardiorrespiratório, exclusão social e diminuição de qualidade de vida. A hipótese de que um programa de exercícios aquáticos desenvolvido especificamente para deficientes visuais pudesse melhorar as condições físicas e a qualidade de vida deles. Objetivo: Adaptar um programa adaptado de exercícios aquáticos para deficientes visuais. Métodos: estudo de adaptação. Para o processo de adaptação do protocolo de intervenção foi necessária a participação de diversos profissionais, incluindo pedagogos especialistas em deficiência visual e fisioterapeuta cega. Resultados: Um protocolo de 15 exercícios com comando áudio-táteis. Discussão: O protocolo vem sendo aplicado há mais de 36 meses com resultados significativos já divulgados em revistas científicas da área e novos exercícios vem sendo adaptados pela mesma equipe de profissionais, permitindo maior leque de opções para fisioterapeutas utilizarem em sua prática clínica, garantindo evidências científicas para tanto. Conclusão: Um protocolo de exercícios aquáticos terapêuticos foi adaptado para deficientes visuais.

\section{Conceito Halliwick: inclusão e participação através das atividades aquáticas funcionais}

\section{Maurício Koprowski Garcia}

\section{Instituto de Medicina Física e Reabilitação da Faculdade de Medicina da USP}

O controle da respiração, do equilíbrio e a liberdade de movimentos são os principais objetivos do Conceito Halliwick. Quando adquirida a habilidade para manter ou mudar a posição do corpo, de forma controlada, o participante torna-se capaz de responder com flexibilidade a diferentes situações, estímulos e tarefa criando ou solicitando movimentos com eficiência e independência. Os participantes são divididos em grupos de acordo com o nível de suas habilidades na água e não pela deficiência: 1ำ nível - Vermelho - habilidades ligadas à adaptação ao meio líquido, independência e controle da respiração, $2^{\circ}$ nível - Amarelo - habilidades ligadas ao controle do equilíbrio e rotações do corpo em seus diversos eixos: transversal, sagital e longitudinal, 3 nóvel - Verde - habilidades ligadas a movimentos, onde o nadador desloca-se na água em progressões simples e os nados adaptados. O trabalho em grupos oferece ao "nadador" a possibilidade de aumentar o aprendizado, pois motiva e oportuniza o aprender uns com os outros, melhorando a comunicação e a socialização. Jogos também são aplicados, pois escondem habilidades específicas em sessões lúdicas focadas no aprendizado pela brincadeira, tornando a sessão muito mais prazerosa. O Programa dos Dez Pontos é um processo de aprendizagem estruturado através do qual o nadador, mesmo sem experiência prévia, progride à independência na água controlando movimentos corporais, melhorando capacidades cardiorrespiratórias, equilíbrio e motricidade. Tornando-se mais confiante e participativo física e socialmente. Para muitos é a oportunidade de ser competente e independente na água e aprender a nadar, enquanto para outros permite a participação e inclusão através de atividades aquáticas diversas. Durante 12 meses acompanhamos: 398 nadadores $(n=398)$ do Nível Vermelho através de questionário 
específico e avaliações mensais, mesmo observador, verificamos quantos, em percentual, adquiriram cada uma das 15 habilidades específicas deste nível. Independentemente da deficiência, notamos que as habilidades de controle da respiração e equilíbrio estático e dinâmico foram conseguidas por um grupo maior de sujeitos. Em contrapartida, habilidades mais complexas, como: entradas e saídas da água a partir da borda, e posição de flutuação tiveram percentual menor de participação. No Nível de Habilidades Amarelo, acompanhamos um grupo de 186 nadadores $(n=186)$ e as habilidades específicas adquirida deste nível: Controle do equilíbrio e rotações do corpo em seus diversos eixos: transversal, sagital e longitudinal, empuxo, equilíbrio e imobilidade. Notamos que habilidades já abordadas no nível anterior facilitam o processo de aprendizagem neste nível. Isso era esperado, pois o Programa dos Dez Pontos do Conceito Halliwick é um processo de aprendizagem estruturado em pré-requisitos. Achamos ainda que, como no nível anterior, novas habilidades e as mais complexas demandam tempo maior para serem alcançadas. No Nível Verde são habilidades com movimentos básicos de propulsão onde o nadador recruta e associa atividades com braços, pernas ou mesmo com o tronco, deslocando-se na água em progressões simples e os nados adaptados. Neste grupo acompanhamos 90 usuários $(n=90)$. Concluímos que o sucesso dos resultados do Conceito Halliwick deve-se ao Programa dos Dez Pontos que estrutura o trabalho a ser desenvolvido na água de forma lógica e fácil de seguir. Através dele o participante melhora e adquire habilidades para iniciar e executar movimentos e muitas atividades, difíceis de serem realizadas em solo, tornan-se possíveis na água. Assim, respostas a maiores e melhores movimentos e sua organização foram observadas consistentemente. Em imersão processos sensório/perceptivo são estimulados repercutindo em coordenação eficaz, orientação especial e compreensão geral. Atividades em grupos promovem habilidades sociais, conversas, comunicação e oportunidade para aprender regras, ganhar e perder através de jogos e competições. Ir para a piscina proporciona estímulo a um número de atividades distintas antes e depois de entrar na água. Por exemplo: fazer a mala, o deslocamento, despir-se e vestir-se. Segundo Harris [1], Adams\& McCubbin [2], Broach \& Datillo [3], Hutzler et al. [4], Cole \& Becker [5], Getz [6], o Halliwick introduz um novo fator ambiental para se trabalhar estratégias no movimento e controle do equilíbrio de forma diferente. Os atributos do ambiente aquático, mais especificamente das propriedades físicas de água, ajudam as pessoas a promover suas habilidades físicas, emocionais e integração social. A qualidade de vida individual está no centro da abordagem holística de saúde usados no modelo Biopsicossocial da Classificação Internacional de Funcionalidade Deficiência e Saúde (CIF) da Organização Mundial de Saúde [7]. A abordagem holística do Halliwick de ensinar as pessoas a participar de atividades aquáticas, mover com independência e a nadar adapta-se bem à estrutura da CIF. O Conceito Halliwick é um guia ou uma ferramenta para intensificar e implementar programas de abordagens múltiplas. A água é lúdica, excitante e tranquilizante, permite a liberdade de movimento, experimentar o corpo de uma forma diferente, desenvolver o contato social. Isso é extremamente motivador!

\section{Referências}

1. Harris SR. Commentary on "The effects of Physical Therapy on cerebral palsy: a controlled trial in infants with spastic diplegia". Physical \& Occupational Therapy in Paediatrics 1989;9(3):1-4. https://doi.org/10.1080/j006v09n03_01

2. Adams CR, McCubbin JA. Games sports and exercises for the physically disabled. 4 ed. Philadelphia: Lea \& Febiger; 1991.

3. Broach E, Dattilo J. A viable therapeutic recreation intervention. Therapeutic Recreation Journal 1996;30(3):213-29.

4. Hutzler Y, Chacham A, Bergman U, Szeinberg A. Effects of a movement and swimming program on vital capacity and water orientation skills of children with cerebral palsy. Dev Med Child Neurol 1998;40(3):176-81. https://doi.org/10.1111/j.14698749.1998.tb15443.x

5. Cole AJ, Becker BE. Comprehensive aquatic therapy. 2 ed. Boston: ButterworthHeinman; 2004.

6. Getz M, Hutzler Y, Vermeer A. Effects of aquatic interventions in children with neuromotor impairments: a systematic review of the literature. Clinic Rehabilitation 2006;20(11):927-36. https://doi.org/10.1177/0269215506070693

7. World Health Organization. International Classification of Functioning, Disability and Health 2001. http://www.who.org/icidh 


\title{
Fisioterapia Aquática na qualidade de vida de idosos
}

\author{
Clara Maria Crispim Muniz
}

Fisioterapeuta e Professora da Unifacisa em Campina Grande-PB

Agradecimento aos egressos da Unifacisa que participaram do projeto "Fonte da Juventude"

Introdução: O processo natural de envelhecimento promove várias alterações fisiológicas no organismo que podem exigir novas adaptações do indivíduo para esta fase da vida, bem como predispor o corpo para a instalação de quadros patológicos crônicos. A fisioterapia aquática é capaz de estimular o corpo humano a desenvolver respostas para estas adaptações, como o alívio da dor, manutenção e melhora do equilíbrio, encorajamento das atividades funcionais e aumento do condicionamento cardiorrespiratório. Objetivo: Avaliar a qualidade de vida (QV), pré e pós-intervenção da fisioterapia aquática, em um grupo de idosos. Metodologia: Esta pesquisa da qualidade de vida dos idosos (CAAE-0111.0.405.000-11) foi parte integrante de um estudo longitudinal com intervenção terapêutica intitulado "Fonte da Juventude" (CAAE-0013.0.405.00011); no qual os idosos foram assistidos por duas sessões semanais de $50 \mathrm{mim}$, no setor de hidroterapia da Clínica Escola da Unifacisa. A amostra constou por 15 idosos. Os instrumentos de coleta de dados foram fichas de avaliação e o Questionário de Qualidade de Vida WHOQOLabreviado. As análises e comparações do WHOQOL-abreviado total, bem como dos domínios físico, psicológico e ambiental, foram consideradas variáveis paramétricas sendo, portanto, utilizado o teste t de Student, para comparação de suas médias pré e pós-intervenção. O domínio social foi classificado como variável não-paramétrica e, por isto, foi analisado através do teste Wilcoxon, ambos com o software estatístico Statistical Package of Social Sciences (SPSS Statistics 20). Resultados: Os resultados constaram que os escores totais da qualidade de vida aumentaram significativamente $(p=0,026)$, assim como o domínio psíquico $(p=0,023)$; os domínios ambiental e social apresentaram um aumento não significativo no escore após a iniciação do programa terapêutico, com $p=0,875$ e 0,138 respectivamente. $O$ domínio físico ( $p$ $=0,053$ ) apresentou um resultado muito próximo a significativo, entretanto, o consideramos significante em virtude do auto relato do WHOQOL-abreviado e achados físicos importantes em outros estudos do Projeto "Fonte da Juventude". Conclusão: Pode-se concluir que a prática da fisioterapia aquática no grupo "Fonte da Juventude" evidenciou melhora da qualidade de vida, segundo a opinião dos idosos, no estado físico, mental, ambiental e social, e a análise estatística evidenciou que o aumento no escore geral da qualidade de vida foi significante e influenciado principalmente pelo domínio psíquico.

\section{Benefícios da Fisioterapia Aquática no período gestacional: evidências científicas}

\author{
Valéria C. Passos de Carvalho \\ Universidade Católica de Pernambuco, Coordenação da Pós-graduação de Fisioterapia em \\ Urologia, Ginecologia e Obstetrícia/IDE/ Faculdade Redentor
}

Introdução: A gestação é um período na único na vida da mulher, que traz diversas alterações biomecânicas e fisiológicas iniciando-se no sistema reprodutivo, no qual o crescimento uterino em direção a região abdominal irá repercutir nos demais sistemas para acomodar e garantir o crescimento fetal, trazendo alguns queixas neste período como por exemplo: quadros de iu e aumento na frequência miccional; câimbras; desconforto respiratório; edema nos membros inferiores; lombalgia gestacional, entre outros. A fisioterapia aquática se apresenta como escolha de tratamento e/ou prevenção para os desconfortos advindos da gravidez, pois é evidente os benefícios fisiológicos desta terapia são bem fundamentados no princípio científica, mas há uma escassez de pesquisa sobre os desfechos relacionados a saúde da grávida. Objetivo: Analisar as evidências científicas sobre os benefícios fisiológicos da fisioterapia aquática no período gestacional. Métodos: Foi realizada uma revisão narrativa da literatura dos últimos 10 anos, com 
os seguintes descritores do Decs: fisioterapia aquática, exercícios aquáticos, gravidez, gestação de forma isolada e em combinação, nas línguas: inglês, espanhol e português, nas seguintes bases de dados: Pubmed, Science Direct, Scielo e Pedro. Como critérios de inclusão: artigos dos últimos 10 anos e que incluísse a temática a ser avaliada. Para a análise da qualidade dos artigos foram utilizados os critérios adotados por Gray [1], no artigo de evidências com cuidados com a saúde. Resultados: Foram selecionados 30 artigos nas bases de dados pesquisadas, deste, 7 foram incluídos na nossa revisão. Pereira et al. [2], realizou um ensaio clínico randomizado, no qual avaliou a associação entre os exercícios aeróbicos e as variáveis cardiovasculares maternas durante a gravidez, parto e resultados neonatais, de acordo com os autores os exercícios moderados não influenciaram na saúde da mãe ou da criança, e que houve menos pedidos de analgesia durante o trabalho de parto no grupo que realizou terapia aquática quando comparada ao controle. Waller et al. [3], realizou uma revisão sistemática avaliando a eficácia da fisioterapia aquática no tratamento da dor lombar, dizendo que existem evidências suficientes de que o tratamento aquático é potencialmente benéfico para as gestantes que sofrem de do lombar. Cavalcante et al. [4], realizaram um estudo randomizado e controlado com 71 gestantes sedentárias e de baixo risco, e demonstraram que o protocolo utilizado se mostrou seguro e sem associação nenhuma alteração na composição corporal materna, tipo de parto, taxa de nascimento prematuro e bem-estar ou peso neonatal. Costa e Assis [5], realizaram uma revisão narrativa, para comprovar os efeitos da hidrocinesioterapia na gestação e observou que os principais efeitos estão relacionados a eliminação de edema nos membros inferiores e alívio da dor na região lombar, mostrando-se como uma modalidade prazerosa, de baixo custo e eficaz. Vallim et al. [6], realizaram um ensaio clínico para avaliar os efeitos de um programa de exercícios na qualidade de vida das gestantes, no qual a maioria delas relatou benéfica a intervenção. Em 2012, Souza e Singer [7] realizaram uma revisão entre os protocolos utilizados para o tratamento da lombalgia gestacional, destacam que a fisioterapia aquática se mostrou eficaz. Silva Jr et al. [8], realizaram um ensaio clínico com 36 gestantes diabéticas, relatando que houve um melhor controle glicêmico e que as propriedades físicas da água tornam os exercícios ideais para as grávidas. Conclusão: Os resultados apontam principalmente para os benefícios relacionados a lombalgia gestacional. Encontramos poucas evidências com boa qualidade metodológica sobre o tema. Se faz necessário mais pesquisas em diferentes contextos socioculturais para avaliar adequadamente os benefícios da fisioterapia aquática associada aos desfechos maternos.

\section{Referências}

1. Gray M, 2004. Evidence-based healthcare. Health Serv Res 2004;39(5):15-24. https://doi.org/10.1111/j.1475-6773.2004.00286.x

2. Baciuk EP, Pereira RI, Cecatti JG, Braga AF, Cavalcante SR. Water aerobics in pregnancy: cardiovascular response, labor and neonatal outcomes. Reprod Health 2008;5:10. https://doi.org/10.1186/1742-4755-5-10

3. Waller B, Lambeck J, Daly D. Therapeutic aquatic exercise in the treatment of low back pain: a systematic review. Clinical Rehabilitation 2009;23:3-14. https://doi.org/10.1177/0269215508097856

4. Cavalcante SR, Cecatti JG, Pereira RI, Baciuk PE, Bernardo AL, Silveira C. Hidroginástica Il: composição corporal materna e resultados perinatais após um programa para gestantes de baixo risco. Reprod Health 2009;6:1. https://doi.org/10.1186/1742-4755-6-1

5. Costa SB, Assis TO. Hidrocinesioterapia como tratamento de escolha para lombalgia gestacional. Revista Tema 2010;9(13)/14.

6. Vallim AL, Osis MJ, Cecatti JG, Baciuk EP, Silveira C, Cavalcante SR. Water exercises and quality of life during pregnancy. Reprod Health 2011;8:14. https://doi.org/10.1186 /1742-4755-8-14

7. Souza LA, Singer AS. Os Benefícios da fisioterapia na lombalgia gestacional. Estação Científica Edição Especial Fisioterapia 2012. https://portal.estacio.br/media/4420/os_beneficios_da_fisioterapia_na_lombalgia_gesta cional.pdf.

8. da Silva Jr JR, Borges PS, Agra KF, Pontes IA, Alves JGB. Effects of an aquatic physical exercise program on glycemic control and perinatal outcomes of gestational 
diabetes: study protocol for a randomized controlled trial. Trials 2013;14:390-5. http://www.trialsjournal.com/content/14/1/390

\title{
Efeitos do método Watsu sobre o nível de estresse pós-traumático em vítimas de escalpelamento
}

\author{
Wellington Pinheiro de Oliveira \\ Centro Universitário do Estado do Pará - CESUPA
}

Introdução: As mulheres são as principais vítimas de escalpelamento, perdendo além do cabelo, o couro cabeludo e até parte do rosto nos eixos de motores das embarcações amazônicas e entram em estado de choque devido ao trauma. O medo e a ansiedade causados pelo trauma liberam os hormônios cortisol e adrenalina, que em excesso, podem ocasionar alterações cardiorrespiratórias compatíveis com transtorno de estresse pós-traumático (TEPT). O Watsu proporciona um canal para interromper esses ciclos de disfunções físicas e psicológicas. Metodologia: Participou deste estudo uma mulher, vítima de escalpelamento, com tempo de lesão de 18 anos, atendida pela organização não governamental dos ribeirinhos vítimas de acidente de motor (ORVAM). Para coleta de dados, antes e depois de cada sessão foram aferidas a pressão arterial sistólica (PAS) e diastólica (PAD), as frequências cardíacas (FC) e respiratória (FR) e a concentração de cortisol salivar, que foi analisada pelo laboratório de análises clínicas do CESUPA. Antes da primeira sessão e ao final da última foram aplicados os questionários para avaliar a qualidade de vida (WHOQOL-BREF) e qualidade de sono (PSQI). A participante foi submetida a 8 sessões do método Watsu com água a $35^{\circ} \mathrm{C}$, 2 vezes por semana, seguindo o protocolo de Fluxo Básico descrito por Dull, na clínica escola de fisioterapia do CESUPA. Resultados: A intervenção obteve redução estatisticamente significante para um $\mathrm{P}<0,05$, nos níveis de PAS (8,0\%), PAD (7,6\%), FC (13,5\%), FR (24,4\%) e concentração de Cortisol $(65,5 \%)$ e apresentou também melhora na qualidade de vida, quanto aos domínios psicológico (17,23\%) e do meio ambiente (27,25\%), bem como a melhora de $66 \%$ na qualidade de sono. Conclusão: O Método Watsu, mostrou-se positivo para a participante, com melhora estatisticamente significante em todos os aspectos fisiológicos relacionados ao estresse avaliados, proporcionando maior bem-estar e melhor qualidade de vida e sono.

\section{Fisioterapia aquática aplicada ao paciente crítico/alta complexidade}

\section{Gustavo Balieiro de Freitas}

\section{Albert Einstein Instituto Israelita de Ensino e Pesquisa}

Introdução: A Fisioterapia Aquática é uma modalidade terapêutica que vem crescendo muito ao longo dos anos e expandindo cada vez mais a sua área de atuação, abrangendo uma gama grande de possibilidade de atendimentos nas mais diversas patologias, desde musculoesqueléticas, cardiopulmonares, geriatria, neurológicos bem como pacientes complexos e em estado crítico muitas vezes com uma ou mais patologias associadas. Entretanto para o tratamento em ambiente aquático o terapeuta conta com algumas técnicas descritas em literatura (Bad Ragaz, Halliwick, Watsu, Water Pilates, Aquadinamic e hidrocinesioterapia) que auxiliam os atendimentos. Porém nem sempre o paciente apresenta condições clínicas para que seja realizado um manejo tão avançado. Desta forma o terapeuta deve considerar como um fator importante a imersão aquática, pois possui efeitos fisiológicos relevantes que se estendem sobre todos os sistemas além da homeostase. Estes efeitos podem ser tanto imediatos quanto tardios, permitindo assim, que a água seja utilizada para fins terapêuticos em uma grande variedade de problemas orgânicos. Tornando assim a água e suas propriedades físicas uma importante ferramenta quando associados a exercícios no meio líquido desta forma para que possamos compreender este recurso fisioterapêutico faz-se necessário o amplo conhecimento sobre as 
propriedades hidrostáticas, hidrodinâmicas e termodinâmica da água (mecânica de fluidos). Objetivo: Avaliar os trabalhos científicos de Reabilitação Aquática, com abordagem terapêutica para pacientes críticos/Alta complexidade, através da busca em bases eletrônicas para averiguarmos se existem evidências científicas sobre os efeitos da fisioterapia aquática para estes pacientes; avaliar o efeito no quadro do paciente pós Traumatismo Crânio Encefálico (TCE), em estado de coma vigil, com a intervenção precoce da fisioterapia aquática. Métodos: $O$ estudo consiste em um relato de caso, realizado no Hospital Israelita Albert Einstein, analisando paciente pós TCE em estado de coma vigil, nível cognitivo II (Rancho Los Amigos), estabilizado clinicamente, com um ano de internação, realizando somente fisioterapia aquática. Resultados: Observou-se melhora do potencial sensorial através da conscientização espacial e do potencial motor através do controle cervical, ajuste tônico e postural e conservação das Amplitudes de Movimento (ADMs), além da redução do reflexo do membro inferior esquerdo. Conclusão: existem fracas evidências na literatura dos benefícios da fisioterapia aquática quando aplicada à pacientes com doenças neurológicas, sendo fundamental a elaboração de um ensaio clínico aleatório de grande amostra para avaliar o efeito da fisioterapia aquática em pacientes com doença neurológica específica. Porém através do presente estudo, conclui-se que o paciente em coma vigil, beneficiou-se com a intervenção da fisioterapia aquática. Devemos levar em consideração, no entanto, que em se tratando de um estudo de caso, analisamos um único paciente, desta forma não podemos nos certificar que haja benefício com um percentual significante de uma população.

\title{
Desafios e contribuições da reabilitação aquática na recuperação funcional de militares do exército brasileiro
}

\author{
Laisa Liane Paineiras Domingos
}

Fisioterapeuta da Policlínica Militar do Rio de Janeiro, Exército Brasileiro, Ministério de Defesa, Brasil, Faculdade Bezerra de Araújo (FABA), Programa de Pós-graduação em Ciências Médicas, Universidade do Estado do Rio de Janeiro (UERJ)

Introdução: A crescente demanda da presença de militares das forças armadas, em especial do exército brasileiro $(\mathrm{EB})$, frente às situações de controle da ordem atualmente ocorre na mesma proporção em que estes militares estão expostos às condições de perigo, enfrentamento, violência e conflitos. Soma-se a isto, as atividades usuais do militar do EB, que envolvem sobrecarga, impacto articular, e total exigência de suas capacidades físicas. Tal cenário reflete nas mais diversas alterações de suas condições clínicas que culmina num quadro de dor e tensão, associado às lesões musculares, ortopédicas, alterações posturais e, ainda mais preocupantes, quadros clínicos neurológicos graves. Isso gera o afastamento de seus postos de trabalho, trazendo com isto a sensação de impotência e, em alguns casos, levando ao quadro de depressão. Dentre as modalidades de tratamento que vem se tornando fundamental na busca de um olhar integralizador (corpo e mente), promovendo uma intervenção preventiva e dinâmica, possibilitando uma recuperação eficaz e assertiva, destacamos a reabilitação aquática (RA), ideal para esses militares, uma vez que conceitua-se numa abordagem prazerosa, com benefícios como a diminuição da sobrecarga nas articulações, uma ação analgésica e um efeito de relaxamento muscular global pela temperatura da água e uma rápida resposta terapêutica. No entanto, há alguns desafios a enfrentar na manutenção desta modalidade, sobretudo a necessidade do aquecimento ideal e constante da água, cuja literatura vem revelando ser um dos maiores desafios neste setor. Objetivo: Apontar os desafios e as contribuições da RA na recuperação funcional de militares do EB. Métodos: Apresentação de 4 casos clínicos com diagnósticos como: ruptura do tendão de Aquiles; lesão do manguito rotador por PAF, amputação transfemural e pós-operatório de artroplastia de quadril, que foram tratados através da RA. Resultados: Por meio de instrumentos de avaliação, validados e comprovados cientificamente, os efeitos benéficos da RA foram encontrados em todos os casos clínicos, atendidos na Policlínica Militar do Rio de Janeiro (PMRJ), aonde funciona o setor de RA desde outubro de 2014. Num aspecto geral, houve redução da dor e melhora da qualidade de vida de todos os pacientes relatados, repercutindo numa recuperação funcional e condições de retorno precoce 
às suas atividades laborativas. Tudo isto, sem comprometer sua performance física e melhorando os aspectos emocionais ligados ao retorno ao trabalho. Conclusão: Mesmo com os desafios de manutenção que a piscina terapêutica requer, podemos considerar que a RA é uma modalidade de tratamento adequado para a recuperação funcional de militares. Seus benefícios favorecem o empenho do fisioterapeuta em buscar a adequada manutenção deste setor e promover a estes pacientes, uma recuperação dinâmica, precoce, com qualidade e completa, para o corpo e para a mente.

\section{Eletromiografia e acelerometria para análise da marcha aquática no Parkinson}

\section{Caroline de Cássia Batista de Souza}

\section{Grupo de Pesquisa Engenharia Biomédica, UFPE, Recife/PE, Brasil}

Introdução: A Doença de Parkinson (DP) é uma das doenças degenerativas mais frequentes do sistema nervoso central, resultante da disfunção dos sistemas dopaminérgicos, colinérgicos, serotoninérgicos e noradrenérgicos, entretanto o padrão básico neuropatológico é decorrente da alteração da via nigro-estriatal, com diminuição da concentração de dopamina ao nível dos receptores dopaminérgicos situados no corpo estriado. As características motoras básicas da DP são: bradicinesia, tremor de repouso, instabilidade postural, perda dos reflexos posturais e o congelamento ou Freezing que é marcado por uma repentina incapacidade de iniciar ou continuar a andar. A análise eletromiográfica da atividade muscular durante a locomoção tem sido estudada por alguns autores. O registro eletromiográfico corresponde à aquisição de sinal bioelétrico resultante da atividade muscular, sobre uma função ou resposta fisiológica A técnica da identificação de movimentos através da acelerometria pode ser usada para medir a atividade física ou seu impacto nas estruturas do corpo humano, como nos exercícios de marcha. Objetivo: Analisar e comparar a caminhada dentro e fora da água em pessoas com Doença de Parkinson através da eletromiografia de superfície em conjunto com acelerometria. Métodos: $O$ estudo foi dividido em duas partes. A primeira parte foi o desenvolvimento e adaptação de um equipamento com eletromiografia e acelerometria para utilização dentro da água. Visando essa atividade, foi desenvolvido um sistema composto por um canal de eletromiografia e dois sensores de acelerometria integrados a um microcontrolador com comunicação a um computador realizada através do protocolo Bluetooth. A finalidade dessa comunicação sem fio é de visualizar os resultados e armazená-los para uma possível análise estatística, em um computador pessoal. Para impermeabilização e selagem dos acelerômetros para o funcionamento dentro da água, foi utilizado um verniz impermeabilizante e cola epoxi Araldite $\AA$. A segunda parte foi a aplicação do instrumento através de um estudo piloto na Clínica Rogério Antunes - Unidade Torreão/PE. Os acelerômetros foram colocados na face interna do pé, embaixo do maléolo medial e o EMG foi colocado no músculo tibial anterior e o eletrodo referência no maléolo lateral. A coleta de dados foi realizada através do projeto previamente autorizado pelo Comitê de Ética em Pesquisa sob CAAE 86285418.7.0000.5208, onde foi analisada a caminhada dentro e fora da água, por um percurso de 8 metros, de um indivíduo com diagnóstico de Doença de Parkinson. Resultados: Com a eletromiografia foi possível observar uma atenuação do sinal dentro da água devido ao contato direto do eletrodo com a água, além da diminuição do esforço muscular proporcionado pelas propriedades físicas da água. Com a acelerometria foi observado a cadência e 0 comprimento, velocidade e altura do passo, bem como o tempo para realização do teste dentro do ambiente aquático e fora dele. Dentro da água, houve um acréscimo de aproximadamente $45,34 \%$ no comprimento do passo e $20 \%$ na altura do passo do paciente. Houve uma redução de $33,33 \%$ da velocidade da caminhada e uma redução de $63 \%$ na cadência. O tempo utilizado para execução da caminhada dentro da água aumentou $51 \%$. Conclusão: A partir dos dados analisados foi possível observar que a caminhada em ambiente aquático proporcionou um aumento no comprimento e altura do passo e uma redução da velocidade e cadência comparada a caminhada em solo. A velocidade reduzida na caminhada dentro da água proporciona uma maior estabilidade para o paciente durante a caminhada e melhora na qualidade do passo. Além 
destes resultados, foi possível também validar a impermeabilização do instrumento, mostrando que uma resina de uso cotidiano é efetiva.

\section{Fisioterapia aquática em lesões complexas de membros inferiores}

Artur Vinicius de A. Magnavita

Especialista em Ortopedia e Traumatologia, Especialista em Fisioterapia Aquática, Professor da Pós-Graduação UCSal e Diretor Rede Fluir

A Fisioterapia Aquática é uma especialidade amplamente utilizada em tratamentos das mais variadas especialidades da Fisioterapia. Muito já se conhece e reconhece sobre os benefícios da Fisioterapia Aquática na reabilitação, aceleração e prevenção de Lesões. As vantagens e benefícios do tratamento da Fisioterapia Aquática se deve graças a interação do indivíduo com as propriedades físicas da água somado aos exercícios terapêuticos feitos durante a imersão. As Lesões Complexas de Membros Inferiores representam um grande desafio a equipe de fisioterapia pela característica de impactar profundamente na capacidade funcional do paciente e possuir recuperação lenta com prognóstico reservado. A Fisioterapia Aquática possui destaque dentro do processo de reabilitação deste grupo de pacientes, sendo grande a prevalência deste tipo de encaminhamento e pela unanimidade nos benefícios para melhora funcional, melhorando o prognóstico da recuperação destes pacientes. O Objetivo deste tema é discutir as abordagens terapêuticas da Fisioterapia Aquática em pacientes portadores de Lesões Complexas de Membros Inferiores. Resultados: Foram apresentados uma serie de casos clínico e artigos, discutindo as abordagens terapêuticas de técnicas da Fisioterapia Aquática como Bad Ragaz e Halliwick, e da releitura de conceitos de Fisioterapia como PNF, Liberação Miofascial Stecco, Mackenzie, Maitland quando associados e potencializados seus benefícios pela interação do paciente com as propriedades físicas da água. Conclusão: Os resultados clínicos e científicos sinalizam a fisioterapia aquática como especialidade indispensável na composição das terapias de reabilitação em pacientes com Lesões Complexas de Membros Inferiores para aumento da capacidade funcional, redução da dor, redução do tempo de recuperação, melhora da qualidade de vida e melhor prognóstico destes pacientes.

\section{Panorama da Fisioterapia Aquática em Pernambuco na assistência às crianças com síndrome congênita do Zika vírus}

Cinthia Rodrigues de Vasconcelos ${ }^{1}$, Rodrigo Marinho Falcão Pinto ${ }^{2}$, Stella Guerra de Amorim³, Ana Carla Gomes Botelho ${ }^{4}$, Anna Catarina Soares dos Santos Melo ${ }^{2}$

${ }^{1}$ Professora Associada do Departamento de Fisioterapia da Universidade Federal de Pernambuco, ${ }^{2}$ Fisioterapeuta do Setor de Fisioterapia Aquática da Associação de Assistência à Criança com Deficiência (AACD-Recife), ${ }^{3}$ Fisioterapeuta da Fundação Altino Ventura (FAV), ${ }^{4}$ Fisioterapeuta do Centro de Reabilitação do Instituto de Medicina Integral Professor Fernando Figueira (IMIP)

Introdução: Pernambuco (PE) foi um dos estados mais atingidos pela epidemia da Síndrome Congênita do Zika Vírus (SCZV), representando 15,18\% das notificações do Brasil, despertando a necessidade de intervenções em nível governamental e da sociedade civil, que pudessem garantir a integralidade do cuidado às crianças acometidas. Frente a esse contexto, o Conselho Regional de Fisioterapia e Terapia Ocupacional da 1를 Região (CREFITO-1), instituiu no estado de PE, um Grupo de Trabalho (GT) no âmbito da Fisioterapia para construir ações voltadas ao enfrentamento da SCZV, tendo como objetivo a garantia à sociedade pernambucana de uma assistência fisioterapêutica de excelência. Objetivo: Traçar o perfil da assistência da fisioterapia 
aquática (FA) em PE na assistência às crianças com a SCZV. Métodos: a identificação dos serviços de fisioterapia aquática em $\mathrm{PE}$ foi conseguida através da consulta à Coordenação da Pessoa com Deficiência da Secretaria Estadual de Saúde de PE, ao Departamento de Fiscalização do CREFITO-1, às instituições de ensino superior (IES) que ofertam cursos de graduação em Fisioterapia no estado, à Associação Pernambucana de Empresas Prestadoras de Serviços de Fisioterapia e de Terapia Ocupacional (APESFITO) e às associações de usuários. A partir da identificação dos serviços, o GT enviou aos mesmos um questionário digital (Google Forms), contendo perguntas que buscavam a identificação das características da assistência prestada, como também dos profissionais envolvidos. Resultados: em PE foram identificados 16 serviços de $\mathrm{FA}$, destes, três, são vinculados à rede de atenção à saúde da pessoa com deficiência do Estado de Pernambuco (SUS), dois vinculados à instituições filantrópicas, quatro vinculados às clínicas escola de IES públicas e privadas, e 07 serviços de natureza privada. Foram registrados acompanhamento de 80 crianças com a SCZV A localização geográfica destes serviços, em sua maioria, está centrada na capital do Estado, mas há distribuição nas regiões do agreste e sertão de Pernambuco (Arcoverde, Caruaru, Garanhuns, Serra Talhada e Petrolina). Além da FA, $81,3 \%$ dos serviços oferecem outras intervenções que garantem a integralidade no cuidado ao usuário, como Fisioterapia (diversas outras especialidades), Terapia Ocupacional, Fonoaudiologia, Pedagogia e Psicopedagogia, Psicologia, Nutrição, Profissional de Educação Física, Odontologia, Biomedicina, Assistente Social, Medicina (traumato-ortopedia, pediatria e uroginecologia), além de acupuntura. A frequência dos atendimentos realizados, em sua maioria, é de uma a duas vezes por semana, com duração média de 30 minutos. A maioria dos profissionais tem mais de 5 anos de formado, $20 \%$ tem algum curso de aperfeiçoamento para assistência fisioterapêutica pediátrica e $25 \%$ tem algum curso de Capacitação ou Especialização em métodos aquáticos. Quando perguntados se utilizavam algum método de intervenção na assistência da FA, todos responderam que sim, sempre associando mais de um método: Halliwick, Bad Ragaz, Watsu, Hidrocinesioterapia e manobras do Conceito Bobath. Quanto aos objetivos terapêuticos das crianças com a SCZV ao início do tratamento, tem-se: desenvolver habilidades funcionais, promovendo o máximo de independência possível, baseando-se nos marcos do Desenvolvimento Infantil; adequar tônus muscular, especialmente dos membros inferiores; ganhar mobilidade articular e promover alongamentos musculares; proporcionar integração sensorial; favorecer à socialização; melhorar a qualidade de vida. Apenas 7,1\% destes profissionais consideram "excelente" o alcance dos objetivos terapêuticos traçados ao início do tratamento para as crianças com a SCZV. Dentre as crianças que não estão mais sendo atendidas nos serviços de $F A, 7,1 \%$ deve-se ao fato de terem recebido alta fisioterapêutica e $87,5 \%$ foram desligadas pelos serviços devido à baixa assiduidade ao tratamento. Considerações Finais: a assistência com a FA em Pernambuco existe, mas ainda precisa ser descentralizada para o interior do estado e precisa ser ampliada, visto que dos 421 casos notificados com a SCZV, menos de $20 \%$ das crianças estão sendo acompanhadas na Fisioterapia Aquática.

\title{
Uso da acelerometria na quantificação de carga durante o exercício aquático
}

\author{
Rogério Azevedo Antunes Pereira
}

\section{CEPRA - Centro de estudo e pesquisa Rogério Antunes}

Introdução: A utilização da água como recurso para a atividade física e principalmente como meio terapêutico é muito antiga. Atualmente, muito utilizada para reabilitação de pacientes nas diversas áreas da saúde, bem como em atividades físicas e nos esportes em geral, vem apresentando uma grande lacuna no que diz respeito a mensuração da carga (esforço) durante o exercício. Segundo alguns princípios da hidrodinâmica (mecânica de fluidos), o esforço do indivíduo durante o exercício é alterado por alguns fatores como o sentido do movimento do corpo, a utilização de resistores, que aumentam a resistência frontal pela área de arrasto, bem como a velocidade na execução dele. Com relação a velocidade, esta é trabalhada de forma empírica por não haver um equipamento aquático que correlacione o esforço à velocidade e à possível carga que o indivíduo está utilizando durante o exercício aquático. Acelerômetros são aparelhos portáteis que são sensíveis à aceleração do corpo e transformam esta informação em unidades de gasto energético. A acelerometria pode ser utilizada como identificadora da 
velocidade durante o exercício aquático, sinalizando com luzes de led (verde, azul e vermelha), o movimento de baixa, média e alta velocidade respectivamente. Objetivo: Desenvolver/adaptar um equipamento de acelerometria, com luzes de led, a uma escala de cores (verde, amarela e vermelha) para determinar o nível de velocidade (leve, moderada e intensa respectivamente) do exercício aquático. Métodos: O desenvolvimento do acelerômetro com luzes de LED e escala de cores que identifique em tempo real, a velocidade do movimento (exercício) executado no meio aquático foi realizado no Departamento de Eletrônica e Sistemas, Sala 412, Laboratório de Interface Homem-Máquina da Universidade Federal de Pernambuco.

\section{Atuação da Fisioterapia Aquática na vertigem postural paroxística benigna}

Fabio Jakaitis

Hospital Israelita Albert Einstein, Universidade Kroton Anhanguera, ABFA. Agradecimento ao Crefito-3 pelo apoio, patrocínio e incentivo ao crescimento científico"

Introdução: A expectativa de vida da população aumentou, e com isso o número de idosos com mais de 60 anos vem crescendo rapidamente, envolvendo doenças crônicas e degenerativas que geram sintomas e problemas como tonturas, quedas, doenças neurológicas e incapacidades físicas. Como resultado, ocorre o acometimento das atividades diárias e o piora da qualidade de vida desses indivíduos. A Vertigem Postural Paroxística Benigna (VPPB) é um distúrbio vestibular no qual os pacientes relatam breves momentos de vertigem e/ou leve instabilidade postural, ocasionados por uma mudança brusca na movimentação cefálica ou corporal. Desde os tempos remotos, a hidroterapia tem sido utilizada como recurso para tratar doenças reumáticas, ortopédicas e neurológicas; entretanto, só recentemente é que essa tem se tornado alvo de estudos científicos para tratamento de enfermidades vestibulares e principalmente a VPPB, favorecendo a melhora do equilíbrio, diminuição das crises vestibulares agudas. Objetivo: Avaliar uma nova proposta de Reabilitação Aquática, com abordagem terapêutica para as disfunções vestibulares. Métodos: 22 pacientes com VPPB. A avaliação diagnóstica foi realizada pelo c-VEMP, prova calórica e vectonistagmografia, desequilíbrio e risco de queda, pelo Dynamic Gait Index (DGl), BERG e teste Romberg. Resultados: Após a avaliação os pacientes foram submetidos a protocolo de Reabilitação Vestibular comporto por exercícios específicos para tratamento da VPPB (Adaptação do Protocolo de Cawthorne \& Cooksey (1940) e Norré (1988) ao meio líquido) Discussão: A Reabilitação Vestibular aplicada aos 22 sujeitos com VPPB apresentaram melhora de $76,48 \%$ nas crises vestibulares e $23,52 \%$ sem significaria estatística. $\mathrm{Na}$ comparação do DGI em vestibulopatas com risco e sem risco de queda, $80 \%$ apresentaram melhora do teste nos com risco queda e $58,80 \%$ nos sem risco. Conclusão: A Reabilitação aquática aplicada ao VPPB, mostra bastante relevância em relação ao processo de melhora clínica e espaçamento maior das crises, favorecendo na melhora da qualidade de vida e menor risco de queda, onde novos estudos são necessários para maior comprovação estatística dos dados supra-citados neste estudo. 


\title{
Fisioterapia Aquática na prevenção e recovery de atletas paralímpicos
}

\author{
Ana Paula de Lima Ferreira \\ Universidade Federal de Pernambuco, Recife-PE
}

Introdução: O Voleibol sentado surgiu na Holanda (1956), a partir da combinação do voleibol tradicional e com o Sitzball, que é um jogo de origem alemã em que o atleta fica sentado no chão e não há uso de rede. O esporte foi incluído nas Paraolimpíadas em 1980 e no Brasil, a prática dessa modalidade teve início em 2002. Deve-se reconhecer a escassez de estudos sobre 0 voleibol sentado, mas sabe-se que existe uma alta prevalência de lesões musculoesqueléticas sobretudo aquelas que atingem o complexo articular do ombro. Cerca de $70 \%$ dos atletas realizam tratamento fisioterapêutico no solo com abordagem na reabilitação, contudo, não é uma prática comum a realização de procedimentos preventivos e recovery através da Fisioterapia Aquática. Objetivo: Avaliar os efeitos de um protocolo de Fisioterapia Aquática para reduzir número/gravidade de lesões musculoesqueléticas e acelerar a recuperação muscular pós treino de alta intensidade em atletas da seleção brasileira masculina de voleibol sentado no ano de 2018. Métodos: Série de casos de 12 atletas que foram acompanhados no Centro de Treinamento Paralímpico (SP) nas 4 semanas de treinamento pré-competição e durante 0 Campeonato Mundial de Volei Sentado realizado na Holanda. A Fisioterapia aquática incluiu procedimentos de cinesioterapia aquática com e sem o auxílio de flutuadores, métodos de Bad Ragaz e Watsu e massagens subaquáticas. Para análise dos resultados, os atletas foram avaliados antes da primeira e após a última semana de treinamento, utilizando-se: Termografia Infravermelha, Escala de Esforço Percebido, Escala Visual Analógica de Dor, Relato de queixas desconforto físico/Dor. Para avaliar a melhoria da condição do atleta pós protocolo Fisioterapêutico foi aplicado o Patient Global Impression of Change (PGIC). Para análise dos dados obtidos foi usado o teste t pareado com nível de significância de $5 \%$. Resultados: A amostra apresentou idade em anos $(32,6 \pm 5,35$, min 24 e máx 43$)$, peso em quilogramas $(91,26$ $\pm 21,65$, min 69,5 e máx 132,3), altura em centímetros (185,06 $\pm 8,85$, min 175 e máx 202) e IMC em $\mathrm{kg} / \mathrm{m}^{2}(26,52 \pm 4,89$, mín 20,8 e máx 36,3$)$. As análises termográficas demonstraram redução de $0,40 \mathrm{C} \pm 0,10 \mathrm{C}$, a Escala de Esforço Percebido (antes $8 \pm 2,6$ e depois $4,56 \pm 0,62 p<0,005$ ), EVA (antes 7,34 $\pm 1,82$ depois $1,36 \pm 0,14 p<0,001$ ), relato de queixas desconforto físico/dor (antes positivo em $80 \%$ dos atletas $(n=12)$ e após $13,33 \%(n=2)$. Após as quatro semanas de treinamento pré-competição, $100 \%$ dos atletas encontravam-se fisicamente disponíveis para que o técnico os colocasse em quadra. Ao término da competição, não houve relato de lesões musculoesqueléticas, apenas fadiga muscular comum da modalidade praticada. O PGIC revelou escore médio 6,25 $\pm 0,72$ (qualitativamente considerado como experiência positiva e importante). Discussão: Acredita-se que o elevado número de atendimentos fisioterapêuticos (média de 40 sessões/semana) pré-competição foi imprescindível no monitoramento, controle e redução de queixas dolorosas viabilizando a prática esportiva plena. Conclusão: A Fisioterapia Aquática contribuiu para o reduzido número e gravidade de lesões musculoesqueléticas, além de acelerar a recuperação muscular pós treino.

\section{Fisioterapia Aquática nos diversos tipos de encefalopatia crônica não progressiva}

\section{Cristina de Fatima Martins Germano}

Professora Adjunta Aposentada do Departamento de Fisioterapia da UFPB Implantação e Coordenação do Atendimento de Crianças e Adolescentes em Piscina Terapêutica na UFPB

Introdução: A Encefalopatia Crônica Não Progressiva (ECNP) é uma das causas mais frequentes de distúrbios do desenvolvimento neuropsicomotor na infância. É o resultado de uma lesão ou mau funcionamento do cérebro, de caráter não progressivo existindo desde a infância. A deficiência motora expressa-se em padrões anormais de movimentos, associado com tônus 
postural anormal. De acordo com a área cerebral lesada e a extensão da lesão, pode-se apresentar vários graus de comprometimento e tipos diversos de ECNP, ocasionando múltiplas sequelas no funcionamento motor-perceptivo-cognitivo-emocional-afetivo-social da criança. Objetivo: observar a evolução dessas crianças no aprimoramento dos automatismos básicos das reações de ajustes posturais. Métodos: Foram avaliadas 20 crianças com ENCP no Serviço de Fisioterapia Infantil da UFPB, com ênfase nas reações básicas automáticas. Um grupo de 10 crianças foi submetido a 1 sessão de hidroterapia e 2 sessões cinesioterapia especial. Outro grupo foi submetido a 3 sessões de cinesioterapia especial, durante 6 meses. As técnicas de Hidro empregadas atuaram em conjunto com os princípios hidrodinâmicos e reações corporais desenvolvidas no meio líquido. Conclusão: No grupo de crianças que foram submetidas aos 2 recursos terapêuticos, houve melhora nas reações cervical, corporal e labiríntica de retificação e na extensão protetora dos braços.

\section{Nada melhor: estimulação aquática para bebês}

\section{Wellington Fabiano Gomes}

Docente do Departamento de Fisioterapia e do Programa de Pós-graduação em Reabilitação e Desempenho Funcional, Universidade Federal dos Vales do Jequitinhonha e Mucuri, Diamantina, Minas Gerais. CREFITO-4 e Pró-reitoria de Extensão e Cultura (PROEXC-UFVJM)

Introdução: O projeto de extensão "Nada Melhor: estimulação aquática para bebês" atende em média 80 crianças da região de Diamantina-MG. Este projeto foi idealizado com finalidade de permitir 0 acesso precoce às crianças na faixa etária de 0 a 2 anos à atividade aquática. $E$ ainda, possibilitar a vivência dos discentes dos cursos de Educação Física e Fisioterapia da UFVJM no atendimento ao público infantil. A atividade aquática tem como base alguns eixos principais: A) Afetivo: pautado no estreitamento das relações afetivas entre o bebê e o(a) cuidador(a). Além da interação com os(as) monitores(as) extensionistas e na socialização com outras famílias. B) Brincadeiras e Jogos: uso de jogos lúdicos, brincadeiras, músicas e atividades coletivas. C) Estimulação Aquática: utilizando o efetivo estímulo da água (temperatura, pressão, tato, controle da respiração) para aprimoramento dos processos de aprendizagem. Objetivo: O objetivo geral do projeto Nada Melhor é o desenvolvimento das habilidades aquáticas dos bebês e crianças por meio da exploração da movimentação corporal e controle da respiração na piscina. Metodologia: O projeto de extensão Nada Melhor está devidamente registrado na PROEXC/UFVJM e completou 10 anos em 2017. A cada semestre letivo uma rotina é executada para o pleno funcionamento das atividades, a saber: Divulgação: continuamente é feita a divulgação do projeto destacando o público-alvo e suas características básicas. Utiliza-se para isso o portal da universidade, as mídias sociais (www.facebook.com/nadamelhorufvjm), cartazes e a própria divulgação oral realizada pelos usuários. Uma lista de espera controla os que aguardam para entrar no projeto e um grupo no whatsapp coordena a comunicação entre os usuários facilitando o controle de faltas e o fornecimento e trocas de informações. Seleção dos monitores: a cada início de semestre letivo são selecionados os monitores voluntários do projeto, dando-se prioridade àqueles que já fazem parte da equipe. Na hipótese de vaga, novos alunos de Fisioterapia e Educação Física são inseridos ao grupo. Treinamento dos monitores: antes do início das atividades com as famílias os monitores, mesmo os veteranos, passam por um treinamento visando discutir o histórico do projeto, seus objetivos e as formas de execução das atividades com base na literatura mais atual. Seleção das crianças: as famílias que já fazem parte do projeto são comunicadas sobre a data de início. Na existência de vagas, crianças da lista de espera são avaliadas e incluídas e seus cuidadores recebem as orientações para o processo de acolhimento. Já para as crianças veteranas no projeto, que completaram 3 anos de idade, suas famílias são orientadas a procurarem um serviço de natação infantil com a devida supervisão de Professores de Educação Física. Execução das atividades: a estimulação aquática é realizada na piscina terapêutica da Clínica-escola de Fisioterapia (campus JK), uma vez por semana para cada turminha. Essas turminhas são compostas por 10 crianças/cada, por seus cuidadores (que executarão a atividade na piscina) e uma equipe de monitores extensionistas (geralmente 4 discentes de graduação) responsáveis por planejar e coordenar a atividade a cada semana. Encerramento do semestre: ao final de cada semestre letivo o grupo 
escolhe a forma de encerramento (aulinha temática especial e fornecimento de diploma às crianças) visando reforçar os laços entre todos os envolvidos no projeto e fornecer orientações específicas para os cuidados no período de férias (risco de afogamento doméstico ou em locais públicos). Interação com a pesquisa: vários trabalhos de conclusão de curso (TCC) e projetos de pesquisas estão vinculados ao projeto Nada Melhor, sendo continuamente iniciados ou concluídos respeitando a legislação específica para pesquisa com humanos. Resultados: $O$ "Nada Melhor" a cada semestre supera seu quantitativo de famílias atendidas, com demandas cada vez maiores, mas, principalmente cumprindo sua principal meta que é desenvolver uma atividade de extensão qualificada com a participação efetiva das comunidades acadêmica e externa. Desde 2007, este projeto extensionista da UFVJM, vem se aprimorando e fornecendo um serviço de qualidade à comunidade e reforçando sua conexão com o ensino e pesquisa. Destaca-se a enorme quantidade de depoimentos positivos dos usuários quanto aos benefícios da atividade, como o prazer que o bebê e/ou criança tem em participar da atividade, a melhora nas ações de cuidados como o banho, o estreitamento afetivo, a melhora na qualidade do sono e a qualificação do desempenho motor do bebê na piscina. Conclusão: O Nada Melhor vem sendo um projeto de extensão de fluxo contínuo e que retorna em serviço de qualidade o investimento da sociedade na universidade pública (UFVJM). Ao estabelecer laços fortes entre a comunidade acadêmica e a comunidade externa, dá empoderamento a esta última tanto no aspecto da percepção de um ambiente universitário para todos(as) quanto nos desfechos relacionados à estimulação aquática infantil, como a segurança (prevenção de afogamento) e a habilidade para conduzir uma atividade com seu filho(a) no meio aquático (brincar na água).

\title{
A Fisioterapia Aquática aplicada ao atleta de alto rendimento
}

\author{
Fernando Calixto
}

\section{Especialista em Fisioterapia Aquática, Professor de Watsu nível 1 e 2 (WABA)}

Introdução: O esporte de alto rendimento apresenta uma infinidade de nuances que devemos considerar ao trabalharmos com atletas profissionais. Os aspectos mentais, físicos e econômicos podem influenciar diretamente o desempenho. A atuação do Fisioterapeuta Esportivo se caracteriza pelo exercício profissional em todos os níveis de atenção à saúde, em todas as fases do desenvolvimento ontogênico, e nos diversos grupos populacionais e atenção aos que necessitam do enfoque esportivo adaptado, com ações de prevenção, promoção, proteção, educação, intervenção terapêutica e recuperação funcional do atleta amador e profissional, nos mais diversos ambientes. A modalidade esportiva, sendo ela individual ou coletiva pode ter influência direta nos tipos de lesões que possam acometer esse atleta. As lesões traumáticas são mais comuns em esportes de contato enquanto as lesões crônicas em esportes que exijam uma postura mantida para a realização dele. A fisioterapia aquática poderá atuar com o alto rendimento nos diversos tipos de lesões, como também, nas diversas fases da reabilitação, podendo ser fundamental nas fases iniciais, como um acelerador do processo, e nas fases finais na manutenção do fortalecimento, condicionamento físico global e prevenção. Um dos papéis importantes da fisioterapia aquática está direcionado aos trabalhos de prevenção de lesões e recuperação deste atleta após treinamentos e/ou competições. Contextualização: Para que tenhamos um trabalho bem-sucedido do ponto de vista preventivo de lesões, como também na reabilitação propriamente dita, é de suma importância que este atleta seja submetido previamente por avaliação fisioterapêutica global prévia. Para alcançarmos os objetivos de tratamento em fisioterapia aquática, temos diversas técnicas e conceitos como abordagens a serem utilizadas em diversas fases do trabalho fisioterapêutico. $O$ Watsu pode contribuir com os objetivos de reequilíbrio muscular através do trabalho das cadeias musculares, na recuperação muscular após treinamentos e competições como também atuando no controle da ansiedade e estresse. O Conceito Halliwick por sua vez, na adaptação de pessoas portadoras de deficiência que possam vir a se tornar atletas de alto rendimento, como nos trabalhos de propriocepção, coordenação motora e estabilização muscular. Com o foco direcionado para o fortalecimento muscular e estabilização articular temos as técnicas de Bad Ragaz. Os exercícios aquáticos terapêuticos nos dão diversos recursos passivos, ativos-assistidos, ativos-resistidos e de relaxamento corporal que vão proporcionar ao atleta benefícios em todas as fases da reabilitação, 
como também na prevenção e recuperação corporal. Conclusão: O fisioterapeuta deve dominar o conhecimento dos princípios físicos e efeitos fisiológicos da imersão para optar pelos métodos e materiais aquáticos mais indicados, conforme os objetivos terapêuticos. Ainda que seja oportuna a escolha como principal recurso de tratamento, a Fisioterapia Aquática precisa ser considerada como adjuvante aos outros recursos utilizados em solo, dependendo da fase de reabilitação.

\title{
A Fisioterapia Aquática do futuro
}

\author{
João Douglas Gil \\ Clínica de Fisioterapia Douglas Gil - São Paulo - SP \\ CEFIT - Centro de Estudos em Fisiologia do Exercícios - São Paulo - SP
}

Com a intensão de apresentar as futuras tecnologias da Fisioterapia Aquática, foi mostrado um vídeo no início da aula com piscinas tecnológicas, hidrodinâmicas, com alturas de pisos reguláveis, correntes aquáticas, jatos, esteiras rolantes, entre outras tecnologias, porém o grande objetivo foi convidar os participantes a uma grande reflexão sobre como será o profissional do futuro. Ao apresentar a necessidade deste profissional ter importantes qualidades como, conhecimento teórico baseado em evidências científicas, habilidade de manuseio, aplicabilidade da tecnologia na prática de fisioterapia aquática, a mensagem a refletir foi de que nada adiantará de toda tecnologia do futuro se o profissional não for humano o suficiente para atender o outro ser humano com compaixão, respeito, cumplicidade, responsabilidade, conhecimento e principalmente amor ao paciente, a profissão e a si mesmo. Foi registrado os trabalhos de John Sarno, médico e pesquisador americano da Universidade de Nova York, um dos primeiros a falar sobre a relação dor e emoção de forma científica, explicando a relação dos neurotransmissores e respostas bioquímicas, sentimentos e emoções nos quadros álgicos de coluna lombar. Após sensibilizar os presentes com um vídeo sobre as relações pessoais e familiares, ficou a mensagem final da aula, encorajar os fisioterapeutas do futuro a desenvolverem proposta de trabalho baseadas em honestidade, respeito, ética, simplicidade, amor, sem esquecer que 0 verdadeiro profissional do futuro, está sendo formado, construído nos dias de hoje. 
Menção honrosa

\title{
Aos oito melhores trabalhos apresentados no III Congresso Brasileiro de Fisioterapia Aquática
}

\author{
1음 Luar \\ Aferição da força aplicada sobre um protótipo humano durante diferentes técnicas de \\ tração lombar em ambiente aquático
}

Belmar José Ferreira Andrade Filho', André Ivaniski Mello', Marcela Zimmermann Casal², Jefferson Fagundes Loss ${ }^{3}$, Flávia Gomes Martinez ${ }^{3}$

'Grupo de Pesquisa em Comportamento Motor e Fisioterapia Aquática, ${ }^{2}$ Programa de PósGraduação em Ciências do Movimento Humano, Universidade Federal do Rio Grande do Sul, Porto Alegre/RS, ${ }^{3}$ Professor Doutor adjunto da Escola de Educação Física, Fisioterapia e Dança, Universidade Federal do Rio Grande do Sul, Porto Alegre

Belmar José Ferreira Andrade Filho: belmar.fisio@gmail.com

Introdução: A terapia por tração da coluna tem sido largamente utilizada para o tratamento de dores lombares há milhares de anos. Existem diversas técnicas descritas de tração da coluna, tais como técnicas manuais, suspensão ou com auxílio de máquinas e pesos, objetivando o aumento do espaço e hidratação dos discos intervertebrais, reduzindo o material herniado. Estas técnicas podem ser aplicadas também em ambiente aquático, somadas aos benefícios conhecidos da água aquecida, com um consequente aumento do relaxamento muscular e elasticidade dos tecidos moles. Estudos que utilizaram pesos conhecidos ou máquinas mostraram os efeitos e benefícios da tração da coluna, porém ainda pouco se sabe sobre a aplicação das técnicas manuais, como a força exercida sobre o corpo e o tempo de aplicação necessários para atingir tais benefícios. Objetivo: Aferir e comparar as forças aplicadas por diferentes terapeutas sobre um protótipo humano e o tempo de manutenção das mesmas durante diferentes técnicas de tração lombar em ambiente aquático. Métodos: Trata-se de um estudo misto, do tipo Ex Post Facto comparativo, com análise quantitativa e questionário de qualidade do protótipo. A amostra foi composta por 13 profissionais experientes em fisioterapia aquática, que executaram cinco diferentes técnicas de tração manual em um protótipo humano. Dentre elas, três técnicas individuais e duas em duplas. Um protótipo foi construído a partir de um manequim humano masculino, confeccionado de material plástico, o qual foi articulado e instrumentalizado com uma célula de carga impermeabilizada posicionada na região lombar para obtenção dos dados. Durante a realização de cada técnica foi aferida da força máxima (FM) de tração e, após esta etapa, foi registrado o tempo de manutenção de cada técnica a $70 \%$ da FM, com auxílio de software para obter feedback visual. Também foi aplicado um questionário sobre a qualidade do protótipo para a reprodutibilidade das técnicas. Para o cálculo da FM de tração foi utilizado o valor do pico máximo de força atingido durante a realização de cada técnica. Após, foi mensurado o tempo máximo mantido em cada técnica a 70\% da FM, considerando variações de até $10 \%$. Os dados foram apresentados em média e desvio padrão. A comparação destas variáveis nas diferentes situações foi realizada por ANOVA de uma via e post test de Bonferroni ou por test $t$, sendo considerado significativo diferenças com $p<0,05$. Resultados: as FMs encontradas variaram entre $22 \mathrm{kgf}$ e $72,3 \mathrm{kgf}$ entre as diferentes técnicas e terapeutas, sendo a técnica com pegada pelos tornozelos a que atingiu os maiores picos de força, significativamente maior do que a pegada pelo tórax $(p<0,001)$. O tempo de manutenção durante as diferentes técnicas variou entre 6 segundos e 3 minutos e 16 segundos, onde a técnica com pegada pelos tornozelos apresentou o maior tempo de manutenção, sendo significativamente maior do que a técnica com pegada pelo tórax $(p<0,05)$ e maior que a técnica com pegada pela cabeça $(p<0,001)$. A qualidade do protótipo foi considerada satisfatória pelo questionário, porém com deficiências em relação à aderência das mãos do terapeuta com a superfície corporal do protótipo. Conclusão: Tais achados indicam que estas técnicas manuais de tração da coluna são capazes de gerar forças suficientes para provocar efeitos benéficos sobre a coluna e podem auxiliar na construção de programas terapêuticos.

Palavras-chave: tração lombar, fisioterapia aquática, protótipo humano. 


\section{Lugar \\ Efeitos da fisioterapia aquática na cognição e motricidade do indivíduo portador de demência senil - um estudo de caso}

Ana Paula Radies Adames ${ }^{1,2}$, Christye Ramos da Silva', Erica Cardaretti do Nascimento Vieira1, Marina Fortuna Lucas ${ }^{1,3}$, Juliana Bittencourt ${ }^{1,2,3}$, Fernanda Manaia Gonçalves Chaves ${ }^{1,3}$, João Pedro Delgado de Almeida1', Igor da Silva Diniz Brauns ${ }^{1,3}$

${ }^{1}$ Centro de Saúde Veiga de Almeida (CSVA/UVA), Universidade Veiga de Almeida, Rio de Janeiro/RJ, 2 Instituto de Neurociências Aplicadas (INA), Rio de Janeiro/RJ, ${ }^{3}$ Laboratório de mapeamento Cerebral de Integração Sensório Motora, Instituto de Psiquiatria da Universidade Federal do Rio de Janeiro (IPUB/UFRJ), Rio de Janeiro/RJ

\section{Email: ana.adames712@gmail.com}

Introdução: De acordo com a Organização Mundial de Saúde [1]] a demência é um problema de saúde pública, representando uma das principais causas de incapacidade e dependência na vida adulta. Embora afete principalmente pessoas idosas, não é uma etapa normal do envelhecimento. A Fisioterapia Aquática pode ser uma abordagem extremamente promissora no tratamento de quadros demenciais por sua gama de recursos hidrodinâmicos e repercussões fisiológicas que incluem processos de enriquecimento ambiental, estimulação sensório-motora, aumento do fluxo sanguíneo cerebral, facilitação da motricidade e intensificação da neuroproteção em resposta a atividade muscular em meio líquido. Objetivo: Verificar os efeitos da Fisioterapia Aquática na função cognitiva e motora de um indivíduo idoso com diagnóstico de demência, e, secundariamente, analisar sua influência em parâmetros específicos como marcha, equilíbrio dinâmico, memória, atenção, organização visuoespacial, controle inibitório e função executiva. Metodologia: A paciente foi submetida a sessões de Fisioterapia Aquática com duração de uma hora e vinte minutos, aplicadas duas vezes por semana durante o período quatro meses, totalizando 32 atendimentos. A terapia incluiu exercícios aeróbicos, atividades cognitivas e psicomotoras, e técnicas da terapia específica da água através dos conceitos Halliwick e Bad Ragaz. Foram avaliadas habilidades cognitivas e cinético-funcionais através da utilização dos Testes de Avaliação Funcional nas Atividades da Vida Diária, Teste de Alcance Funcional, Mini Exame do Estado Mental, Teste de Stroop, Teste do Relógio e Teste de Fluência Verbal. A primeira bateria avaliativa foi realizada em um momento pré-tratamento e as baterias subsequentes foram aplicadas a cada 8 sessões ao longo dos 4 meses de intervenção, totalizando assim, 5 baterias avaliativas. Ao final das 32 sessões, foi feita uma análise comparativa de todos resultados encontrados para quantificar a eficácia do tratamento e a evolução da paciente. Resultados: A paciente apresentou aumento progressivo dos escores do Teste do Relógio, Teste de Fluência Verbal e dos Testes de Avaliação Funcional das Atividades de Vida Diária até a Quarta Avaliação, mantendo estes resultados na Avaliação Final. No Teste de Stroop os resultados foram ascendentes em todas as avaliações. Houve uma pequena queda dos escores do Teste de Alcance Funcional e do Mini Exame do Estado Mental na Quarta Avaliação, que foi superado na Avaliação Final. Discussão: A termodinâmica, a flutuabilidade e a viscosidade são princípios capazes de promover efeitos neuroterapêuticos importantes, possibilitando que indivíduos com dificuldade de locomoção aumentem sua percepção proprioceptiva, ampliem a aquisição de força, e consigam executar atividades funcionais com maior facilidade e segurança em meio aquático, o que favorece a criação de um engrama motor [2-4]. Além disso, a imersão em água é uma forma de estimulação sensorial multimodal capaz de modular a integração sensório-motora e otimizar o processamento cerebral, facilitando assim a reabilitação motora e cognitiva [5,6]. De forma complementar, o exercício físico em meio aquático parece superar o terrestre em termos de secreção de citocinas e neurotrofinas, em especial do Fator Neurotrófico Derivado do Cérebro [7]. Este, por sua vez tem sido correlacionado com a melhora da cognição e ao aumento volumétrico do hipocampo, região cerebral fortemente vinculada à memória e ao aprendizado espacial [8]. Por fim, Sherlock et al. [9] sugere que o exercício aquático conta com mecanismos de enriquecimento ambiental podendo ter maior impacto sobre a cognição do que o exercício em solo. Esses achados justificam e corroboram com os resultados expostos no presente estudo, uma vez que os testes 
demonstram melhora dos parametros avaliados. Conclusão: Conclui-se que a utilização de um programa específico de Fisioterapia Aquática que envolva exercícios aeróbicos, atividades cognitivas e psicomotoras, e técnicas de terapia específica da água foi capaz de melhorar a motricidade geral e a cognição global do indivíduo portador de demência, assim como aspectos pontuais das duas vertentes. Apesar da ausência de estudos que revelem diretamente os motivos pelos quais a Fisioterapia Aquática mostrou-se tão benéfica no quadro demencial exposto, uma vasta literatura se complementa ao mostrar seu potencial no processo de reabilitação neurológica. Diante da positiva repercussão do tratamento, sugere-se as futuras pesquisas sejam feitas com amostras maiores, utilizem recursos de neuroimagem e investiguem os níveis séricos de neurotrofinas em resposta a essa abordagem na população com demência.

Palavras-chave: fisioterapia aquática, demência, neurologia.

\begin{tabular}{|l|c|c|c|c|}
\hline \multicolumn{7}{|c|}{ Análise Qualiquantitativa (Roleau et al., 1992) } \\
\hline Avaliação Inicial & Segunda Avaliação & Terceira Avaliação & Quarta Avaliação & Avaliação Final \\
\hline & & & \\
\hline
\end{tabular}

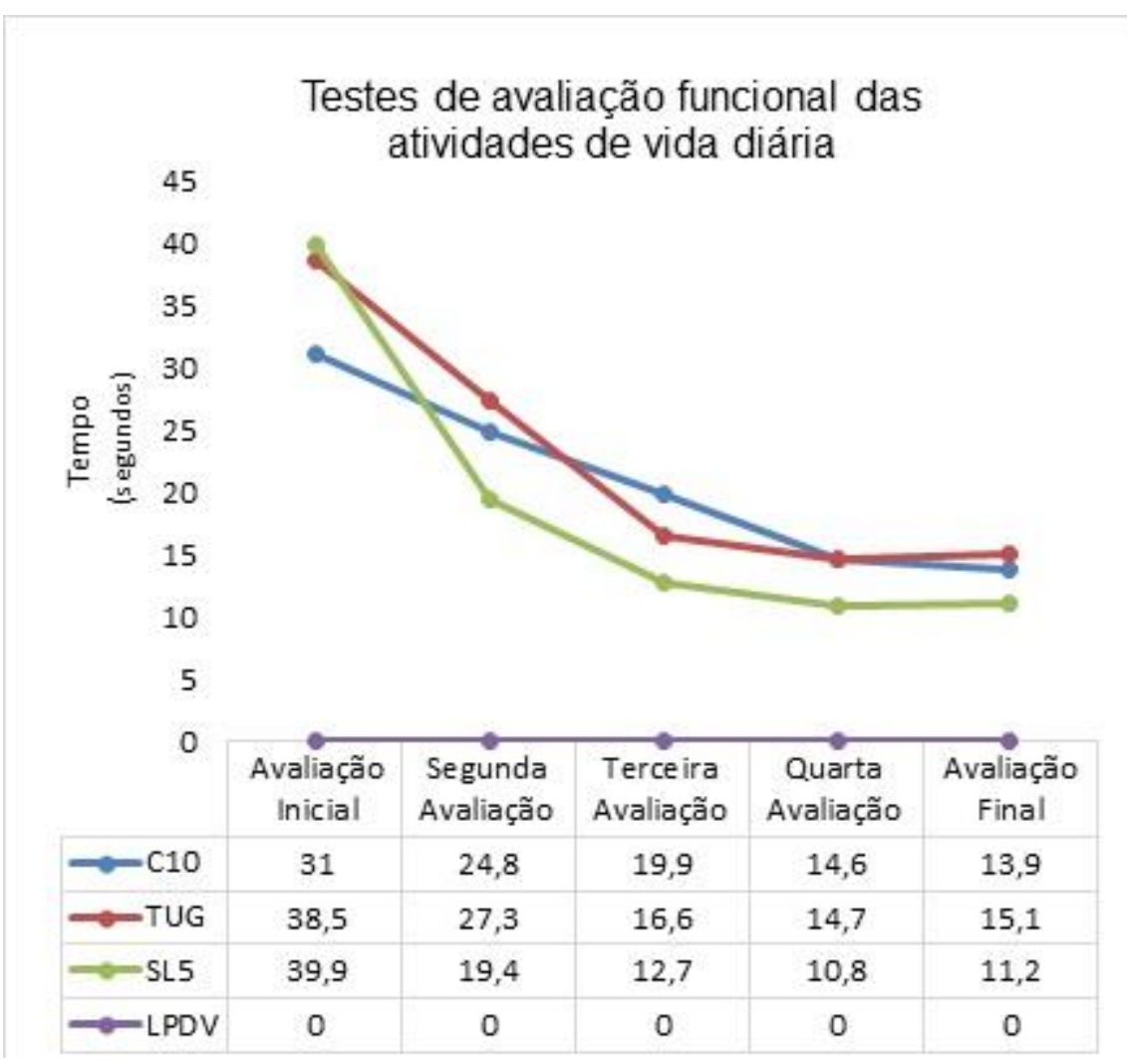




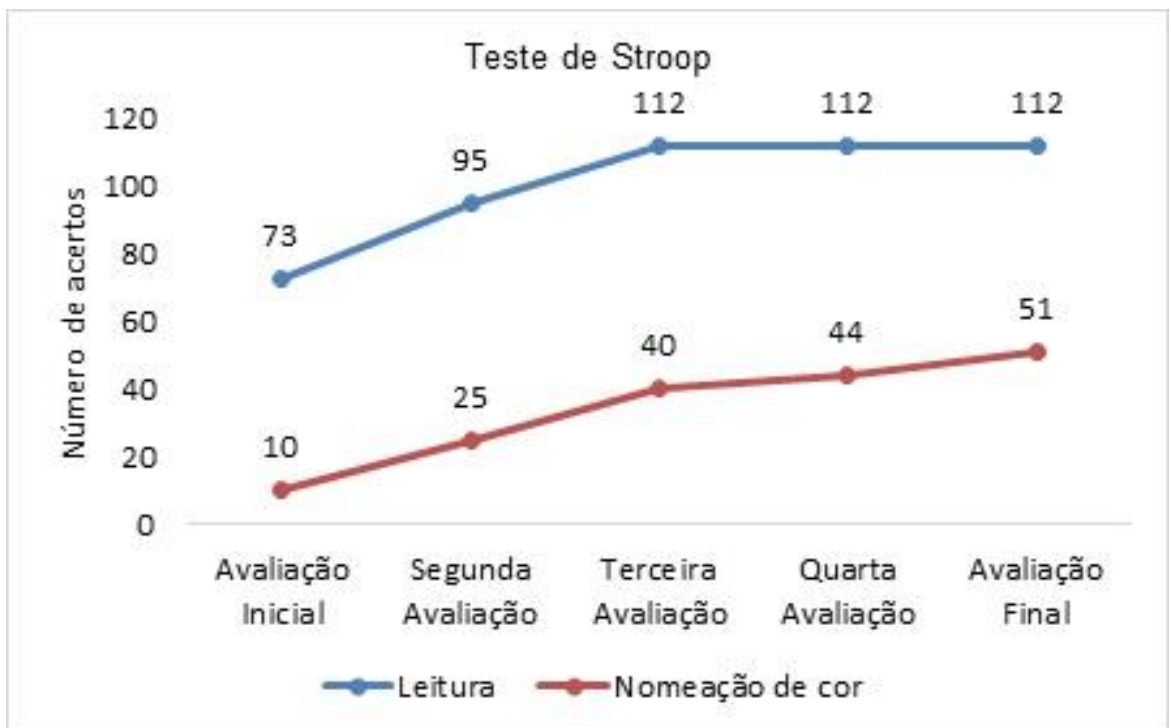

C10 = Teste de caminhada de 10 metros; TUG = Timed up and Go test; SL5 = Teste de Sentar e Levantar de 5 repetições; LPDV = Levantar de Pé partindo do Decúbito Ventral

\section{Referências}

1. World Health Organization. Dementia: a public health priority. Geneva: World Health Organization; 2012.

2. Frohman AN, Okuda DT, Beh S, Treadaway K, Mooi C, Davis SL et al. Aquatic training in MS: neurotherapeutic impact upon quality of life. Ann Clin Transl Neurol 2015;2(8):864-72. https://doi.org/10.1002/acn3.220

3. Marinho-Buzelli AR, Bonnyman AM, Verrier MC. The effects of aquatic therapy on mobility of individuals with neurological diseases: a systematic review. Clin Rehabil 2015;29(8):741-51. https://doi.org/10.1177/0269215514556297

4. Volpe D, Pavan D, Morris M, Guiotto A, lansek R, Fortuna S et al. Underwater gait analysis in Parkinson's disease. Gait Posture 2017;52:87-94. https://doi.org/10.1016/j.gaitpost.2016.11.019

5. Sato $D$, Onishi $H$, Yamashiro $K$ et al. Water immersion to the femur level affects cerebral cortical activity in humans: functional near-infrared spectroscopy Study. Brain Topogr 2012;25:220-7. https://doi.org/10.1007/s10548-011-0204-z

6. Sato D, Yamashiro $\mathrm{K}$, Onishi $\mathrm{H}$ et al. The effect of water immersion on short-latency somatosensory evoked potentials in human. BMC Neurosci 2012;13:13. https://doi.org/10.1186/1471-2202-13-13

7. Bansi J, Bloch W, Gamper U, Kesselring J. Training in MS: influence of two different endurance training protocols (aquatic versus overland) on cytokine and neurotrophin concentrations during three weeks randomized controlled trial. Mult Scler J 2013;19(5):613-21. https://doi.org/10.1177/1352458512458605

8. Erickson KI, Voss MW, Prakash RS, Basak C, Szabo A, Chaddock L et al. Exercise training increases size of hippocampus and improves memory. Proc Natl Acad Sci USA 2011;108(7):3017-22. https://doi.org/10.1073/pnas.1015950108

9. Sherlock LA, Hornsby JR, Guyton W, Rye J. Physiological effects of aquatic exercise on cognitive function in the aging population. International Journal of Aquatic Research and Education 2013;7(3):9. https://doi.org/10.25035/ijare.07.03.09 


\section{3ํㅡㅁ Lugar \\ Análise da caminhada dentro d'água em pessoas com doença de Parkinson: um estudo com acelerometria}

Caroline de Cássia Batista de Sousa ${ }^{1}$, Erico Leite Cavalcante ${ }^{1}$, Ana Vitória de Morais Inocêncio", Gustavo Ribeiro Porpino Esteves ${ }^{1}$, Rafael José Rodrigues Silva Lucena1, Kétura Rhammá Cavalcante Ferreira ${ }^{1}$, Maria das Graças Wanderley de Sales Coriolano ${ }^{2}$, Marco Aurélio Benedetti Rodrigues $^{1}$

${ }^{1}$ Grupo de Pesquisa Engenharia Biomédica, UFPE, Recife/PE, ${ }^{2}$ Departamento de Anatomia Humana, UFPE, Recife/PE, Brasil

Caroline de Cássia Batista de Sousa: carolinecbsouza@gmail.com

Introdução: A doença de Parkinson (DP) é uma doença neurodegenerativa, resultante de disfunções nos núcleos da base, localizados no cérebro, relacionados com o controle da motricidade automática. As características motoras básicas da DP são: bradicinesia, tremor de repouso, instabilidade postural, perda dos reflexos posturais e o congelamento ou Freezing que é marcado por uma repentina incapacidade de iniciar ou continuar a andar. A técnica da identificação de movimentos através da acelerometria pode ser usada para medir a atividade física ou seu impacto nas estruturas do corpo humano, como nos exercícios de marcha. Objetivo: Analisar e comparar a caminhada dentro e fora da água em pessoas com Doença de Parkinson através da acelerometria. Métodos: O estudo foi dividido em duas partes. A primeira parte foi a adaptação de um equipamento para trabalhar com acelerometria e utilização dentro da água. Visando essa atividade foi desenvolvido um sistema composto por dois sensores de acelerometria integrados a um microcontrolador com comunicação a um computador realizada através do protocolo Bluetooth. A finalidade dessa comunicação sem fio é de visualizar os resultados e armazená-los para uma possível análise estatística, em um computador pessoal. Para impermeabilização e selagem do equipamento de hardware, para o funcionamento dentro da água, foi utilizado um verniz impermeabilizante e cola epoxi Araldite®. A segunda parte foi a aplicação do instrumento através de um estudo piloto na Clínica Rogério Antunes - Unidade Torreão/PE. Os acelerômetros foram colocados na face interna do pé, embaixo do maléolo medial. A coleta de dados foi realizada através do projeto previamente autorizado pelo Comitê de Ética em Pesquisa sob CAAE 86285418.7.0000.5208, onde foi analisada a caminhada dentro e fora da água, por um percurso de 8 metros, de um indivíduo com diagnóstico de Doença de Parkinson, com o auxílio da acelerometria. Resultados: Com a acelerometria foi possível observar a cadência e o comprimento, velocidade e altura do passo, bem como o tempo para realização do teste dentro do ambiente aquático e fora dele. Quando comparado com a água, houve um acréscimo de aproximadamente $14 \%$ na largura do passo do paciente e uma redução de $52,8 \%$ da velocidade da caminhada. Houve também um aumento de $96,51 \%$ no tempo utilizado para execução do teste. Durante o teste fora da água a cadência observada foi de 46,31 passos por minuto e dentro da água foi de 20,73 passos por minuto. Conclusão: A partir dos dados analisados foi possível observar que a caminhada em ambiente aquático proporcionou um aumento na largura do passo e uma redução da velocidade do paciente comparada a caminhada em solo. A cadência reduzida na caminhada dentro da água proporciona uma maior estabilidade para o paciente durante a caminhada. Além destes resultados, foi possível também validar a impermeabilização do instrumento, mostrando que uma resina de uso cotidiano é efetiva.

Palavras-chave: hidroterapia, doença de Parkinson, acelerometria. 


\section{4은 Lugar \\ Efeitos da Fisioterapia Aquática no índice de massa magra na síndrome de Guillain-Barré (SGB)- estudo de caso}

Maria Cristina Parisotto', Adriana Maria Bufo², Antonio Marcos Castro², Fernanda Campana', Bruna Plassa ${ }^{2}$

${ }^{1}$ Universidade Paulista-UNIP, Assis/SP, ${ }^{2}$ Clínica Spazio Plathanus, departamento de Hidroterapia, Marilia/SP

Email: que.mais@hotmail.com

Introdução: Paciente P.P.P., D.N.08/06/1971, sexo masculino, com história previa de Síndrome de Guillain-Barré (SGB) diagnosticada em maio de 2013, que evolui para tetraparesia flácida grau IV. Em 2015 procurou o serviço de Hidroterapia, em cadeira de rodas, com maior comprometimento de hemicorpo a esquerda. Objetivo: Comparar e analisar a eficácia de um programa de reabilitação aquática no índice de massa magra, e consequente melhoria da independência funcional na fase crônica após da SGB. Métodos: Trata-se de um estudo de caso comparativo, através de analise sequenciada de janeiro de 2015 a julho de 2018, do índice de massa livre de gordura (IMLG) total e por segmento corporal, e taxa metabólica basal com exame de Bioimpedância elétrica (BIA) InBody230, escala de Medida de Independência Funcional (MIF), e Escala de severidade de Fadiga (ESF). Foi submetido a protocolo de fisioterapia aquática na Clínica Spazio Plathanus, até julho de 2018, com sessões de 50 minutos em média, alternando trabalho de alta intensidade, em 2 dias da semana. Resultados: Após período de tratamento, observou-se melhora da força muscular em MMII, e do equilíbrio, com adequação do andador para a marcha, evoluindo para muleta canadense. O reflexo foi observado nos resultados de BIA, e nas escalas MIF e ESF. No que se refere ao trabalho de alta intensidade (HIIT) e baixo volume, que usa intensidades próximas do máximo em sessões de curta duração, ele parece gerar maior estimulação periférica local do músculo esquelético, melhorar a composição corporal e aumentar a saúde cardiorrespiratória, porém deve ser utilizado com critérios de execução, uma vez que a fadiga pode sobrecarregar a unidade motora, que pode resultar em reversões no IMLG. Conclusão: A análise constante do quadro evolutivo do paciente, balizou a utilização de recursos no processo de reabilitação aquática para aumentar IMLG, facilitando a melhora da independência nas atividades da vida diária e a aptidão muscular. No entanto, a literatura apresenta lacunas, e essa área requer mais estudos, de maior qualidade metodológica.

Palavras-chave: Fisioterapia aquática, síndrome de Guillain-Barré, treinamento intervalado de alta intensidade.

\section{5은 Lugar}

Avaliação do equilíbrio em ambiente aquático através da acelerometria em paciente pós acidente vascular cerebral (AVC)

Amanda Maria da Conceição ${ }^{1}$, Caroline de Cássia Batista de Souza ${ }^{2}$, Maria Clara Porfirio de Souza ${ }^{2}$, Kétura Rhammá Cavalcante Ferreira ${ }^{1}$, Leiliane Patrícia Gomes de Macêdo², Malkiçedheq Benjamim Celso da Silva Silva ${ }^{1}$, Ana Vitória de Morais Inocêncio ${ }^{1}$, Marco Aurélio Benedetti Rodrigues ${ }^{3}$

${ }^{1}$ Grupo de Pesquisa Engenharia Biomédica, UFPE, Recife, ${ }^{2}$ Fisioterapeuta; Faculdade São Miguel, Recife, ${ }^{3}$ Programa de Pós-Graduação em Engenharia Elétrica

Amanda Maria da Conceição: amanda.1fisio@hotmail.com

Introdução: O Acidente Vascular Cerebral (AVC) é caracterizado como um déficit focal neurológico, de causa presumida vascular, com início súbito, de duração superior a 24 horas ou que leve o paciente a óbito. O AVC Compromete o Sistema Nervoso Central (SNC) sendo responsável por uma série de lesões que podem ser transitórias ou permanentes e que 
comumente deixam sequelas como o déficit de equilíbrio. $O$ acelerômetro é um instrumento utilizado para mensurar a aceleração, onde pode-se calcular a velocidade dos movimentos, a partir das oscilações do corpo, podendo ser empregado na avaliação do equilíbrio. Objetivo: Avaliar o equilíbrio após um AVC, através da acelerometria em ambiente aquático. Métodos: Trata-se de um estudo do tipo piloto. A pesquisa foi composta por duas etapas sendo a primeira o desenvolvimento e adaptação de um equipamento para a aquisição e o armazenamento dos sinais através de acelerômetros, realizado em um laboratório devidamente equipado. O sistema é composto por dois sensores de acelerometria integrados a um microcontrolador com comunicação a um computador através do protocolo Bluetooth. A segunda parte foi a aplicabilidade do instrumento dentro da água. e a sua verificação de funcionamento. Para impermeabilização e selagem do sistema foi utilizado um verniz impermeabilizante e cola epóxi Araldite ${ }^{\circledR}$. O Acelerômetro foi colocado na região lombar da paciente, o equilíbrio foi avaliado mediante uma caminhada de 8 metros na água e em solo através da análise do sinal de acelerometria. A coleta de dados foi realizada através do projeto previamente autorizado pelo comitê de ética sob CAAE 86285418.7.0000.5208. O estudo foi realizado na clínica Rogério Antunes, unidade Torreão Recife/PE, em parceria com a Universidade Federal de Pernambuco (UFPE). Resultados: Diante das disfunções encontradas na caminhada decorrente do déficit de equilíbrio, comumente observado após um AVC, realizou-se uma caminhada em ambiente aquático a fim de avaliar o equilíbrio. O diferencial da pesquisa foi a utilização do acelerômetro para verificar sua usabilidade como ferramenta de auxílio na avaliação do equilíbrio dentro da água. O equipamento utilizado possibilitou observar a velocidade do passo e o deslocamento do centro de massa da paciente durante a caminhada dentro da água através da variação da acelerometria nos três eixos ( $\mathrm{XYZ}$ ). EM relação ao equilíbrio pode-se identificar que a variação do centro de massa é menor durante o exercício dentro da água que fora da água, tornando a caminhada mais constante, sem variações abrutas ou desequilíbrios rápidos. A caminhada dentro da água foi realizada durante $8 \mathrm{~m}$, perfazendo um tempo médio de 23,24 segundos para completar o percurso. Assim a velocidade média para esse percurso foi de $0,344 \mathrm{~m} / \mathrm{s}$. Conclusão: Após a análise dos dados pôde-se concluir que o instrumento, utilizando acelerômetros, pode ser eficaz na avaliação do equilíbrio durante a caminhada em ambiente aquático. Conclui-se com a utilização do equipamento, que o exercício dentro da água proporciona ao paciente um exercício mais estável e com menores variações em relação ao centro de massa.

Palavras-chave: acidente vascular cerebral, equilíbrio, acelerometria.

\title{
6은 Lugar \\ Reabilitação aquática em criança com miosite ossificante: relato de caso
}

Kétura Rhammá Cavalcante Ferreira ${ }^{1}$, Izaura Muniz Azevedo², Rogério Azevedo Antunes Pereira $^{3}$

\begin{abstract}
${ }^{1}$ Mestranda do Programa de Pós-graduação em Engenharia Biomédica da Universidade Federal de Pernambuco, ${ }^{2}$ Mestranda do Programa de Pós-graduação em Gerontologia da Universidade Federal de Pernambuco, ${ }^{3}$ Especialista em traumato-ortopedia (COFFITO), docente do Programa de Pós-graduação em Fisioterapia Aquática
\end{abstract}

Kétura Rhammá Cavalcante Ferreira: ketura.cavalcante@hotmail.com

Introdução: Uma situação patológica onde há formação de tecido ósseo, no qual não deveria existir é chamada de ossificação heterotópica e pode ser ocasionada por traumas ou distúrbios genéticos. A miosite ossificante decorrente de traumas em músculos estriados esqueléticos, desencadeiam um processo de calcificação e posterior ossificação. Levando a atrofia muscular, rigidez, dor e consequentemente diminuição da amplitude de movimento. Comumente sua manifestação corresponde de 60 a 70 porcento dos casos, havendo predominância no gênero masculino e em membros inferiores. A fisioterapia aquática aponta como estratégia para os achados clínicos de pacientes com miosite ossificante, em detrimento de seus efeitos fisiológicos e propriedades físicas da água, auxiliando no processo de reabilitação. Objetivo: Relatar o caso de uma criança com miosite ossificante traumática, submetida ao atendimento fisioterapêutico em meio aquático, apresentando as manifestações clínicas antes da intervenção e os ganhos 
advindos da reabilitação através da análise dos ângulos (goniometria). Métodos: Trata-se de um relato de caso realizado com uma criança do gênero masculino, com sintomatologia álgica, diminuição de amplitude de movimento e edema em membro inferior, ocasionados após evento traumático. A criança não recebeu nenhum tipo de intervenção fisioterápica no período de seis meses após a lesão. O menor foi atendido na Clínica Rogério Antunes, em Recife/PE, onde passou por uma avaliação inicial no serviço de fisioterapia e foi encaminhado ao setor de fisioterapia aquática. A intervenção com a fisioterapia aquática ocorreu por um período aproximado de três meses, uma vez por semana, com duração de trinta minutos cada sessão. Durante as sessões, o limiar de dor e desconforto do paciente foi respeitado, levando em consideração a escala analógica de dor. Foram atribuídos exercícios com enfoque na amplitude de movimento, mobilizações, manipulações, estimulação sensorial, fortalecimento de membros inferiores, treino proprioceptivo e treino de marcha, com o equilíbrio estático e dinâmico. Resultados: O trauma, como fator causal, repercutiu em: edema, alteração sensorial, rigidez e alterações biomecânicas, ocasionando uma precária funcionalidade da articulação do joelho esquerdo do menor. Com a reabilitação aquática, houve ganho na amplitude de movimento para $110^{\circ}$ de flexão no joelho esquerdo, equiparando-se ao joelho direito, fortalecimento muscular e ausência de edema. Conclusão: Em decorrência das propriedades físicas da água e dos efeitos fisiológicos da imersão, os quais favorecem a redistribuição do fluxo sanguíneo e diminuição da sensibilidade nas terminações nervosas, o meio aquático possibilitou minimizar o quadro álgico durante os manuseios, estimular sensorialmente, aumentar a flexibilidade e amplitude do movimento, assim como, aquisições na propriocepção e fortalecimento muscular do paciente. Evidenciou-se a contribuição da fisioterapia aquática gerando impacto direto na diminuição da sobrecarga articular e amenizando as atitudes compensatórias, oferecendo maior mobilidade e funcionalidade ao menor.

Palavras-chave: hidroterapia, miosite ossificante

\section{$7^{\circ}$ Lugar \\ Influência da Fisioterapia Aquática no risco de queda em idosos: ensaio clínico}

Christye Ramos da Silva ${ }^{1}$, Ana Paula Radies Adames ${ }^{1}$, Bianca Muniz ${ }^{1}$, João Pedro Delgado de Almeida', Marina Fortuna Lucas ${ }^{2}$, Erica Cardaretti do Nascimento Vieira ${ }^{1}$, Fernanda Manaia Gonçalves Chaves², Igor da Silva Diniz Brauns²

${ }^{1}$ Centro de Saúde Veiga de Almeida (CSVA/UVA), Universidade Veiga de Almeida, Rio de Janeiro/RJ, 'Laboratório de mapeamento Cerebral de Integração Sensório Motora, Instituto de Psquiatria da Universidade Federal do Rio de Janeiro (IPUB/UFRJ), Rio de Janeiro/RJ.

\section{Christye Ramos da Silva: christyeramos@yahoo.com.br}

Introdução: Ao envelhecermos, nosso corpo passa por algumas alterações. Essa mudança sistêmica reflete em um aumento na predisposição de queda em indivíduos com idade mais avançada, segundo o Datasus 2012 [1] a internação hospitalar por queda na população idosa foi a mais elevada especialmente em indivíduos com 70 anos ou mais, alcançando uma taxa de 57,53 a cada 10.000 habitantes brasileiros. Visto que, a queda é uma consequência da incapacidade dos sistemas de controle postural em adequarem-se a uma perturbação em decorrência da deterioração ocasionada nos sistemas sensoriais, neurais e/ou musculoesquelético ocasionados pelo envelhecimento [2]. Objetivo: Verificar a influência do protocolo de Fisioterapia aquática no risco de queda em idosos e analisar as diferenças dos valores dos testes funcionais (Timed up and go test, sentar e levantar em 30 segundos e alcance funcional) após 6 meses de acompanhamento. Metodologia: Estudo experimental, ensaio clínico. Realizado no Centro de Saúde da Universidade Veiga de Almeida (CSVA). Participaram do estudo idosos acima de 60 anos que relataram queda nos 6 meses antecedentes a intervenção e que concordaram em participar voluntariamente do estudo através da assinatura do Termo de Consentimento Livre e Esclarecido, CAAE 80453417.8.0000.5291. Foram excluídos indivíduos que realizavam outros tipos de tratamentos paralelos a Fisioterapia Aquática, doenças neurológicas, incontinência fecal e/ou urinária. O grupo foi submetido a 30 sessões de Fisioterapia Aquática, com duração de 50 minutos cada e frequência de 2 vezes/semana. $O$ 
tratamento consistiu em exercícios aeróbios nos primeiros 16 minutos e técnicas da terapia específica da água ao decorrer dos 34 minutos que consistiram em Controle de Rotação de Halliwick e Método de Anéis de Bad Ragaz. A piscina manteve-se com a temperatura de $33^{\circ}$ graus em todos os atendimentos. A análise estatística foi realizada através do MedCalc Software versão 14.0. A distribuição dos dados foi analisada pelo teste Shapiro-Willk $(p<0,05)$, assumindo a normalidade. Foi utilizado o Teste Anova para medidas repetidas para avaliar as diferenças de variância para o grupo em momentos distintos (4 avaliações com intervalo de 10 sessões) através das variáveis Timed Up and Go, Alcance Funcional e Sentar e Levantar em 30 segundos. Resultados: Os resultados encontrados apontaram diferença significativa $(p>0,05)$ entre as avaliações para todos os testes aplicados. No teste de alcance funcional, foi observada uma média inicial (média \pm dp 22,23 $\pm 9,33$ ) apresentando aumento constante e significativo em centímetros na segunda (média \pm dp $26,76 \pm 11,12$ ) e na terceira avaliação (média \pm dp 29,88 \pm 8,99), com maior diferença na quarta avaliação, intervalo de 30 sessões, onde os pacientes atingiram uma média (média \pm dp $34,47 \pm 9,19$ ). No teste de sentar e levantar em 30 segundos, foi observada uma média inicial (média \pm dp 9,11 $\pm 10,76$ ) repetições, também com evolução crescente de desempenho na segunda (média \pm dp 10,76 $\pm 3,88$ ) e terceira avaliação (média \pm dp 12,05 $\pm 3,54$ ) e na quarta avaliação os pacientes atingiram o maior valor de repetições (média $\pm \mathrm{dp} 13 \pm 4,25$ ). No Timed Up and Go Test, foi observada uma média inicial (média $\pm d p$ $15,64 \pm 9,88$ ) segundos que apresentou redução para o segundo e terceiro teste e na quarta avaliação os pacientes atingiram o menor tempo em segundos (média \pm dp 9,17 $\pm 5,51$ ) o que significa melhor execução do teste, ou seja, percorreram o mesmo trajeto em menos tempo. Conclusão: Através desse ensaio clinico podemos evidenciar a eficácia da Fisioterapia aquática na redução do risco de queda dos participantes, baseado na melhora dos testes funcionais e da correlação dos valores de predição de queda de cada teste utilizado que, antes incluíam os indivíduos em valores preditos a alto risco de quedas e ao final das 30 sessões os participantes alcançaram valores de classificação para baixo risco de quedas, acreditamos que a Fisioterapia Aquática proporcionou melhora na velocidade da marcha, maior força em membros inferiores e melhora do controle de tronco contribuindo para a integridade do equilíbrio estático e dinâmico. Consequentemente acreditamos que a reintegração desses indivíduos às suas atividades pode ser influenciada positivamente, amenizando assim, os efeitos do envelhecimento, reduzindo a morbidade, mortalidade e patologias secundárias à queda. $\mathrm{O}$ ambiente aquático demonstrou grande efetividade no potencial para facilitar o controle de movimento durante as transferências através da lentificação dos movimentos dentro desse meio promovido pelas propriedades físicas da água, permitindo que os indivíduos errassem e acertassem, estimulando o efeito aprendizagem, possibilitando uma melhora da experimentação e programação motora. Palavras-chave: Fisioterapia aquática, redução de queda, idosos.

\section{Referências}

1. http://datasus.saude.gov.br

2. Maki BE, Mcllroy WE. Control of rapid limb movements for balance recovery: agerelated changes and implications for fall prevention. Age and ageing 2006;35(2Suppl)):ii12-ii18. 


\title{
8은 Lugar \\ Efeitos da Fisioterapia Aquática no tratamento da síndrome da fibromialgia em mulheres: uma revisão
}

\author{
Rubenyta Podmelle ${ }^{1}$, Veridiane Freitas ${ }^{1}$, Edleuza Cabral Silva ${ }^{1}$, Amanda Maria Conceição $^{2}$ \\ ${ }^{1}$ Faculdade São Miguel, Recife/PE, ${ }^{2}$ Grupo de Pesquisa Engenharia Biomédica, Recife/PE, \\ UFPE
}

Email: rmartins63@hotmail.com

Introdução: A Síndrome da Fibromialgia é uma síndrome não inflamatória muito frequente, caracterizada por dor muscular difusa associada à dor em pontos superficiais específicos (tender points) e fadiga. Os sintomas mais frequentes são distúrbios do sono, rigidez articular matinal, ansiedade e depressão. A população acometida por essa síndrome é composta, em sua maioria, por mulheres, numa proporção de 6-10, atingindo principalmente pacientes adultos jovens e idosos, com idade entre 30 e 60 anos. A fisioterapia aquática mostra-se eficaz, no controle do quadro álgico e na manutenção da funcionalidade dos pacientes. apresentando efeitos benéficos, pois trata-se de uma abordagem terapêutica que utiliza exercícios em meio aquático aquecido proporcionando o alívio dos sintomas. Objetivo: Avaliar os benefícios da fisioterapia aquática no tratamento de mulheres com a Síndrome da Fibromialgia. Métodos: Trata-se de um estudo do tipo revisão de literatura, utilizando as bases de dados LILACS, SCIELO, PubMed, o portal de dados Biblioteca Virtual em Saúde. Para as buscas das referências foram selecionados artigos publicados no período entre 2009 e 2018. Definiram-se como descritores: sistema musculoesquelético, fibromialgia, hidroterapia e seus correlatos nos idiomas, inglês espanhol. Tivemos como critérios de inclusão: estudos que abordaram a Fisioterapia Aquática como tratamento para a fibromialgia em mulheres. Foram adotados como critérios de exclusão: estudos que abordassem outras patologias associadas à fibromialgia nas quais os sintomas se confundam, bem estudos que abordaram fibromialgia em outro tipo de população. Resultados: Foram encontradas 160 referencias na combinação dos descritores, das quais 54 foram selecionadas após a leitura dos títulos e dos resumos, após serem aplicados os critérios de elegibilidade 8 referencias permaneceram para análise final. As pesquisas realizadas para 0 presente estudo mostraram que a fisioterapia aquática melhora a qualidade de vida de mulheres acometida pela fibromialgia. A imersão no ambiente aquático promove uma melhora na circulação sanguínea e diminuição dos espasmos, além de minimizar os sintomas dolorosos. Conclusão: Diante do exposto, constatou-se que a fisioterapia aquática proporciona uma melhora relevante do quadro clínico da fibromialgia. A melhora do quadro deve-se aos vários benefícios obtidos, como: a promoção do alívio das dores e relaxamento muscular, a redução da rigidez articular, atenuação dos níveis de ansiedade e auxílio no controle do sono. Como limitação, vale ressaltar que os estudos encontrados não apresentaram com clareza os exercícios realizados durante as sessões de fisioterapia aquática. Sugere-se novos estudos de intervenção em que os exercícios aquáticos utilizados sejam descritos com clareza, para, assim, permitir a construção de uma prática baseada em evidências.

Palavras-chave: Hidroterapia, sistema musculoesquelético, fibromialgia 
Resumos

Análise autonômica cardíaca (domínio frequência) em idosos submetidos a exercícios na
água

Sousa EGD¹, Gouveia GPM², Castro LTG¹ , Silva PA¹, Araújo RL¹ , Oliveira TR¹

${ }^{1}$ Grupo de Pesquisa em Fisioterapia Avaliativa e Terapêuticas- GPFAT, Universidade Federal do Piauí, Parnaíba/PI, ${ }^{2}$ Coordenador do Grupo de Pesquisa em Fisioterapia Avaliativa e Terapêuticas- GPFAT

\section{Email: laryssatheodora@hotmail.com}

Introdução: A variabilidade da frequência cardíaca (VFC) é um importante marcador da atividade cardíaca neural. Como ocorre com a capacidade aeróbia, a VFC diminui durante o processo de envelhecimento devido a alterações do SNA. Alguns fatores, incluindo a prática de exercício físico regular, parecem atenuar essas adaptações. Tem sido referido que a prática de exercício físico em nível moderado pode aumentar a modulação vagal. Objetivo: Analisar a influência do exercício aquático em piscina aquecida na variabilidade da frequência cardíaca no domínio frequência: Transformada Rápida de Fourier (FFT). Métodos: O presente trabalho tratou-se de um estudo intervencionista, descritivo, transversal de caráter quantitativo. Estiveram envolvidos 12 sujeitos com idade média de 67,77 $\pm 5,94$ (60-78) anos, residentes no município de Parnaíba$\mathrm{PI}$, sob aprovação do Comitê de Ética da Universidade Federal do Piauí/PI, com parecer número 2.379.589. Verificou-se a VFC domínio frequência nos voluntários, sendo monitorada por um frequencímetro Polar Rs800x® antes e após cada intervenção, utilizando-se da técnica de análise espectral da variabilidade cardíaca. $O$ protocolo constituiu-se de uma série de alongamento, exercícios resistidos para membros superiores e inferiores, equilíbrio e relaxamento, executados duas vezes por semana durante seis semanas. O protocolo consistiu em aquecimento (caminhada frontal, lateral e estacionária) por 5 minutos, alongamentos por 30 segundos de cada grupamento muscular e fortalecimento deles, equilíbrio e propriocepção com apoio unipodal em superfície instável, marcha estática, um pé a frente do outro sobre uma superfície instável durante 30 segundos e relaxamento por 5 minutos. Realizou-se o teste descritivo e o de normalidade de Shapiro-Wilk que confirmou uma distribuição normal para as variáveis em estudo, obtendo $p>0,05$, sendo utilizado o teste t pareado. Resultados: Ao inferir dados da variabilidade da frequência cardíaca, antes e após, o protocolo de exercícios resistidos, quanto às variáveis $L F, H F$ e a relação $L F / H F$ da transformada rápida de Fourier, por meio do teste t pareado, não obteve significância estatística para referidas variáveis, apresentando valores de $p=0,088 ; 0,372$ e 0,569, respectivamente. Conclusão: Conclui-se que o protocolo realizado não refletiu na redução do tônus vagal cardíaco, não havendo aumento da frequência cardíaca, possibilitando atendimento seguro ao grupo estudado.

Palavras-chave: Idosos, sistema nervoso, hidroterapia. 
Efeitos da Fisioterapia Aquática para alívio da dor no período pós-operatório do paciente com paralisia cerebral grave: série de casos

\author{
Barbosa JLR ${ }^{1}$, Castro $\mathrm{CR}^{2}$, Braga $\mathrm{DM}^{3}$ \\ ${ }^{1}$ Fisioterapeuta do setor de fisioterapia aquática da $A A C D$, São Paulo/SP, ${ }^{2}$ Fisioterapeuta do \\ setor de fisioterapia aquática da $A A C D$, São Paulo, $S P,{ }^{3}$ Coordenador do serviço de fisioterapia \\ aquática da $A A C D$, São Paulo/SP
}

Email jluis-fisio@hotmail.com

Introdução: A Paralisia Cerebral (PC) descreve um grupo de desordens permanentes do movimento e da postura. A prevalência de luxação do quadril na PC varia entre 3 e $60 \%$ nos pacientes tetraparéticos ou GMFCS (Gross Motor Function Classification System) níveis III, IV, e V. Entre os problemas desencadeados pela luxação do quadril se destaca o aumento da morbidade em termos de dor. A fisioterapia aquática é uma modalidade terapêutica a mais para atuar no quadro álgico e os efeitos da imersão podem influenciar nos níveis de dor. Objetivo: Avaliar a eficácia da fisioterapia aquática no controle da dor em pacientes com PC no pósoperatório de cirurgia ortopédica de quadril. Métodos: Foi realizado um estudo clínico na AACD, no setor da fisioterapia aquática aprovado pelo comitê de ética, sob o Parecer: 1.936.086/2017. A amostra foi constituída por pacientes com diagnóstico de PC do tipo tetraparesia espástica GMFCS V, submetidos a cirurgias ortopédicas de quadril. Foram excluídos pacientes que apresentavam instabilidade clínica e não consolidação óssea. Inicialmente os pais responderam 03 questionários: a Escala Visual Analógica (EVA) relacionado a impressão dos pais quanto a intensidade da dor durante o manuseio da criança após o procedimento cirúrgico, questionário Child Health Questionnare (CHQ - PF50) relacionado à qualidade de vida e NOPPAIN um instrumento utilizado para avaliar a dor em pacientes não comunicativos. Foi monitorado os itens de dor a cada 2 semanas até o término das 12 semanas. O programa de intervenção na fisioterapia aquática consistia em sessões de 35 minutos, 2 vezes por semana durante 12 semanas, a temperatura da água entre $33,5 \mathrm{C}^{\circ}$ e $34,5 \mathrm{C}^{\circ}$. Foi aplicado um protocolo composto por massagem, mobilização articular dos membros inferiores, alongamento muscular dos flexores e adutores de quadris. Para caracterização da amostra foi utilizada media e porcentagem, para as variáveis intensidade da dor na opinião dos pais mensuradas através das escalas: EVA da dor e Noppain no momento pré, na segunda semana e pós-período de intervenção foi utilizado o teste de Wilcoxon $(p<0,05)$, o tamanho do efeito ( $d$ de Cohen) foi calculado para verificar $o$ impacto do Programa de intervenção nos parâmetros intensidade da dor (EVA/Noppain) e qualidade de vida (CHQ - PF50). Resultados: Participaram do estudo 3 pacientes de ambos os sexos, duas mulheres e um homem, com faixa etária média de 15 anos de idade que iniciaram a fisioterapia aquática após 77 dias, todos já recebiam medicação para dor, mas apresentavam queixa de dor relatado pelos cuidadores após cirurgia. A dor é o principal desfecho desta pesquisa, pois muitos pacientes relatam no pós-operatório de quadril, sendo está responsável por alterações fisiológicas e emocionais, se não adequadamente controlado, pode resultar em sofrimento e exposição dos doentes a riscos desnecessários. Achados na literatura reforçam a ideia de que um dos principais efeitos do corpo em imersão é a analgesia. Nesse estudo verificou-se através da EVA que ocorreu uma redução gradativa da dor após 12 semanas $(p=$ 0,043 ) de fisioterapia aquática (cohen $=0,99$ ), sendo o pico de percepção de queixa álgica após duas semanas $(p=0,033$; cohen $=0,98)$. Dados estes que coincidem com os resultados da NOPPAIN inicial e após 12 semanas $(p=0,046$; cohen $=0,99)$, e após duas semanas observamos diminuição do pico de percepção de queixa álgica de $45,4 \%$ porém não sensível no Noppain $(p=0,01$; cohen $=0,95)$. Podemos relacionar a alguns fatores, a modulação da dor é influenciada pelo aumento do limiar da dor, acreditamos que este benefício ocorreu devido às propriedades físicas da água como a temperatura e a turbulência. Além disso, há um efeito de relaxamento do tônus muscular, que pode ocorrer devido à vasodilatação e diminuição da sobrecarga corporal, que atuam na tensão muscular exacerbada. Observamos melhora da qualidade de vida $(55,49 \%), \mathrm{CHQ}-\mathrm{PF} 50$ inicial e final (cohen $=0,33$ ), que impacta significativamente na Saúde global (cohen $=0,55$ ), Comportamento (cohen $=0,51$ ) e Alteração de saúde (cohen $=0,72)$. O item 5 da escala, que avalia a dor corporal $(p=0,463$; cohen $=0,97$ ), vai de encontro com os resultados da escala EVA e NOPPAIN, fatores estes que interferiram positivamente nos itens Impacto emocional nos pais (cohen= 0,47 ) e Impacto no tempo dos pais (cohen 0,45 ), pois acreditamos que a redução da dor repercutiu na redução do tempo de 
cuidados dos responsáveis dedicados as crianças. Conclusão: Verificamos que a fisioterapia aquática foi eficaz no controle da dor em pacientes com PC GMFCS $V$ no pós-operatório de cirurgia ortopédica de quadril influenciando na qualidade de vida.

Palavras-chave: paralisia cerebral, hidroterapia.

\title{
Efeitos de exercícios aquáticos adaptados no equilíbrio e na qualidade de vida de deficientes visuais: série de casos
}

\author{
Sarah Santiago Lenci ${ }^{1}$, Nuno Miguel Lopes Oliveira ${ }^{2}$, Suraya Gomes Novais Shimano ${ }^{3}$ \\ ${ }^{1}$ Universidade Federal do Triângulo Mineiro, Uberaba/MG, ${ }^{2}$ Departamento de Fisioterapia \\ Aplicada, Universidade Federal do Triângulo Mineiro, Uberaba/MG
}

\section{Email: sarahsantiagolenci@gmail.com}

Introdução: A deficiência visual somada ao sedentarismo resulta em alterações, como perda de equilíbrio e consequentemente gera impactos na qualidade de vida. Objetivos: Avaliar o efeito de um programa adaptado de fisioterapia aquática no equilíbrio e na qualidade de vida de deficientes visuais. Métodos: Este estudo foi realizado no Instituto de Cegos do Brasil Central, aprovado pelo comitê de ética local (no 2.496.643). Participaram desta série de casos quatro deficientes visuais considerados ativos pelo IPAQ que realizaram fisioterapia aquática por um período de 12 semanas, duas vezes por semana, com tempo de 60 minutos por sessão. $O$ protocolo de exercícios foi elaborado contendo comandos verbais e táteis, divididos em três etapas: 20 minutos de aquecimento, 30 minutos de exercícios para equilíbrio e coordenação e 10 minutos de alongamento. Foi realizada uma avaliação inicial(Al), uma avaliação após 6 semanas de intervenção(AV6) e após 12 semanas (AV12), para avaliar o equilíbrio e a qualidade de vida foram utilizados o teste de Berg, Romberg, Alcance funcional e o questionário Whoqolbref que considera os domínios físico, psicológico, relações sociais e meio ambiente. Os dados foram organizados e uma análise descritiva dos resultados das variáveis foi realizada e apresentada em valores percentuais. A relevância clínica foi avaliada utilizando o teste $D$ de Cohen para grupos dependentes. Resultados: No equilíbrio corporal, todos apresentaram pontuação máxima em todas as avaliações que foram realizadas, não evidenciando déficit de equilíbrio, que é esperado em pessoas com deficiência visual, e havendo manutenção deste. $O$ mesmo ocorreu no equilíbrio avaliado pelo teste de Romberg. Já no teste de Alcance Funcional houve um aumento de $5,28 \%$ na AV6 e $11,75 \%$ na AV12, porém apresentando pouca relevância clínica. A qualidade de vida pode sofrer influência de fatores externos, não relacionados diretamente ao tipo de exercício realizado. Isto ocorreu em alguns domínios, que apresentaram piora nos resultados. Porém o domínio social, que demonstrou melhora reflete os ganhos obtidos em um trabalho, que apesar de ter acompanhamento individualizado é realizado em grupo. Com relação à qualidade de vida, o domínio físico teve declínio na AV6 e AV12 em relação à Al, sendo clinicamente relevante. O domínio psicológico manteve-se inalterado. No domínio social houve melhora nos resultados na $A \vee 6$ e na $A \bigvee 12$, porém com pequena relevância clínica. No domínio ambiental ocorreu piora na AV6 e na AV12, com grande relevância clínica. Estes resultados refletiram na qualidade de vida total, que obteve declínio na AV6, mas melhorou na AV12. Conclusão: Sugere-se que a fisioterapia aquática adaptada para pessoas com deficiência visual promove a manutenção do equilíbrio corporal e melhora na percepção das relações sociais. Palavras-chave: fisioterapia aquática, deficiência visual, equilíbrio. 
Os benefícios da Fisioterapia Aquática para crianças portadoras do transtorno do espectro autista: uma revisão sistemática

\author{
Lambertucci MS ${ }^{1}$, Araújo TM¹, Borin PLH² \\ 1Programa de pós-graduação em reabilitação aquática no Hospital Israelita Albert Einstein, São \\ Paulo/SP, 2Fisioterapeuta aquática no Hospital Israelita Albert Einstein, São Paulo/SP \\ Email: marianasivieri@gmail.com
}

Introdução: O transtorno do espectro autista é um transtorno do neurodesenvolvimento que possui como características dificuldades na comunicação e interação social. Atualmente a literatura mostra que esses indivíduos também apresentam alterações motoras como a alteração postural, dispraxia, distribuição de peso anormal, atraso de desenvolvimento neuropsicomotor, alterações em tônus muscular, e de movimentos sincronizados de marcha. O meio líquido é descrito como um ambiente que permite várias sensações e ações favorecendo tanto a percepção sensorial e ambiental como também favorece a ação motora. A fisioterapia aquática através de suas propriedades físicas é aplicável aos distúrbios motores e cognitivos, trazendo componentes motores e lúdicos, tornando-se uma indicação para tratamentos a pacientes com autismo. Objetivo: Evidenciar os benefícios da fisioterapia aquática no tratamento de crianças autistas. Métodos: Os estudos foram selecionados por meio de pesquisa bibliográfica eletrônica no browser Google Scholar e nas bases de dados PubMed e SciELO, incluindo publicações feitas entre janeiro de 2008 a março de 2018 limitando a busca para artigos em inglês, espanhol e português. Resultados: Usando os descritores de saúde foi realizada a busca ampla totalizando 1.289 artigos. Excluídos 1.276 por título, 7 artigos por serem estudos de caso e revisões, foram selecionados 7 artigos para leitura na íntegra. Segundo critérios de inclusão e exclusão, 1 artigo foi excluído totalizando assim 6 artigos inclusos no presente estudo. Todos os artigos apresentaram resultados positivos em aspectos motores como força muscular, melhora cardiovascular, melhora de equilíbrio. Nos aspectos comportamentais observou-se melhora da interação social, estilo e qualidade de vida. Além disso, em todos os artigos houve melhora também nas habilidades aquáticas. Conclusão: os estudos selecionados mostram que a fisioterapia aquática é de grande valia para pacientes autistas devido aos seus impactos em todos os âmbitos motores, sociais e cognitivos, trazendo maior funcionalidade e qualidade de vida a estes pacientes.

Palavras-chave: hidroterapia, criança, autismo. Efetividade da Fisioterapia Aquática no tratamento da dor lombar crônica inespecífica em
idosos: revisão sistemática com metanálise

Soares $\mathrm{ML}^{1}$, Pinheiro $\mathrm{F}^{2}$

${ }^{1}$ Programa de Pós-Graduação em Saúde da Criança e do Adolescente, Universidade Federal de Pernambuco, Recife/PE, ${ }^{2}$ Centro Universitário Brasileiro, Recife/ PE

E-mail: luanatsousa@gmail.com

Introdução: A dor lombar crônica inespecífica pode ser definida como a dor contínua ou recorrente com duração mínima de três meses estendendo-se da região infra-glútea à $12^{a}$ vértebra torácica. De etiologia idiopática, não desaparece com procedimentos terapêuticos convencionais, sendo causa de incapacidades e inabilidades prolongadas. A fisioterapia aquática compõe um dos recursos do tratamento conservador utilizado na reabilitação desses pacientes. Objetivo: Verificar a efetividade da fisioterapia aquática no tratamento da dor lombar crônica inespecífica em idosos. Métodos: Foi realizada uma revisão sistemática nas bases de dados Medline, Lilacs, PEDro e Web of Science, incluindo publicações nos idiomas inglês, português e espanhol. A pesquisa nas bases de dados foi realizada no período de maio à junho de 2018 , sem restrição temporal, avaliando os desfechos: dor, amplitude de movimento, rigidez e capacidade 
aeróbica; Como critérios de elegibilidade, os artigos incluídos foram do tipo ensaio clínico randomizado e que abordassem a fisioterapia aquática como recurso de tratamento para dor lombar crônica inespecífica em idosos; Foram excluídos artigos que abordavam intervenções cirúrgicas, artigos de revisão e artigos experimentais. A estratégia de busca foi efetuada baseada nas recomendações do The Prisma Statement, onde cada etapa do estudo foi realizada por dois revisores de forma independente e, posteriormente, comparada. A qualidade metodológica dos artigos selecionados foi avaliada segundo critérios da Cochrane Colaboration, com análise do risco de viés pela Cochrane Risk of Bias Assessment Tool (aleatorização, sigilo de alocação, cegamento de participantes, mascaramento do avaliador e intenção de tratar) e da qualidade da evidência pelo sistema de avaliação proposto por Tugwell (Platinum, Gold, Silver e Bronze). Para avaliar o percentual de concordância entre os revisores foi utilizado o coeficiente de Kappa e para a Metanálise a diferença média ou a diferença média padronizada, com intervalo de confiança de $95 \%$. Para as análises foi utilizado o programa SPSS e para a Metanálise o RevMan 5.1, apresentando significância estatística quando $p<0,05$. Resultados: Foram encontrados 342 artigos, 20 foram excluídos por estarem duplicados. Dos 322 selecionados 302 foram excluídos por não se adequarem aos critérios de inclusão. Dos 40 artigos elegíveis, 21 foram excluídos pelo título/resumo e 19 lidos na íntegra. Destes, 4 foram excluídos por não se tratar de ensaio clínico e 3 por associar a fisioterapia aquática a intervenção cirúrgica. Os programas de fisioterapia aquática variavam de 3 a 32 semanas, 2 a 5 vezes por semana, com uma maior prevalência do gênero feminino. De acordo com risco de viés, quanto ao item alocação 4 apresentaram alto risco de viés, 2 risco indeterminado e 6 baixo risco; Quanto ao item sigilo de alocação 8 apresentaram alto risco, 2 risco indeterminado e 2 baixo risco; Quanto ao item mascaramento do avaliador 7 apresentaram alto risco de viés, 3 risco indeterminado e 2 baixo risco; Quanto ao item intenção de tratar 5 apresentaram alto risco e 7 baixo risco. A concordância intra-avaliadores variou de 0,63 a 0,84, com índice de Kappa de 0,8. Para o desfecho dor foi encontrado uma diferença da média de $-1,58 \quad(p<0,002)$ e para o desfecho amplitude de movimento uma diferença da média de 2,54 $(\mathrm{p}<0,03)$, não apresentando significância para os demais desfechos avaliados. A evidência dessa revisão foi classificada como Silver. A aplicabilidade da fisioterapia aquática aponta que a mecânica dos fluidos, a temperatura da água, o tipo de exercício (adequado a sua intensidade, duração e frequência) e a experiência do profissional são os principais itens que explicam como a hidrocinesioterapia promove o reparo tecidual, promovendo a melhora da sensibilidade central e uma inibição adequada do quadro álgico. Conclusão: A fisioterapia aquática é um dos recursos amplamente empregados na reabilitação de pacientes com dor lombar crônica inespecífica. Nas suas implicações para a prática clínica os artigos demonstraram que a utilização da hidrocinesioterapia promoveu uma melhora significativa na dor e na amplitude de movimento em idosos com dor lombar crônica. Os demais desfechos não apresentaram resultados estatisticamente significantes e podem ter sido influenciados pelo baixo rigor metodológico dos estudos incluídos na metanálise. Desfechos como força muscular, melhora na funcionalidade e na qualidade de vida são um bom ponto de partida para novas pesquisas e, mesmo que alguns riscos de viés diminuam a relevância dos achados, não se tira o mérito do recurso ser benéfico para o público em questão.

Palavras-chave: dor crônica, hidroterapia, modalidades de fisioterapia

Efeitos do método Watsu em crianças em idade escolar com asma moderada: ensaio clínico randomizado controlado

\author{
Soares $\mathrm{ML}^{1}$, Lima $\mathrm{PF}^{2}$ \\ ${ }^{1}$ Programa de Pós-Graduação em Saúde da Criança e do Adolescente, Universidade Federal de \\ Pernambuco, Recife/PE, ${ }^{2}$ Centro Universitário Brasileiro, Recife/PE
}

Email: luanatsousa@gmail.com

Introdução: A asma é uma doença inflamatória crônica caracterizada por hiperresponsividade das vias aéreas inferiores e por limitação variável do fluxo aéreo, reversível espontaneamente ou com tratamento específico, manifestando-se clinicamente por episódios recorrentes de sibilância, dispnéia e tosse normalmente à noite ou ao amanhecer. Resulta de interação entre 
genética e exposição ambiental a alérgenos e irritantes levando ao desenvolvimento e manutenção dos sintomas, conduzindo a limitações na interatividade social e na qualidade de vida das crianças. O Watsu é uma técnica que atua em todos os níveis do ser humano, seja ele físico, emocional ou psicológico. Objetivo: Avaliar os efeitos do método Watsu na função pulmonar e na qualidade de vida em crianças em idade escolar com asma moderada. Métodos: O estudo foi do tipo ensaio clínico randomizado controlado; A pesquisa foi realizada no serviço de Função Pulmonar do Hospital das Clínicas da Universidade Federal de Pernambuco, no período de janeiro à junho de 2018, autorizado pelo CEP sob o no 14273913.3.0000.5207/2018. Como critérios de elegibilidade foram incluídas crianças com diagnóstico de asma clinicamente moderada e estar dentro da faixa etária entre 7 à 12 anos; Foram excluídas as crianças com VEF1 basal $<60 \%$ do predito, incapazes de realizar manobras de expiração forçada, com outras co-morbidades que poderiam afetar a função pulmonar ou com história de infecção pulmonar ? 30 dias. $O$ estudo foi composto por 86 crianças, divididas em dois grupos: controle $(n=40)$ e intervenção ( $n=46)$ acompanhadas em um programa de tratamento de 10 sessões, duas vezes por semana durante 60 minutos; As crianças foram encaminhadas do ambulatório de alergia e pediatria do HC/UFPE, após leitura e assinatura pelos pais do Termo de Consentimento Livre e Esclarecido (TCLE). Foram submetidas ao questionário padrão de asma do serviço de alergia e imunologia do HC/UFPE, além do questionário de qualidade de vida na asma (QQV), inventário de depressão de Beck (IDB) e o inventário de ansiedade IDATE-TRAÇO de Spielberger (AIT). Foi realizada uma avaliação inicial com cirtometria torácica, espirometria e oscilometria de impulso, além da mensuração de dados bioantropométricos. No início de cada sessão eram aferidos a frequência cardíaca, frequência respiratória e saturação periférica de oxigênio. Ao término das dez sessões se repetiu a avaliação inicial. Para variáveis contínuas foi utilizada média e desvio-padrão e para natureza categórica foi utilizada proporção. A análise univariada foi usada para avaliar efetividade entre as intervenções e correção de Bonferroni para as comparações múltiplas. Para intenção de tratar foram realizadas imputações por meio de regressão sequencial. Todas as análises foram conduzidas no SPSS com nível de significância de 5\%. Resultados: A cirtometria torácica pré e pós-tratamento aumentou a medida axilar, sendo na $1^{1}$ expiração de $2 \mathrm{~cm}$, na inspiração de $3 \mathrm{~cm}$ e na $2^{a}$ expiração de $5 \mathrm{~cm}$. Na medida xifóide ocorreu um aumento na $1^{\text {a }}$ expiração de $7 \mathrm{~cm}$, na inspiração de $5,5 \mathrm{~cm}$ e na $2^{\mathrm{a}}$ expiração de 6,5 $\mathrm{cm}$. Na medida umbilical, ocorreu apenas de $0,5 \mathrm{~cm}$ na $2^{\circ}$ expiração. Nos valores espirométricos, pré e pós-tratamento, pode-se observar um aumento de $300 \mathrm{ml}$ no VEF1 (12\%), aumento de 8,29 L no VEF1/CVF (11\%) e aumento de 102,1 L/min no PFE (39\%). A CVF apresentou uma pequena diminuição $(-0,3 \%)$. A Oscilometria de impulso apresentou redução nos volumes de R5 e R5-R20; No AIT, ocorreu queda de 9 pontos na 1를 sessão, na 6ª sessão queda de 14 pontos e na $10^{\underline{a}}$ sessão uma diminuição de 11 pontos modificando o escore do estado de ansiedade para de não ansiedade ao final das sessões. Para o QQV, no mesmo período, pode-se notar a diminuição de $6,5 \%$ na limitação das atividades físicas devido aos sintomas da asma, diminuição de $33,4 \%$ na frequência e gravidade dos sintomas, aumento de $16,7 \%$ na adesão ao tratamento, aumento de 8,3\% no domínio socioeconômico e diminuição de $7,1 \%$ no domínio psicossocial. 0 Watsu trouxe benefícios nos parâmetros avaliativos, funcionalidade e na qualidade de vida das crianças com asma moderada. Conclusão: O método Watsu promove benefícios clínicos com relação à mobilidade torácica, ventilação, ansiedade e qualidade de vida em crianças em idade escolar; Utilizar por um maior número de sessões em outros fenótipos da asma seria um bom ponto de partida para novas pesquisas e, mesmo que alguns riscos de viés diminuam a relevância dos achados, não se tira o mérito do recurso ser benéfico para o público em questão. Palavras-chave: hidroterapia, asma, ansiedade, modalidades de fisioterapia, qualidade de vida.

\title{
Associação entre objetivo funcional e nível de lesão de pacientes diagnosticados com mielomeningocele - um enfoque na CIF
}

\author{
Gouvêa JXM¹, Scontri $\mathrm{CMCB}^{2}$, Werneck $\mathrm{MS}^{1}$, Braga DM¹
}

${ }^{1}$ Departamento de Fisioterapia Aquática, Associação de Assistência à Criança Deficiente (AACD) - Unidade Ibirapuera, São Paulo/SP, ${ }^{2}$ Programa de Aperfeiçoamento em Fisioterapia nas Disfunções Neurológicas da Criança e do Adulto - AACD, São Paulo/SP 
Email: jgouvea@aacd.org.br

Introdução: A mielomeningocele (MMC) se caracteriza pela presença de uma bolsa extrusa que contém em seu interior medula espinhal e raízes nervosas envoltas por líquido cerebrorraquidiano com consequente paraplegia flácida e alteração sensitiva abaixo do nível de lesão. Pode ser classificada em níveis funcionais de acordo com seu comprometimento neurológico. $O$ tratamento inclui a atuação multidisciplinar com enfoque no desempenho funcional. A fisioterapia aquática fornece estímulos motores e sensoriais, facilitando a aquisição das etapas motoras de acordo com o nível da lesão. Objetivo: Traçar o perfil dos pacientes com MMC de seus verificando se os objetivos funcionais estão de acordo com o componente de Atividade e Participação da Classificação Internacional de Função, Deficiência e Saúde (CIF) e com o esperado para o nível da lesão. Métodos: Estudo clínico retrospectivo, aprovado pelo Comitê de Ética em Pesquisa da Associação de Assistência à Criança Deficiente (2.682.491/2018). Foram coletados dados dos prontuários dos pacientes, com diagnóstico de MMC, atendidos no setor de fisioterapia aquática na AACD-lbirapuera entre 2013 e 2018. Foram coletados: dados demográficos e clínicos, objetivos funcionais, tempo de permanência em terapia e código da CIF. Um total de 150 prontuários foram analisados, sendo 97 excluídos por estarem incompletos, com código CIF ausente, pelos pacientes ainda estarem em terapias e/ou apresentam outra doença neurológica associada e complicações clínicas, sendo analisados 53 prontuários que apresentaram critérios de elegibilidade. A caracterização da amostra e os dados foram apresentados por meio da média, desvio padrão e porcentagem; posteriormente, foi observada a porcentagem associada com as variáveis dos níveis da lesão, objetivos funcionais e códigos da CIF. Resultados: Dos 53 prontuários (média de idade esteve em 1 ano e 4 meses), $41(77,3 \%)$ apresentaram o objetivo funcional, na alta do setor da fisioterapia aquática, de acordo com o nível da lesão. Dos 10 prontuários com nível torácico, todos atingiram o objetivo de arrastar-se como forma de deslocamento e/ou a transferência de deitado para sentado; 6 códigos do componente de Atividade e Participação da CIF foram usados para classificar os objetivos funcionais propostos, sendo que 3 códigos tentavam classificar o arrastar em prono; os mais utilizados foram: (3) d4558 deslocar-se, outro especificado (arrastar em prono) e (3) d4153 permanecer sentado. Dos 23 analisados no nível lombar alto, 14 (60,8\%) alcançaram os objetivos de engatinhar e/ou manter ortostatismo com apoio e o código mais utilizado foi (12) d4550 engatinhar. Oito $(72,7 \%)$ dos 11 prontuários de nível lombar baixo, alcançaram os objetivos de realizar a marcha lateral e anterior com apoio; dos 5 códigos utilizados, os principais foram (2) d4500 Andar distâncias curtas, (2) d4602 deslocar-se fora de casa e de outros prédios e (2) d465 deslocar-se utilizando algum tipo de equipamento. No nível sacral, os 8 alcançaram o objetivo de treino de marcha sem apoio; dos 5 códigos mais utilizados, os principais foram: (3) d4500 Andar distâncias curtas e (2) d4501 Andar distâncias longas. No nível de lesão classificado como misto - lombar baixo/ sacral, foi considerado o objetivo do nível mais alto e este foi alcançado, o código utilizado foi o d4508 Andar, outro especificado (andar longas distâncias na marcha com andador). Conclusão: Os objetivos funcionais traçados no setor de fisioterapia aquática foram alcançados, em sua maioria, de acordo com o esperado para o nível da lesão. Observou-se que a maioria dos objetivos propostos também estavam de acordo com os códigos da CIF do domínio de Atividade e Participação.

Palavras-chave: meningomielocele, hidroterapia, reabilitação, Classificação Internacional de Funcionalidade, incapacidade e saúde.

\section{Protocolo de controle de tronco no ambiente aquático para crianças com paralisia cerebral: ensaio clínico randomizado}

Oliveira $\mathrm{LMM}^{1}$, Kakihata $\mathrm{AM}^{2}$, Albuquerque $\mathrm{CP}^{3}$, Braga $\mathrm{DM}^{4}$, Branco $\mathrm{FR}^{5}$, Oliveira $\mathrm{LC}^{6}$, Kanashiro $\mathrm{MS}^{7}$, Ramalho VM ${ }^{8}$

${ }^{1,6}$ Fisioterapeutas referência da clínica de Paralisia Cerebral do setor da Fisioterapia Aquática da Associação de Assistência à Criança Deficiente - AACD, São Paulo/SP, ${ }^{2,8}{ }^{2}$ Fisioterapeutas Aprimorandas da AACD em 2015, São Paulo/SP, ${ }^{3}$ Terapeuta Ocupacional do setor da Terapia Ocupacional da AACD, São Paulo/SP, ${ }^{4}$ Fisioterapeuta supervisor do setor da Fisioterapia 
Aquática da AACD, São Paulo/SP, ${ }^{5}$ Fisioterapeuta Gerente da Reabilitação da AACD, São Paulo/SP, ${ }^{6}$ Fisioterapeuta que atuou no setor da Fisioterapia Aquática da AACD, São Paulo/SP

Email: lucianammag@hotmail.com

Introdução: O controle de tronco é essencial para atividades funcionais e muitas vezes se encontra prejudicado em crianças com paralisia cerebral (PC). A reabilitação em ambiente aquático pode estimular o controle de tronco favorecendo a funcionalidade em solo. Objetivo: Avaliar os efeitos de um protocolo de controle de tronco em ambiente aquático em indivíduos com PC diparesia espástica classificados no nível IV do Gross Motor Function Classification System (GMFCS). Métodos: Trata-se de um ensaio clínico controlado, randomizado, cego, de caráter descritivo-analítico, quantitativo. O estudo foi realizado na AACD. Aprovado pelo Comitê de Ética em Pesquisa da AACD (43791215.0.0000.0085/2015), conforme a resolução 466/12 do Conselho Nacional de Saúde (CNS). Aprovado pelo Registro Brasileiro de Ensaios Clínicos, parecer RBR-5rh6cg. Foram triados 92 prontuários dos quais 24 crianças foram incluídas e 22 finalizaram o estudo. Dentre os critérios de inclusão, encontram-se: pacientes com diagnóstico clínico de PC do tipo diparesia espástica, classificados nos níveis IV do GMFCS, com idade entre 4 a 10 anos e 11 meses. Os critérios de exclusão se restringiam a pacientes não colaborativos, incapazes de compreender as atividades propostas, submetidos à cirurgia ortopédica a menos de 12 meses e a bloqueios periféricos a menos de 6 meses. Os pacientes foram alocados por estratificação pelo GMFCS em grupo controle (GC), que realizou terapias convencionais e grupo intervenção (Gl) que realizou o protocolo de exercícios aquáticos. Os grupos foram avaliados pré e pós intervenção através das seguintes escalas e instrumentos: Trunk Control Measurement Scale (TCMS), Pediatric Reach Test (PRT), Eletromiografia de Superfície (EMG) dos músculos reto abdominal e grande dorsal, Mapeamento de pontos de pressão sentado e Flexômetro de Wells. A análise estatística foi realizada através dos testes Kolmogorov-Smirnov, Mann-Whitney, teste de Wilcoxon e Correlação de Spearman. Para análises dos testes foi considerado um intervalo de confiança (IC) de 95\%, o nível de significância de $p<0,05$ e os dados apresentados em mediana. Foram utilizados os softwares SPSS V17, Minitab 16 e Excel Office 2010. Resultados: $\mathrm{Na}$ análise intra-grupo constatou-se melhora na reação de equilíbrio, o $\mathrm{Gl}(\mathrm{p}=0,019)$ melhorou $30 \%$ a mais em relação ao GC. No mapeamento de pressão, observou-se diminuição da pressão no $\mathrm{Gl}$ em membros inferiores durante a realização dos itens $07(p=0,032)$ e 13 $(p=0,005)$ da TCMS. No PRT, o GC apresentou maior deslocamento pós intervenção $(p=0,006)$ que o Gl. Houve melhora da flexibilidade de cadeia posterior e membros inferiores em ambos os grupos. Neste estudo observou-se que o ganho principal nessas crianças, estava relacionado ao controle de tronco. Os exercícios do protocolo foram fundamentados para a estabilização do tronco durante as atividades funcionais, pois estudos demonstram que exercícios com enfoque em tronco auxiliam a estabilização proximal, principalmente ao redor do quadril, resultando assim em maior controle de tronco na posição sentada e maior qualidade nas funções de MMSS em crianças com PC. Conclusão: No presente estudo, observamos que a fisioterapia aquática traz resultados positivos e ganhos motores relacionados ao controle de tronco e funcionalidade para crianças PC diparéticas espásticas GMFCS nível IV, sendo esta uma importante colaboração para a literatura e uma opção de tratamento para a prática clínica.

Palavras-chave: paralisia cerebral, hidroterapia, tronco, reabilitação.

\section{A importância da Fisioterapia Aquática na melhora da qualidade de vida de mulheres fibromiálgicas: uma revisão de literatura}

Kamila Steffanie Farias Barreto ${ }^{1}$, Luana Feitosa Calado ${ }^{1}$, Nathaly Thays Silva Farias ${ }^{1}$, Clarissa Pessoa Lopes ${ }^{1}$, Carlos Eduardo Alves de Souza ${ }^{1}$, Clara Beatriz Torres Maciel ${ }^{2}$

${ }^{1}$ Graduanda em Fisioterapia, Centro Universitário Tabosa de Almeida, Caruaru/PE, ${ }^{2}$ Docente do curso de Fisioterapia, Centro universitário Tabosa de Almeida, Caruaru/PE

Email: kamila-steffanie@hotmail.com 
Introdução: A fibromialgia é uma síndrome de característica crônica, considerada de origem idiopática que causa grandes transtornos na vida do paciente que convive com a mesma. Causa dores constantes em várias regiões anatômicas. Afeta mulheres acima dos 35 anos, ademais, pode estar associada a outros sinais e sintomas que ajudam dar um melhor diagnostico ao paciente, como por exemplo; fadiga muscular, distúrbio do sono, rigidez durante o dia, limitação na funcionalidade, distúrbio psicológicos e distúrbio no sono, geralmente, as pacientes apresentam uma característica comum entre elas, quadros de ansiedade e depressão. A doença causa um grande impacto social as pacientes, pois além de afetar o estado físico das mesmas, também afeta o psicológico, e, causa grandes repercussões sobre a qualidade de vida delas, visto que, muitas são impossibilitadas de realizar sua atividade do dia-a-dia, e a dificuldade em manter sua vida ativa pode gerar problemas no ponto de vista psicossocial, e é diante desse olhar que vem a importância de se buscar novos recursos para assim minimizar o impacto que a fibromialgia causa em suas portadoras. Objetivo: Descrever, de forma sintetizada, a importância da fisioterapia aquática em mulheres fibromiálgicas. Métodos: Trata-se de uma revisão de literatura do tipo narrativa. A busca foi realizada nas bases de dados SciELO, Bireme, Medline. Os critérios de inclusão foram artigos científicos brasileiros e estrangeiros dotados em até 15 anos, com pacientes portadoras da síndrome com faixa etária de idade acima dos 35 anos, como critérios de exclusão os artigos que relatassem a fisioterapia aquática associada a outro recurso. Resultados: A hidrocinesioterapia no tratamento de fibromialgia é praticada em água aquecida entre $32^{\circ}$ e $34^{\circ} \mathrm{C}$, e é um recurso recomendado para o tratamento da fibromialgia, o mesmo apresenta muitos efeitos terapêuticos, pois a água proporciona um efeito de relaxamento muscular pela redução da tensão e a sua ação faz com que ocorra a diminuição da rigidez articular, além disso, o aumento da temperatura promove uma redução da sensibilidade à dor, pois durante a imersão os estímulos nervosos sensoriais agem sobre os estímulos nociceptivos. Outro efeito importante da água aquecida, é a facilidade da execução de movimentos das articulações. Este recurso promove uma redução da sintomatologia e na melhora da realização de atividade de vida diária e profissional de mulheres portadoras, no seu estudo, o mesmo verificou que o programa preestabelecido de exercícios aquáticos terapêuticos durante a sua avaliação muitos pacientes tiveram uma melhora significativa do sono e também aumento da flexibilidade articular. $\mathrm{O}$ método Watsu traz consigo grandes benefícios pela sua alternância de massagem, alongamento e flutuação. As pacientes que passaram pelo tratamento com Watsu relataram redução da intensidade da dor, além disso houve também diminuição do quadro depressivo delas. Conclusão: A fisioterapia aquática traz grandes benefícios as pacientes portadoras desta síndrome, uma vez que o recurso proporciona uma melhora na qualidade do sono, diminuição da dor, ganho de flexibilidade muscular, melhora da sua postura e bem-estar de forma global das pacientes.

Palavras-chave: fibromialgia, fisioterapia, hidroterapia.

Caracterização dos pacientes com lesão medular atendidos no setor de Fisioterapia Aquática da associação de assistência à criança deficiente (AACD)

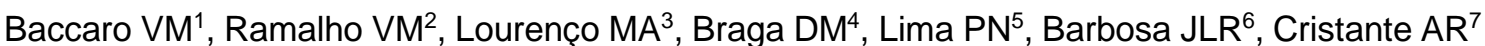

${ }^{1}$ Fisioterapeuta do setor de fisioterapia aquática da Associação de Assistência à Criança Deficiente (AACD), São Paulo, SP, Brasil, ${ }^{2}$ Residente de fisioterapia da AACD, São Paulo/SP, ${ }^{3}$ Fisioterapeuta do setor de fisioterapia aquática da $A A C D$, São Paulo/SP, ${ }^{4}$ Coordenador do setor de fisioterapia aquática da $A A C D$, São Paulo/SP, ${ }^{5}$ Fisioterapeuta do setor de fisioterapia aquática da $A A C D$, São Paulo/SP, ${ }^{6}$ Fisioterapeuta do setor de fisioterapia aquática da $A A C D$, São Paulo/SP, ${ }^{7}$ Médica da $A A C D$, São Paulo/SP

Email jluis-fisio@hotmail.com

Introdução: A lesão medular (LM) é definida como qualquer agressão à medula espinhal, dentro do programa de reabilitação, a fisioterapia aquática é mais um recurso visando favorecer as atividades funcionais do indivíduo com LM. Porém são escassos os trabalhos que traçam a características destes pacientes relacionados com o perfil de funcionalidade. Objetivo: Caracterizar os pacientes com diagnóstico de LM atendidos no setor de fisioterapia aquática de 
um centro de reabilitação e relacionar estas características com a funcionalidade. Métodos: Estudo retrospectivo descritivo baseado na análise de prontuários de pacientes atendidos entre o ano de 2010/2015. Aprovado pelo Comitê de Ética da AACD sob o parecer: 1.834.990/2016. Elaborou-se uma ficha contendo informações como: sexo, idade, diagnóstico clínico e quadro motor segundo a American Spinal Injury Association (ASIA); etiologia e data da lesão; pontuação inicial e final da Medida de Independência Funcional (MIF) e informações sobre os atendimentos na Fisioterapia Aquática. Análise estatística: Foi feita a caracterização da amostra e os dados estão apresentados em média, desvio padrão e porcentagem que foi correlacionada com as variáveis ASIA e MIF. Analisamos os objetivos funcionais e a relação destes com o grau de independência (MIF) e utilizado o programa Excel Office 2010. Resultados: Foram analisados 95 prontuários, a média de idade (44,5 anos) foi maior em relação a outros estudos, os quais a idade permaneceu em 30 anos. Acredita-se que essa diferença se dá em decorrência das causas da lesão, pois a maior parte da população tem como a principal causa à traumática e no nosso estudo ocorreu $64,2 \%$ causa não traumática. A paraplegia foi prevalente em $64,9 \%$ dos casos que vai de encontro com este estudo $62,1 \%$ (lesão incompleta $98,9 \%$ e ASIA D 57,9\%). Os objetivos funcionais mais trabalhados estavam relacionados à ativação muscular de membros inferiores $(81,8 \%)$, treino de equilíbrio tanto na postura sentada quanto de pé $(72,7 \%)$, treino de marcha $(52,7 \%)$ e ortostatismo $(32,7 \%)$ estes dados refletem na funcionalidade observada através da MIF, pois 55 pacientes finalizaram o tratamento no setor, tendo alta por objetivos atingidos. Destes 27 realizaram MIF inicial (média de 90,4 pontos) e final (média de 100,2 pontos), observamos aumento dos pacientes considerados independentes. Foram descartadas $28 \mathrm{MIF}$ por falha no procedimento de aplicação. Após o tratamento proposto, os pacientes apresentaram aumento da pontuação da MIF este achado reflete na ASIA dos pacientes, apresentando incremento na pontuação final dos pacientes (ASIA C e D). Diante disso, considera-se que o indivíduo melhorou a capacidade de desempenhar as atividades de vida diária após o tratamento. Como sugestão acreditamos que se faz necessário investigar protocolos mais detalhados direcionados a uma função específica. Conclusão: Neste estudo prevaleceram os pacientes do sexo masculino e adultos jovens, causa não traumática e paraplégicos. A fisioterapia Aquática pode exercer influência positiva na funcionalidade do paciente LM.

Palavras-chave: medula espinal, hidroterapia.

Efeitos da Fisioterapia Aquática em face dos comprometimentos neurológicos apresentados por crianças portadoras da síndrome congênita do Zika vírus

\author{
Barros $\mathrm{TA}^{1}$, Santos $\mathrm{JAA}^{2}$, Costa $\mathrm{VAA}^{2}$, Santana $\mathrm{AFSG}^{3}$ \\ ${ }^{1}$ Discente em Fisioterapia pelo Centro Universitário Tiradentes - UNIT, Maceió/AL, \\ ${ }^{2}$ Fisioterapeuta pelo Centro Universitário Tiradentes - UNIT, Maceió/AL, ${ }^{3}$ Docente do Centro \\ Universitário Tiradentes - UNIT, Maceió/AL
}

Email: tati-tatiane@hotmail.com

Introdução: As crianças com microcefalia decorrente da infecção pelo vírus da Zika apresentam várias deficiências simultâneas, que incluem hipertonia global grave com hiperreflexia, irritabilidade, hiperexcitabilidade, choro excessivo, crises epilépticas e atrasos no desenvolvimento neuropsicomotor que variam de acordo com o grau de acometimento cerebral. Essas alterações afetam de maneira adversa o desenvolvimento motor, levando a posturas e padrões de movimentos anormais, deformidades musculoesqueléticas e atrasos na aquisição das habilidades motoras. Neste sentido, a fisioterapia aquática pode ser um método terapêutico eficaz para essas crianças, uma vez que proporciona a normalização do tônus temporariamente, permitindo o manuseio adequado para a reeducação motora e reabilitação funcional. Objetivo: Analisar os efeitos da fisioterapia aquática em face dos comprometimentos neurológicos apresentados por crianças portadoras da Síndrome Congênita do Zika Vírus. Metodologia: Tratou-se de um ensaio clínico, com amostra por conveniência, uma abordagem transversal e quantitativa que se desenvolveu na Clínica Escola de Fisioterapia do Centro Universitário Tiradentes. As crianças antes de iniciarem o tratamento por meio da fisioterapia aquática passaram por uma avaliação da função motora, através da escala GMFM-66. Posteriormente, 
antes e após cada sessão de fisioterapia aquática as crianças foram submetidas à aplicação da Escala modificada de Ashworth para avaliar o grau de espasticidade. As sessões aconteceram 1 vez por semana, com duração de 40 minutos, totalizando 12 sessões de tratamento. Ao final do procedimento, as crianças foram reavaliadas, comparando-se o quadro inicial com o final. Estes resultados foram analisados após uma nova aplicação da escala GMFM-66. Resultados: Participaram do estudo 2 crianças, do sexo masculino, com idade entre 6 e 20 meses. $\mathrm{Na}$ avaliação da função motora e do desempenho funcional antes da intervenção da fisioterapia aquática, as crianças apresentaram no GMFN, Dimensão A, a média de $17,6 \%$ e na Dimensão B a média de 6,6\%, totalizando 4,9\%. Na reavaliação, após as 12 sessões de fisioterapia aquática, as crianças apresentaram na Dimensão $\mathrm{A}$, a média de $11,7 \%$ e na Dimensão $\mathrm{B}$ a média de $15 \%$, totalizando $5,74 \%$. Com base nesses resultados as crianças foram classificadas no nível 5 do GMFN (nível mais severo), por serem totalmente dependentes. Com relação ao grau de espasticidade, às crianças no início de cada sessão apresentaram no MMID a média 2,3 $\pm 1,08$, no MMIE 2,2 $\pm 1,0$, no MMSD 2,1 $\pm 1,07$ e no MMSE 2,2 $\pm 1,07$. No final das sessões as crianças apresentaram a média do grau de espasticidade no MMID de 1,5 $\pm 0,85$, MMIE 1,7 $\pm 1,0$, MMSD $1,6 \pm 0,6$ e no MMSE 1,7 $\pm 0,6$. Conclusão: A fisioterapia aquática representa uma grande promessa como recurso complementar às terapias já existentes para o tratamento dos distúrbios de desenvolvimento das crianças portadoras da Síndrome Congênita do Zika Vírus, fazendo com que se tenham resultados benéficos no que diz respeito à normalização do tônus muscular, aumento da amplitude de movimento e controle de movimentos involuntários.

Palavras-chave: Hidroterapia, Microcefalia, Zika vírus.

\title{
Efeitos da Fisioterapia Aquática no tratamento da fibromialgia
}

\author{
Macedo $A M^{1}$, Oliveira $A J^{2}$, Soares $\mathrm{ML}^{2}$
}

${ }^{1}$ Graduandas em Fisioterapia, Centro Universitário Brasileiro, Recife/PE, ${ }^{2}$ Pós-graduação em Saúde da Criança e do Adolescente, Universidade Federal de Pernambuco, Recife/PE

\section{Email: anadancamil@gmail.com}

Introdução: A Fibromialgia é uma síndrome reumatológica de natureza crônica com etiologia multifatorial, apresentando um quadro clínico de dor difusa, rigidez articular, matinal, que provoca diminuição da funcionalidade e das atividades desempenhadas pelo indivíduo. A Fisioterapia aquática possui técnicas e propriedades físicas que podem proporcionar ao fibromiálgico melhora no quadro clínico e na qualidade de vida desses pacientes. Objetivo: Descrever, através de uma revisão narrativa, os efeitos da fisioterapia aquática em pacientes com fibromialgia. Métodos: Foi realizada uma revisão narrativa nas bases de dados Medline, Lilacs, Scielo e PEDro, com artigos científicos publicados entre os anos de 2008 a 2018, sem restrição linguística, utilizando junto aos Descritores em Ciências da Saúde: Fibromialgia, Hidroterapia e Qualidade de vida o operador booleano AND. Foi utilizado como estratégia de busca o The Prisma Statement e como critérios de elegibilidade os artigos foram incluídos por abordar a terapia aquática pra reabilitação de pacientes com fibromialgia e publicados nos últimos 10 anos e excluídos por serem artigos de revisão, artigos duplicados ou aqueles que abordavam outras formas de tratamento. Resultados: Foram incluídos 05 artigos que apontavam condutas de tratamento com pacientes fibromiálgicos submetidos à prática de exercícios aquáticos de forma comparativa com outras práticas terapêuticas e artigos que observaram resultados isolados da prática de exercícios aquáticos. Foram encontrados 15 artigos sobre o tema e 05 foram incluídos sendo $60 \%$ em português e $40 \%$ em inglês. Dentre os incluídos $40 \%$ foram de intervenção (ensaio clínico) e $60 \%$ foram observacionais. A literatura científica aponta efeitos benéficos para o tratamento da hidroterapia em relação à sintomatologia da fibromialgia tanto no aspecto da diminuição da dor, quanto ao acréscimo da funcionalidade dos acometidos por essa síndrome, porque relatavam melhora de flexibilidade articular, relaxamento da musculatura após as sessões de hidroterapia resultando no aumento da qualidade de vida. Além da melhora da autopercepção do fibromiálgico acontece também melhora na qualidade do sono que também são apontados como efeitos positivos do tratamento. Conclusão: Apesar do número reduzido de artigos encontrados, a ausência de um protocolo definido na literatura científica sobre exercícios 
aquáticos a serem aplicados nessa população, pode-se afirmar que a fisioterapia aquática proporciona aos pacientes com fibromialgia melhora nos sintomas dessa síndrome à medida que promove amenização no quadro álgico, na rigidez muscular e articular colaborando para o aumento da funcionalidade do corpo resultando em uma melhora significativa da saúde desses pacientes como um todo. Como ponto de partida para novas pesquisas, a padronização no diagnóstico e o uso de técnicas associadas poderão ser utilizadas para aumentar a quantidade de literatura disponível e a qualidade da evidência dentro do público em questão.

Palavras-chave: fibromialgia, hidroterapia, qualidade de vida.

\section{Utilização da Fisioterapia Aquática no tratamento da osteoartrite}

Cabral W' ${ }^{1}$, Silva $\mathrm{J}^{1}$, Melo $\mathrm{L}^{1}$, Evangelista $\mathrm{N}^{1}$, Bomfim $\mathrm{R}^{1}$, Soares $\mathrm{ML}^{2}$

${ }^{1}$ Graduando em Fisioterapia, Centro Universitário Brasileiro, Recife/PE, ${ }^{2}$ Pós-graduação em Saúde da Criança e do Adolescente, Universidade Federal de Pernambuco, Recife/PE

Email: lanavmelo@hotmail.com

Introdução: A osteoartrite é uma doença típica das articulações sinoviais, com acometimento cartilagíneo das grandes articulações, responsáveis pela sustentação do peso corporal como a coluna lombar, joelhos e quadris. A fisioterapia aquática é bastante utilizada na reabilitação de diversas enfermidades, principalmente em pacientes reumáticos, devido aos benefícios oferecidos pelas propriedades físicas da água e seus efeitos terapêuticos e fisiológicos, sendo indicada para pacientes com osteoartrite para melhora do quadro sintomático e restabelecimento funcional. Objetivo: Descrever, através de uma revisão narrativa, a utilização da fisioterapia aquática no tratamento de pacientes com osteoartrite. Métodos: Foi realizada uma revisão narrativa, através das bases de dados Medline, Lilacs e Scielo, realizada no período de dezembro de 2017 a julho de 2018, sem restrição temporal. Foram utilizados como estratégia de busca, com o operador booleano AND, os Descritores em Ciências da Saúde (DECS): Hidroterapia, Fisioterapia Aquática, Osteoartrite. Como critérios de elegibilidade foram incluídos os artigos dos últimos 10 anos nos idiomas português e inglês e que abordavam a utilização da terapia aquática na osteoartrite e foram excluídos os artigos de revisão, os artigos duplicados e os artigos que abordavam o tratamento cirúrgico e os estudos com animais. Resultados: Foram encontrados quinze artigos dos quais dez foram selecionas, sendo oito incluídos e dois excluídos. A hidroterapia é um tratamento favorável para os pacientes com $\mathrm{AO}$, devido aos exercícios com carga pois aceleram o processo degenerativo. A flutuação é uma das mais importantes para a reabilitação utilizadas pela fisioterapia aquática, onde diminui o peso corpóreo e reduz impacto sobre as articulações e o risco de lesões. Uma das técnicas bastante benéfica na prática da fisioterapia na água é a Hidrocinesioterapia, tratamento individualizado, onde promove rapidez na reabilitação, adequado para cada paciente, buscando aprimorar o condicionamento físico e o reestabelecimento da funcionalidade dele. Exercícios na água traz alguns benefícios aos efeitos fisiológicos, como no sistema respiratório, onde durante as atividades na água a um aumento do fluxo sanguíneo pulmonar, contribuindo para uma troca gasosa. Conclusão: A utilização da fisioterapia aquática no tratamento osteoartrite vêm sendo muito satisfatório demonstrando melhora da dor, aumento da amplitude de movimento, e da capacidade funcional e da qualidade de vida do paciente. Como ponto de partida para novas pesquisas, a utilização de novas técnicas de reabilitação aquática para o público em questão parece ser um ponto importante, aumentando a literatura ofertada e a qualidade da evidência disponível.

Palavras-chave: osteoartrite; fisioterapia aquática; hidroterapia. 
A Fisioterapia Aquática como escolha de tratamento para crianças com síndrome de Down: uma revisão de literatura

\author{
Araújo TM¹, Lambertucci MS ${ }^{1}$, Borin $\mathrm{PLH}^{2}$ \\ ${ }^{1}$ Departamento de Pós-Graduação em Reabilitação Aquática no Hospital Israelita Albert Einstein, \\ São Paulo/SP, ${ }^{2}$ Fisioterapeuta Aquática Plena no Hospital Israelita Albert Einstein, São Paulo/SP \\ Email: thais@araujo.fst.br
}

Introdução: A Síndrome de Down (SD) é uma alteração causada pela existência de um cromossomo extra no par 21 da célula genética. O cromossomo é uma pequena parte da célula que carrega informações como cor dos olhos, formato do nariz, entre outras características. As crianças com SD podem desenvolver incapacidades motoras, que levam ao desenvolvimento de algumas deficiências como a frouxidão ligamentar, a hipotonia muscular, a deficiência intelectual, as cardiopatias e os problemas respiratórios. A água estimula e facilita o desenvolvimento motor, sensorial e afetivo da criança. Favorecendo maior confiança e autoestima e estimulando os sistemas (cardíaco, respiratório, esquelético e muscular) a se desenvolverem e adaptar-se. Através dos princípios físicos da água, dos seus efeitos fisiológicos e do exercício, a fisioterapia aquática torna-se bastante aplicável a distúrbios motores e cognitivos, formando um ambiente lúdico e estimulante e acrescentando significativamente na reabilitação de crianças com síndrome de down. Objetivo: Verificar a eficácia da fisioterapia aquática em crianças de 0 a 10 anos com síndrome de Down através de uma revisão sistemática. Metodologia: Realizou-se uma busca bibliográfica eletrônica nas bases de dados SciELO, PubMed e Lilacs, no período de 2013 a 2018. As estratégias dos critérios de inclusão foram: 1- população (crianças com SD), 2 intervenção (hidroterapia, hidroterapia com fisioterapia ou fisioterapia aquática), 3- desfecho (melhora ou piora do tratamento). Foram excluídos artigos publicados antes de 2013, artigos que não se enquadravam no enfoque do estudo, revisões bibliográficas e os que não apresentavam detalhamento metodológico. Resultados: Foram encontrados 175 artigos. A partir dos critérios de exclusão e inclusão 170 estudos foram excluídos por não se tratar da amostra escolhida e 1 por não utilizar humanos em sua pesquisa. Foram analisados 4 estudos. Os estudos mostraram melhorias significativas na qualidade de vida, equilíbrio e tônus de crianças com síndrome de Down. Em crianças de até 18 meses os exercícios aquáticos associados à fisioterapia motora, aprimorou a aquisição das posturas antigravitacionais. E na faixa etária de 8 a 10 anos houve maior independência para AVDs e melhora do estado mental e psicológico. Conclusão: A fisioterapia aquática é um recurso a ser recomendado e considerado para tratamento desta população visto que a água é um meio privilegiado para o desenvolvimento infantil. Deste modo, considera-se pertinente realizar novos estudos com esta população visto que o número de artigos publicados ainda é reduzido.

Palavras-chave: hidroterapia, síndrome de Down, fisioterapia.

\title{
Os benefícios da Fisioterapia Aquática no tratamento de hérnia de disco lombar: uma revisão de literatura
}

Kamila Steffanie Farias Barreto, Luana Feitosa Calado, Maytta Rochelly Lopes da Silva, Carlos Eduardo Alves de Souza, Nathaly Thays Silva Farias, Clarissa Pessoa Lopes, Clara Beatriz Torres Maciel

\section{Centro Universitário Tabosa de Almeida - ASCES/UNITA, Caruaru/PE}

\section{Email: luanafcalado@outlook.com}

Introdução: A hérnia de disco lombar é uma condição reumatológica muito frequente, que afeta os discos intervertebrais da coluna. Quando há rompimento do anel fibroso e o conteúdo gelatinoso interno, chamado de núcleo pulposo, se desloca através de uma fissura nessa membrana. As raízes nervosas que passam pelo espaço intervertebral atingido, comprimem-se, 
causando os sintomas clínicos característicos da hérnia discal: fortes dores na região lombar, normalmente associadas à irradiação para os membros inferiores, diminuição da força muscular destes membros e formigamento nas pernas. As doenças da coluna estão entre as que mais incapacitam a população economicamente ativa. A intervenção da Fisioterapia Aquática, busca diminuir a sintomatologia dolorosa, mantendo a funcionalidade desses pacientes. As propriedades físicas da água, diminuem o impacto articular, promovendo relaxamento e permitindo a realização dos exercícios. Objetivo: Descrever, através de revisão literária, os benefícios da fisioterapia aquática no tratamento de pacientes com hérnia discal lombar, associando aos ganhos relacionados à melhora da independência funcional deles. Métodos: Trata-se de uma revisão de literatura do tipo narrativa. A busca foi realizada nas bases de dados SciELO, Bireme, Scholar, com temática central acerca da fisioterapia aquática no tratamento da hérnia de disco lombar, como critérios de inclusão foram artigos científicos brasileiros e estrangeiros datados em até 10 anos, adultos com idade acima de 30 anos e como critérios de exclusão foram artigos científicos publicados há mais de 10 anos e que não estavam dentro do assunto pesquisado. Resultados: De acordo com as literaturas investigadas, foi possível analisar os benefícios da fisioterapia aquática. A redução considerável da gravidade no ambiente aquático torna o meio ideal para a reabilitação nos casos de hérnia de disco lombar, visto que, diminui a sobrecarga, promovendo relaxamento e permitindo a realização de exercícios. A Fisioterapia em ambiente aquático, por meio das propriedades físicas da água, é favorável para aumentar o espaço intervertebral e aliviar a dor, possibilitando melhorias na funcionalidade, diminuindo de forma quantitativa as queixas dos pacientes acometidos pela compressão do disco intervertebral. Conclusão: Diante dos dados mencionados, conclui-se que, o tratamento com fisioterapia aquática ,foi considerado como o mais adequado, pois as propriedades físicas da água, principalmente, a flutuação e temperatura da água, possuem repercussões positivas em relação aos pacientes com hérnia discal, proporcionando alívio da dor, melhora da postura e mobilidade além da normalização dos sinais neurológicos e da funcionalidade.

Palavras-chave: Hérnia de disco, hidroterapia, tratamento.

\section{Efeitos da Fisioterapia Aquática no tratamento de osteoartrites: uma revisão sistemática}

Oliveira $F A^{1}$, Gouveia GPM², Costa BC ${ }^{1}$, Lopes TS1, Silva $\mathrm{RL}^{1}$, Sousa $A \mathrm{AS}^{1}$, Souza $\mathrm{LM}^{1}$, Fernandes $\mathrm{LBO}^{1}$

${ }^{1}$ Universidade Federal do Piauí, Parnaíba/PI, ${ }^{2}$ Grupo de Pesquisa em Fisioterapia Avaliativa e Terapêuticas - GPFAT, Parnaíba/PI

\section{Email: feandoli@outlook.com}

Introdução: a Osteoartrite $(\mathrm{OA})$ também denominada osteoartrose ou artrose, é uma doença crônico-degenerativa caracterizada por alterações na integridade da cartilagem articular e do osso subcondral. Tornando-se a causa mais frequente de doença crônica musculoesquelética, sendo sem dúvida a maior causa de limitação das atividades diárias entre a população idosa. Não há cura para osteoartrose. Recomenda-se uma abordagem múltipla que envolve alternativas farmacológicas e não-farmacológicas. O tratamento em água aquecida tem importante papel na reabilitação, auxiliando tanto no alívio dos sintomas quanto na execução das atividades de vida diária, melhorando a funcionalidade e contribuindo para a melhoria da qualidade de vida (QV), proporcionada pelos efeitos físicos, fisiológicos e terapêuticos da água aquecida. Objetivo: identificar os efeitos da fisioterapia aquática (FA) no tratamento de osteoartrites. Métodos: o estudo trata-se de uma revisão sistemática, desenvolvida através de uma busca bibliográfica nas bases de dados eletrônicas Pubmed e PEDro, além de pesquisa em capítulos de livros e revistas especializadas. Os descritores foram selecionados a partir da Biblioteca Virtual em Saúde (BVS), usados no idioma inglês, sendo eles physiotherapy, hydrotherapy e osteoarthritis. Realizou-se a leitura dos títulos dos trabalhos, do resumo e foram selecionados aqueles que incluíam o tratamento com FA, a comparação da hidroterapia com outras abordagens de reabilitação, estudos com a população adulta mais velha, osteoartrites em regiões específicas e de modo geral. Resultados: A busca somou-se em 127 artigos, desses, 55 eram artigos de revisão e 53 mostraram relação distinta de tratamento e outra abordagem de estudo, no final selecionou-se 
19 artigos para leitura na íntegra e serem introduzidos no trabalho. Os ensaios clínicos selecionados mostraram efeitos positivos quanto as diferentes abordagens da FA. As intervenções duraram de semanas à meses com métodos específicos para indivíduos com osteoartrite de joelho, quadril ou extremidade inferior de modo geral por ter impacto na mobilidade e acaba incapacitando a realização das atividades diárias. Conclusão: diante dos estudos avaliados pode-se observar que a FA apresenta efeitos benéficos no tratamento de pacientes portadores de osteoartrites. As abordagens da FA demonstraram benefícios sobre a dor e função física, permitindo uma melhora no equilíbrio e na QV. Programas e exercícios aquáticos oferecem uma boa opção terapêutica e pragmática para promover uma melhora da capacidade funcional e QV.

Palavras-chave: hidroterapia, tratamento, osteoartrite.

\section{Aplicabilidade da Fisioterapia Aquática na lombalgia gestacional: uma revisão integrativa}

Damasceno ILMํำ Viana GC ${ }^{1}$, Barbosa VK¹, Teles PKS1, Matias PHVS²

${ }^{1}$ Discente do Centro Universitário Tiradentes - UNIT, Maceió/AL, ${ }^{2}$ Docente das disciplinas recurso cinesioterapêutico e funcional, fisioterapia aquática e administração em fisioterapia do curso de fisioterapia do Centro Universitário Tiradentes - UNIT, Maceió/AL

Email: isis_larissa96@outlook.com

Introdução: Durante o período gestacional ocorre uma série de mudanças fisiológicas no corpo da mulher para adaptar-se ao desenvolvimento do feto, como aumento do útero, alteração do centro de gravidade, mudanças hormonais, frouxidão ligamentar e muscular. Essas modificações podem causar uma lordose excessiva, gerando um processo doloroso, denominado lombalgia, definida por uma dor localizada na região lombar e/ou irradiada para os membros inferiores. A ocorrência de dor lombar no período gestacional é considerada uma queixa comum, podendo ser um fator limitante das atividades diárias das gestantes. Entre os recursos utilizados para alívio da dor, a fisioterapia aquática busca promover o relaxamento da musculatura, a redução da carga corporal, do impacto articular e do risco de lesões, devido a ação da gravidade. Objetivos: Realizar uma revisão de literatura integrativa sobre a aplicabilidade da Fisioterapia Aquática no tratamento da lombalgia gestacional. Métodos: Foi realizada buscas de artigos científicos disponibilizados nas bases eletrônicas SciELO, Lilacs, PEDro e Pubmed através dos descritores: hidroterapia, gestantes, dor lombar, fisioterapia. Os critérios de inclusão desta pesquisa foram artigos publicados em português e inglês, entre os anos de 2008 a 2018, referentes a aplicabilidade da fisioterapia aquática na lombalgia gestacional. Foram excluídos artigos que não apresentavam conteúdos de acordo com o tema proposto ou não estavam disponibilizados na íntegra. Resultados: Foram encontrados 78 artigos relacionados aos descritores, porém apenas 10 atenderam os critérios de inclusão. Os estudos demonstraram que a lombalgia gestacional possui alta prevalência, principalmente, nos últimos meses de gestação, levando a limitações físicas, sendo a fisioterapia aquática de grande relevância na redução do quadro álgico. Conclusão: A Fisioterapia Aquática pode proporcionar as gestantes uma redução do quadro álgico lombar, melhorando o desempenho funcional da gestante nas atividades de vida diária.

Palavras-chave: dor lombar, gestantes, fisioterapia, hidroterapia.

Influência do Watsu e da flutuação simples na qualidade de vida e depressão em mulheres de 45 a 55 anos

Veras $\mathrm{DS}^{1}$, Moura $\mathrm{AM}^{2}$, Brito $\mathrm{JF}^{3}$, Ibiapina $\mathrm{TF}^{4}$, Carvalho $\mathrm{B}^{5}$, Machado $\mathrm{DC}^{6}$

${ }^{1}$ Fisioterapeuta (UFPI), Mestranda em Saúde da Mulher (UFPI) e Especialista em Fisioterapia Aquática (CEPRA), ${ }^{2}$ Fisioterapeuta (UFPI), Pós-graduada em Fisioterapia Intensiva (Inspirar-SL), 
${ }^{3}$ Fisioterpeuta (UFPI), Pós-graduada em Fisioterapia na Saúde da Mulher (UniNOVAFAPI), ${ }^{4}$ Graduando em Fisioterapia (UFPI), ${ }^{5}$ Pós-graduada em Fisioterapia Traumato-ortopédica $e$ desportiva (Faculdade Einsten - Facei), ${ }^{6}$ Doutora em Saúde Mental (UFRJ), Fisioterapeuta, Professora Adjunta (UFPI)

Email: daniella_veras@hotmail.com

Introdução: A diminuição dos hormônios esteroides sexuais em mulheres na faixa etária de 45 a 55 anos está associada à ocorrência de problemas vasomotores, modificações do humor, distúrbios do sono e repercussões em longo prazo, como osteoporose e aumento da morbidade cardiovascular. Estes sintomas podem comprometer a qualidade de vida feminina. O objetivo deste estudo foi verificar os efeitos da intervenção pelo método Watsu e flutuação simples nos escores do Questionário de Saúde da Mulher (QSM) e no Inventário de Beck. Métodos: A amostra consistiu em 20 mulheres entre 45 a 55 anos, avaliadas usando os instrumentos QSM e Inventário de Beck e distribuídas em dois grupos (grupo Watsu versus grupo flutuação simples). Cada voluntária recebeu sete atendimentos da técnica referente ao grupo em que pertencia e foi avaliada ao início e ao final do estudo para comparação entre os momentos e as técnicas terapêuticas recebidas. Resultados: A ANOVA one-way mostrou efeito principal para momento da análise do QSM antes e após as modalidades utilizadas na intervenção. Quanto ao Inventário de Beck, houve diminuição nas pontuações comparando-se a avaliação inicial e final. Conclusão: As duas técnicas foram efetivas para promover o relaxamento das participantes e proporcionar benefícios referentes aos itens avaliados pelo QSM e Inventário de Beck.

Palavras-chave: fisioterapia aquática, qualidade de vida, climatério.

Fisioterapia Aquática como primeira escolha dos profissionais para o tratamento da síndrome de Down na cidade de Fortaleza

Renata Monteiro Bastos Frota, Edilberto Frota Filho

Centro Universitário Estácio do Ceará, Fortaleza/CE

Email: renatabastos89@htomail.com

Introdução: A síndrome de Down (SD) é caracterizada como uma condição genética, reconhecida há mais de um século. É de fundamental valor para evolução da criança com síndrome de Down a inclusão de uma equipe multidisciplinar de saúde e educação em seu tratamento, sendo a Fisioterapia de vital importância no processo de desenvolvimento dessa criança em todos os aspectos biopsicossociais e o acompanhamento deve ser iniciado o mais precoce possível. Objetivo: Analisar a Fisioterapia Aquática como primeira escolha dos profissionais para o tratamento da síndrome de Down na cidade de Fortaleza. Métodos: Tratase de uma pesquisa de caráter descritivo, observacional, transversal com estratégia de análise quantitativa dos resultados. A pesquisa foi desenvolvida no Centro Universitário Estácio do Ceará, nas clínicas, consultórios, ambulatórios e hospitais cadastrados no Conselho Regional de Fisioterapia e Terapia Ocupacional Região 6 (CREFITO6) da cidade de Fortaleza. O período de realização da pesquisa foi de fevereiro a junho de 2011. A população foi composta por todos os fisioterapeutas responsáveis técnicos pelo serviço das clínicas, consultórios, ambulatórios e hospitais cadastrados no CREFITO6 que possuíam endereço e telefone, que permaneceram prestando serviço de fisioterapia, e que aceitem participar da pesquisa. Resultados: Foi encontrado que das instituições entrevistadas, $63,42 \%$ tem como primeira escolha no tratamento da síndrome de Down a Fisioterapia Aquática. Conclusão: A Fisioterapia Aquática é de fundamental importância para reabilitação do paciente com síndrome de Down, minimizando efeitos negativos desta disfunção.

Palavras-chave: Síndrome de Down, modalidades de fisioterapia, fisioterapia. 
Efeitos da Fisioterapia Aquática na qualidade do sono e qualidade de vida de indivíduos adultos

\author{
Magalhães MGS ${ }^{1}$, Silva $\mathrm{BLL}^{2}$, Costa $\mathrm{ASO}^{3}$, Lima AKP4, Carvalho VCP${ }^{5}$, Uchoa EPBL ${ }^{6}$ \\ ${ }^{1}$ Mestrando no Programa de Pós-graduação em Fisioterapia da Universidade Federal de \\ Pernambuco (UFPE), Recife/PE, ${ }^{2}$ Pós-graduada em Fisioterapia Aquática pelo Centro \\ Universitário Maurício de Nassau (UNINASSAU), Recife/PE, ${ }^{3}$ Residente em Saúde da Família \\ no Instituto de Medicina Integral Professor Fernando Figueira (IMIP), Recife/PE, ${ }^{4}$ Mestre em \\ Psicologia Clínica pela Universidade Católica de Pernambuco (UNICAP). Docente no curso de \\ Fisioterapia da UNICAP, Recife/PE, ${ }^{5}$ Doutora em Neuropsiquiatria e Ciências do Comportamento \\ pela Universidade Federal de Pernambuco (UFPE), Recife/PE, ${ }^{6}$ Doutora em Psicologia Clínica \\ pela Universidade Católica de Pernambuco (UNICAP). Docente no curso de Fisioterapia da \\ UNICAP, Recife/PE
}

\title{
Email: matheus_gustavo94@outlook.com
}

Introdução: $O$ ambiente aquático além de possibilitar a realização de atividades diferenciadas ao solo, proporciona um momento lúdico, agradável e extremamente favorável para o atendimento fisioterapêutico. A água aquecida beneficia o usuário através de uma redução do tônus muscular que atua no relaxamento das tensões musculares e limitação de quadros álgicos, desta maneira, influenciando na melhora do sono e consequentemente na qualidade de vida do indivíduo. Objetivo: Verificar se os atendimentos fisioterapêuticos na piscina são eficazes na melhora da qualidade do sono e qualidade de vida dos indivíduos adultos. Métodos: Trata-se de um estudo quase-experimental de corte transversal, aprovado pelo Comitê de Ética e Pesquisa com número de aprovação 226.764, realizado nos laboratórios de Fisioterapia e Terapia Ocupacional da Universidade Católica de Pernambuco, que incluiu indivíduos adultos, de ambos os sexos, na faixa etária de 35 a 60 anos. Inicialmente foram aplicados o Índice de Qualidade do Sono de Pittsburgh (PSQI) e o WHOQOL versão abreviada para análise da qualidade de vida. Foram realizados atendimentos individualizados na piscina através do protocolo baseado em aquecimento (caminhadas), alongamentos globais, exercícios auxiliados por flutuadores e relaxamento com o indivíduo em flutuação. Isso ocorreu com frequência de uma ou duas vezes por semana, totalizando dez intervenções. Após o período de tratamento, os dois questionários foram novamente aplicados. Todos os testes e gráficos foram realizados no software $R$ versão 3.2.4 revisado (2016). Resultados: A amostra da pesquisa foi composta por 13 indivíduos, com idade entre 49 a 59 anos, sendo $23,08 \%(n=3)$ do sexo masculino e $76,92 \%(n=10)$ do sexo feminino. Observou-se que após a intervenção fisioterapêutica houve aumento significativo no valor geral do índice BPWHOQOL dos pacientes $(p<0,05)$. $O$ ambiente lúdico e os efeitos fisiológicos da água aquecida atuam diretamente nos domínios psicológico e físico do indivíduo, podendo interferir positivamente na interação e qualidade de vida. Quanto a qualidade de sono, inferiu-se possível melhora tendo em vista que houve uma diminuição significativa no valor geral do índice PSQI dos pacientes $(p<0,001)$ após o tratamento. Em função das atividades realizadas no ambiente aquático é favorecida uma elevação da taxa de serotonina e, consequentemente, de melatonina, ambas favoráveis ao sono. Ao correlacionar a qualidade de sono e qualidade de vida, não houve correlação significativa. Contrariamente, outros autores conseguiram estabelecer uma correlação entre esses dois fatores, utilizando a hidrocinesioterapia em pacientes com fibromialgia. Conclusão: A Fisioterapia Aquática mostrou-se benéfica como forma de intervenção objetivando a melhora da qualidade de sono e da qualidade de vida, porém não foi evidenciada correlação significativa entre essas duas variáveis.

Palavras-chave: fisioterapia, hidroterapia, qualidade de vida, sono. 
Fisioterapia Aquática na hemipelvectomia interna

\author{
Santos KNA ${ }^{1}$ Oliveira LS ${ }^{1}$, Teixeira SS ${ }^{2}$ \\ ${ }^{1}$ Programa de Pós-graduação em Ciências Biomédicas, Universidade Federal do Piauí, \\ Parnaíba/PI, ${ }^{2}$ Departamento de Fisioterapia, Universidade Federal do Piauí, Parnaíba/PI
}

Email: kyvianaysis@gmail.com

Introdução: A hemipelvectomia é normalmente indicada para o tratamento dos sarcomas da região glútea e da porção proximal posterior da coxa, bem como dos tumores ósseos da pelve. Quanto ao procedimento cirúrgico, pode ser externa ou interna. A externa, que consiste na ressecção de toda a hemipelve e do membro inferior, é indicada em pacientes com tumores extensos. Já a forma interna consiste na ressecção de segmentos ósseos e tecidos comprometidos da cintura pélvica, preservando-se o feixe vásculo-nervoso femoral e nervo ciático e, desta forma, é possível preservar o membro inferior dos pacientes. Esta última deve ser considerada sempre que possível, pois este procedimento apresenta baixa taxa de recidiva comparável a outras ressecções radicais. Além disso, preserva-se o membro inferior do paciente, influenciando de forma positiva em sua qualidade de vida. A fisioterapia aquática é um recurso terapêutico que utiliza os efeitos físicos, fisiológicos e cinesiológicos advindos da imersão do corpo em piscina aquecida como recurso auxiliar da reabilitação ou prevenção de alterações funcionais, podendo ser um importante tratamento na reabilitação de pacientes submetidos à hemipelvectomia interna. Objetivos: Relatar a abordagem fisioterapêutica na hemipelvectomia interna por meio da fisioterapia aquática. Métodos: Trata-se de uma revisão bibliográfica, desenvolvida com artigos publicados no período de 2007 a 2017, coletados nas bases eletrônicas SciELO e LILACS, utilizando os descritores: "Hemipelvectomia", "Hidroterapia", "Fisioterapia Aquática" e "Reabilitação". Os critérios de inclusão definidos para a seleção dos artigos foram: artigos publicados em português; artigos na íntegra que retratassem a temática delimitada e artigos publicados e indexados no referido banco de dados nos últimos dez anos. Resultados: Consequentemente, a hemipelvectomia traz modificações funcionais como déficit de equilíbrio e da força muscular, alterações posturais e da mecânica respiratória, dores musculares, e comprometimento na deambulação. Em vista disso, como objetivos da fisioterapia aquática temos: melhorar equilíbrio e propriocepção; ganhar força muscular e flexibilidade; promover condicionamento aeróbico; prevenir deformidades e aderências. Nos protocolos de intervenção da fisioterapia aquática para o paciente submetidos a hemipelvectomia são indicados: diagonais de Bad Ragaz, que é um método bastante usado para reeducação muscular, fortalecimento, alongamento, relaxamento e inibição do tônus; treino de equilíbrio e marcha e exercício proprioceptivos, que auxiliam no fortalecimento, coordenação, equilíbrio, repercutindo assim na melhora da marcha e redução do risco de quedas; alongamento, mobilização passiva e ativa dos membros, que permitem o aumento da amplitude de movimento das articulações; relaxamento com flutuação, pompagem e hidromassagem, que são usadas para controle do estresse, alívio da dor e relaxamento. Conclusão: Com isso percebemos que a fisioterapia aquática pode trazer inúmeros efeitos benéficos na capacidade física e funcional em pacientes com hemipelvectomia interna. Sua prática mostra-se eficiente para produzir melhora na flexibilidade, na força muscular e no equilíbrio, além de proporcionar analgesia, controle postural e condicionamento aeróbico, por meio de suas variadas técnicas e protocolos. Conclui-se que a fisioterapia aquática é uma prática benéfica, bem aceita, com baixos riscos para reverter déficits causados pela cirurgia e melhorar a qualidade de vida.

Palavras-chave: hemipelvectomia, hidroterapia, reabilitação. 
Efeito da Fisioterapia Aquática no equilíbrio de pacientes com doença pulmonar obstrutiva crônica: uma revisão integrativa de literatura

\author{
Cardoso RAM ${ }^{1}$, Machado YA 1 , Silva DV² \\ ${ }^{1}$ Universidade Federal do Piauí, Parnaíba/PI, ${ }^{2}$ Mestrando em Saúde da Mulher e Especialista em \\ Fisioterapia Aquática, Parnaíba/PI
}

\title{
Email: rayanacardoso96@gmail.com
}

Introdução: A doença pulmonar obstrutiva crônica (DPOC) é caracterizada pela limitação do fluxo aéreo devido à complexa interação entre a destruição do parênquima pulmonar e inflamação das pequenas vias aéreas. A sensação de falta de ar é o sintoma predominante na DPOC. Além disso, vem sendo observado uma associação entre a presença da doença e maior risco de quedas. Os impactos da DPOC ocorrem nos diversos sistemas do corpo, gerando fadiga, fraqueza muscular e anormalidades na marcha em comparação a indivíduos saudáveis, tornando-os mais suscetíveis a quedas. A força muscular dos membros inferiores pode ser reduzida devido ao desequilíbrio entre a síntese proteica e a proteólise muscular. Essas vias, juntamente com outros fatores desencadeantes como inatividade física, podem levar às alterações observadas nos músculos periféricos dessa população. As consequências da inatividade física podem ser revertidas pelo treinamento. $\mathrm{O}$ ambiente aquático tem sido amplamente utilizado como uma modalidade terapêutica para melhorar o equilíbrio estático e dinâmico em várias populações de pacientes. Consiste em exercícios realizados em piscina aquecida que promovem alterações fisiológicas nos diversos sistemas do corpo, facilitando a realização das atividades com maior independência do paciente. Objetivo: O objetivo desse estudo foi realizar uma revisão de literatura sobre a aplicabilidade da fisioterapia aquática na melhora do equilíbrio e redução do número de quedas de paciente com DPOC. Métodos: Foram definidos os conceitos-chave da pesquisa: Equilíbrio, risco de quedas e marcha na DPOC, Terapia na água para DPOC e Terapia aquática na melhora do equilíbrio; em seguida determinou-se o período de pesquisa que envolveu os anos de 2007 a 2018 e as bases de dados pesquisadas: SciELO, PEDro, MedLine e Pubmed. Resultados: A pesquisa realizada com os descritores propostos gerou um total de 1666 artigos. Foram utilizados filtros limitando data, artigos em inglês, português e que possuíssem texto completo, totalizando 333 artigos. Após a primeira análise, 288 foram excluídos por não serem compatíveis com o tema proposto ou se repetirem, 45 foram selecionados para a leitura do resumo. Destes, 19 foram escolhidos para a leitura do texto completo por possuírem metodologia de tratamento parecida, focadas nos efeitos da fisioterapia aquática para o equilíbrio de pacientes com características semelhantes ao DPOC e artigos sobre as principais alterações físicas do paciente com DPOC que interferem no equilíbrio, finalizando em 19 artigos. Os protocolos de hidrocinesioterapia encontrados nos artigos eram compostos basicamente pelas seguintes atividades: caminhadas na piscina, fortalecimento e alongamentos musculares, exercícios de resistência, respiração, atividades para treinamento do equilíbrio postural estático e dinâmico, além de adaptação ao meio líquido e atividades lúdicas. Conclusão: A terapia na água tem excelentes resultados em pacientes com DPOC, podendo ser utilizada em associação com a reabilitação pulmonar, melhorando a função respiratória, qualidade de vida e funcionalidade do mesmo, beneficiando o paciente de forma integral. Pode-se observar melhora do equilíbrio em diferente população de pacientes após a utilização de fisioterapia aquática, embora ainda haja uma escassez de estudos específicos sobre a atuação da terapia na água na melhora do equilíbrio do paciente com DPOC, sugerindo que mais estudos devam ser realizados.

Palavras-chave: Hidroterapia, DPOC, equilíbrio. 
Efeitos do método Watsu na funcionalidade de indivíduos com fibromialgia: revisão sistemática

\author{
Costa BC 1 , Sousa LM², Gouveia GPM², Souza ATS ${ }^{1}$, Silva ESMํ, Costa RAS ${ }^{1}$ \\ ${ }^{1}$ Universidade Federal do Piauí, Parnaíba/PI, ${ }^{2}$ Grupo de Pesquisa em Fisioterapia Avaliativa e \\ Terapêuticas - GPFAT, Parnaíba/PI
}

Email: brunocunha09@hotmail.com

Introdução: A fibromialgia é considerada uma síndrome de caráter crônico e não inflamatório, sua etiologia ainda é desconhecida e sua principal característica é a dor difusa, juntamente com um aumento da sensibilidade na palpação. Pode estar relacionada a diversos sintomas como a fadiga, insônia, ansiedade, depressão e intolerância ao frio. Em relação a funcionalidade nestes pacientes, esta encontra-se bastante afetada, causando um grande impacto na qualidade de vida. Uma das técnicas bastante utilizada no tratamento da fibromialgia é o Watsu, na qual consiste em uma modalidade de terapia aquática em piscina aquecida, com ambiente tranquilo e com a realização de alongamentos passivos, mobilização articular, pressão em pontos de acupuntura visando o equilíbrio de energias nos meridianos e proporcionando relaxamento. Objetivos: Analisar o efeito do método Watsu na funcionalidade de pacientes com fibromialgia. Métodos: O estudo trata-se de uma revisão sistemática, desenvolvida mediante uma busca bibliográfica nas bases de dados eletrônicas Pubmed, Scielo, além de pesquisa em capítulos de livros e revistas. Os descritores foram selecionados a partir da Biblioteca Virtual em Saúde, usados no idioma inglês, sendo eles Watsu, Aquatic physiotherapy, Fibromyalgia. Após a leitura dos títulos foram selecionados aqueles que incluíam o tratamento para indivíduos diagnosticados com fibromialgia. Resultados: A busca somou-se em 20 artigos, desses, 13 foram utilizados, sendo 9 artigos originais, 2 livros, 1 tese e 1 artigo de revisão. Os ensaios clínicos selecionados mostraram efeitos positivos quanto a técnica do Watsu, no tratamento de fibromialgia. Os estudos mostraram que após as intervenções com o método Watsu houve melhora na condição de vida dos pacientes acometidos com a fibromialgia. Conclusão: Após apreciação dos títulos, pôde-se afirmar que há eficácia no tratamento em pacientes com fibromialgia por meio do método Watsu, visto que ele se utiliza de água aquecida. O método associado aos efeitos fisiológicos e terapêuticos, proporcionados pelo ambiente aquático, expressaram melhora na condição clínica e da qualidade de vida desses indivíduos.

Palavras-chave: Watsu, fisioterapia aquática, fibromialgia.

\title{
A Fisioterapia Aquática no tratamento dos distúrbios do equilíbrio
}

Douglas Pereira Silva1', Allyson Honório Medeiros², Carla Patrícia Novaes Santos Fechine ${ }^{3}$, Ulisses Freire Ayres Lima ${ }^{3}$

\begin{abstract}
${ }^{1}$ Associação Paraibana de Ensino Renovado (ASPER), João Pessoa/PB, ${ }^{2}$ Departamento de Fisioterapia Faculdades Asper, João Pessoa/PB, ${ }^{3}$ Curso de Bacharelado em Fisioterapia Faculdades Asper, João Pessoa/PB
\end{abstract}

Email: fisioterapiadouglas@gmail.com

Introdução: A Fisioterapia Aquática (FA) é tida como uma técnica terapêutica que utiliza alguns princípios físicos para a reabilitação em meio líquido com temperatura adequada a cada tipo de patologia. Objetivos: Esta pesquisa tem como objetivo caracterizar o atendimento da fisioterapia aquática em pacientes com distúrbios no equilíbrio. Descrever quais são os principais efeitos da hidroterapia para os distúrbios do equilíbrio; avaliar como a hidroterapia auxilia na melhoria da condição motora dos pacientes com distúrbios do equilíbrio; relatar e discutir se as práticas terapêuticas aquáticas auxiliam na melhora do controle postural. Métodos: Trata-se de uma pesquisa de campo, descritiva, com abordagem quantitativa envolvendo a FA, o levantamento de dados foi obtido a partir da entrevista de 5 pacientes da Clínica Escola de Fisioterapia da 
ASPER no estado da Paraíba, apresentando disfunções neuromotoras há pelo menos um ano, entre 11 e 71 anos de idade, onde foi realizado um questionário de 10 perguntas e avaliado 0 tônus muscular dos mesmos através da escala de ASHWORTH modificada. A coleta de dados foi formalizada mediante a aprovação pelo Comitê de Ética, respeitando a Resolução do Conselho Nacional de Saúde (CNS/MS) 466/12. Número de aprovação do Parecer Comitê de ética em Pesquisa: 2.322.001. Resultados: Todos os pacientes foram avaliados no primeiro e no último dia de tratamento, os pacientes foram submetidos ao tratamento da FA duas vezes por semana, num total de 5 atendimentos, com duração de 40 minutos cada sessão. Todos os pacientes começaram os exercícios de fortalecimento sem carga na primeira sessão, da segunda em diante os pacientes foram aumentando o peso, com o uso das caneleiras para hidroterapia, entre $1 \mathrm{~kg}$ e $2 \mathrm{~kg}$. Os exercícios realizados na piscina foram executados sempre respeitando os limites, dores e amplitudes dos pacientes em questão. O tônus de cada indivíduo foi avaliado através da Escala de Ashworth de acordo com o déficit de equilíbrio e Membros Inferiores (MMII) focando nos padrões de flexão e extensão do quadril e joelhos. Entretanto, com os resultados obtidos por meio da aplicação da escala, podemos perceber toda eficácia no tratamento mediante a intervenção da Fisioterapia com o recurso da Fisioterapia Aquática. É importante ressaltar que os pacientes foram submetidos à fisioterapia aquática utilizando o método da hidrocinesioterapia, para potencializar os efeitos terapêuticos junto com a água aquecida. Conclusão: De acordo com os dados obtidos e apresentados neste trabalho é possível perceber que as contribuições da FA com seus métodos de fisioterapia contribuem para a reabilitação de pacientes com distúrbios do equilíbrio principalmente em indivíduos de meia e terceira idade, nos quais requer atenções maiores devido à rigidez e fraqueza muscular.

Palavras-chave: fisioterapia aquática, equilíbrio, hidrocinesioterapia.

\section{A Fisioterapia Aquática no tratamento de pacientes com distrofia muscular: uma revisão de literatura}

Kamila Steffanie Farias Barreto, Luana Feitosa Calado, Nathaly Thays Silva Farias, Clarissa Pessoa Lopes, Maytta Rochelly Lopes da Silva. Clara Beatriz Torres Maciel

\section{Centro Universitário Tabosa de Almeida - ASCES/UNITA, Caruaru/PE}

Email: luanafcalado@outlook.com

Introdução: Distrofia muscular se refere ao grupo de doenças genéticas nas quais os músculos que controlam o movimento enfraquecem progressivamente. No geral, apenas os músculos de movimentos voluntários são afetados, mas algumas formas dessa doença também podem atingir o coração e outros órgãos de movimentos involuntários. Nos casos mais graves, os pacientes apresentam fraqueza muscular rápida e severa, causando incapacidade funcional. A intervenção da Fisioterapia Aquática, busca retardar a evolução clínica e prevenir complicações secundárias da doença, mantendo assim a funcionalidade desses pacientes. As propriedades físicas da água, diminuem o impacto articular, promovendo relaxamento muscular, permitindo a realização dos exercícios. Objetivos: Descrever, através de revisão literária, os efeitos da fisioterapia aquática no tratamento de pacientes com distrofia muscular, associando aos ganhos relacionados à melhora da independência funcional dos mesmos. Métodos: Trata-se de uma revisão de literatura do tipo narrativa. A busca foi realizada nas bases de dados SciELO, Bireme, Scholar, com temática central acerca da fisioterapia aquática no tratamento de pacientes com distrofia muscular, como critérios de inclusão foram artigos científicos brasileiros e estrangeiros datados em até 10 anos e como critérios de exclusão foram artigos científicos publicados há mais de 10 anos e que não estavam dentro do assunto pesquisado. Resultados: De acordo com as literaturas investigadas, foi possível analisar os efeitos da fisioterapia aquática no tratamento das distrofias musculares. A água aquecida promove facilitação dos movimentos pelo efeito do empuxo e alívio de dores pelo calor, além de fornecer um ambiente favorável para realização de atividades. Em relação às respostas fisiológicas, decorrentes da imersão e realização de fisioterapia aquática nos pacientes portadores de distrofia muscular, foi possível observar alterações significativas em relação às pressões inspiratória e expiratória máximas, e discretas alterações nos valores de frequência cardíaca, e níveis de saturação de oxigênio. Conclusão: 
Diante dos achados mencionados, conclui-se que, o tratamento com fisioterapia aquática, associada à atividade física de baixa a moderada intensidade não é uma sobrecarga física para os pacientes portadores de distrofia muscular. Foi possível comprovar sua eficácia na melhora da agilidade do deslocamento e na funcionalidade de membros superiores. Pesquisas adicionais com maior tempo de seguimento e maiores tamanhos de amostra são sugeridos.

Palavras-chave: hidroterapia, distrofia muscular, tratamento.

Análise da autonomia cardíaca por meio do gráfico de poincaré em idosos submetidos a ambiente aquático

\author{
Sousa EGD1, Gouveia GPM 2, Castro LTG ${ }^{1}$, Silva PA ${ }^{1}$, Araújo RL1, Oliveira TR \\ ${ }^{1}$ Grupo de Pesquisa em Fisioterapia Avaliativa e Terapêuticas- GPFAT, Universidade Federal do \\ Piauí, Parnaíba/PI, ${ }^{2}$ Coordenador do Grupo de Pesquisa em Fisioterapia Avaliativa e \\ Terapêuticas- GPFAT
}

Email: laryssatheodora@hotmail.com

Introdução: A Variabilidade da Frequência Cardíaca (VFC) descreve as oscilações dos intervalos entre batimentos cardíacos consecutivos (intervalos $\mathrm{R}-\mathrm{R}$ ), sendo estas normais, indicando a habilidade do coração em responder aos múltiplos estímulos, como por exemplo, o exercício físico. Portanto, a água e suas propriedades físicas somando-se aos efeitos fisiológicos do exercício podem atuar de maneira benéfica e ainda mais satisfatória ao organismo comparandose à reabilitação convencional isolada. Dentre os métodos utilizados para análise da VFC, encontra-se o gráfico de Poincaré, uma técnica dinâmica não linear que retrata a natureza das flutuações dos intervalos RR das séries temporais. Objetivos: Este estudo objetivou analisar a variabilidade da frequência cardíaca por meio do índice geométrico do gráfico de poincaré. Métodos: O presente trabalho tratou-se de um estudo intervencionista, descritivo, transversal de caráter quantitativo. Estiveram envolvidos 12 sujeitos com idade média de 67,77 $\pm 5,94$ (60-78) anos, residentes no município de Parnaíba/PI, sob aprovação do Comitê de Ética da Universidade Federal do Piauí-PI, com parecer número 2.379.589. Verificou-se a VFC em 12 voluntários, sendo monitorada por um frequencímetro Polar Rs800x® antes e após cada intervenção, utilizando-se da técnica de análise espectral da variabilidade cardíaca. O programa de exercícios em ambiente aquático constituiu-se de uma série de alongamento e exercícios resistidos para membros superiores e inferiores, além de equilíbrio, propriocepção e relaxamento, executados durante uma hora, duas vezes por semana em dias alternados, durante seis semanas. Realizou-se teste descritivo e o de normalidade de Shapiro-Wilk que confirmou uma distribuição normal para as variáveis em estudo, obtendo $p>0,05$ sendo, portanto, utilizado o teste T pareado. Resultados: Ao inferir os dados da variabilidade da frequência cardíaca, antes e após, o protocolo de exercícios aquáticos resistidos, quanto às variáveis SD1 e SD2 do índice geométrico de Poincaré, por meio do teste t pareado, não obteve significância estatística para o valor de SD1 $(p=0,303)$, porém houve significância para o valor de SD2 $(p=0,040)$. Conclusão: Conclui-se que o protocolo realizado não refletiu na alteração do tônus vagal cardíaco parassimpático, porém apresentou um aumento da variabilidade simpática. Infere-se, portanto, que o protocolo refletiu na modulação do sistema autonômico.

Palavras-chave: hidroterapia, sistema nervoso, idosos.

Efeito da Fisioterapia Aquática no condicionamento cardiovascular e na qualidade de vida
de pacientes após acidente vascular encefálico

Costa MRDV ${ }^{1}$, Lima RC1, Lopes $\mathrm{CP}^{1}$, Shirahige $\mathrm{L}^{2}$, Albuquerque $\mathrm{PL}^{3}$, Souza $C E A^{4}$

${ }^{1}$ Centro Universitário Tabosa de Almeida - ASCES/UNITA, Caruaru/PE, ${ }^{2}$ Programa de Pósgraduação em Neuropsiquiatria e Ciências do Comportamento da Universidade Federal de 
Pernambuco - UFPE, Recife/PE, ${ }^{3}$ Programa de Pós-graduação em Neuropsiquiatria e Ciências do Comportamento da UFPE, Docente do departamento de Fisioterapia do Centro Universitário Tabosa de Almeida - ASCES/UNITA, Caruaru/PE, ${ }^{4}$ Docente do departamento de Fisioterapia do Centro Universitário Tabosa de Almeida - ASCES/UNITA, Caruaru/PE

Email: clarissaplopes@hotmail.com

Introdução: os efeitos do treinamento cardiovascular são potencializados quando realizados na piscina terapêutica devido às propriedades físicas da água. Objetivo: avaliar os efeitos de um protocolo de fisioterapia aquática na qualidade de vida e no condicionamento cardiovascular de pacientes pós-AVE. Métodos: Trata-se de um estudo piloto do tipo experimental, realizado no período de julho e agosto de 2014, no ambulatório de fisioterapia da Associação Caruaruense de Ensino Superior, localizado em Caruaru, Pernambuco. Antes de serem submetidos aos procedimentos experimentais da pesquisa, todos os indivíduos leram e assinaram 0 consentimento e assinatura do Termo de Consentimento Livre e Esclarecido (TCLE), elaborado segundo as normas das recomendações da resolução 466/2012 do Conselho Nacional de Saúde, tendo sido aprovado pelo Comitê de Ética e Pesquisa da Associação Caruaruense de Ensino Superior (CEP/ASCES), CAAE: 32898614.4.0000.5203. Foram incluídos 10 pacientes pós acidente vascular encefálico, de ambos os sexos, com idade superior a 25 anos. Apenas indivíduos que possuíam boa compreensão foram incluídos (de acordo com os escores do Mini Exame do Estado Mental - MEEM). Os dez pacientes foram divididos nos grupos: controle (exposto ao protocolo de exercícios no solo) e experimental (submetidos a 10 sessões de fisioterapia aquática). As medidas para frequência cardíaca e respiratória, o número de voltas, saturação de oxigênio durante o teste de caminhada de seis minutos e qualidade de vida segundo a escala EQVE-AVE, foram avaliadas antes e após o programa de atividades. Resultados: Por meio da análise intra-grupo, o teste-t pareado (antes e após experimento) identificou uma redução significativa da frequência cardíaca após o teste de caminhada de seis minutos para o grupo controle $(p=0,003$, diferença de média $6,0 \pm 0,56)$ e um aumento significativo na quantidade de voltas no grupo controle $(p=0,001$, diferença de média $-0,6 \pm 0,56)$ e no grupo experimental $(p=0,01$, diferença de média $-1,8 \pm 0,37)$ em relação à condição inicial. Apenas o grupo experimental $(p=0,046$, diferença de média $-42 \pm 32,9)$ apresentou aumento significativo para o índice geral de qualidade (EQVE-AVE) em relação à condição basal. O teste t para amostras independentes revelou diferença significativa entre os valores aferidos para a pressão diastólica de repouso após o período do experimento entre os grupos controle e experimental ( $p=0,05$, diferença de média $-10 \pm 4,23)$, indicando valores pressóricos mais baixos para o grupo controle. Conclusão: De acordo com os resultados obtidos neste estudo, pode-se concluir que o programa de exercícios na piscina terapêutica apresentou resultados semelhantes aos exercícios de solo para a redução da frequência cardíaca de repouso e ao aumento do número de voltas no teste de seis minutos. Adicionalmente foi capaz de aumentar o índice de qualidade de vida em relação à condição inicial.

Palavras-chave: acidente vascular cerebral, fisioterapia aquática, qualidade de vida, resistência física. 
Desvendando o comportamento motor aquático: descrição e reflexão sobre o movimento funcional

Bruna Yamaguchi ${ }^{1}$, Dielise Debona lucksch ${ }^{1}$, Luize Bueno de Araujo ${ }^{1}$, Karize Rafaela Mesquita Novakoski ${ }^{1}$, Carolina Fernandez Carneiro ${ }^{2}$, Tainá Ribas Mélo ${ }^{1,3}$, Vera Lúcia Israel ${ }^{1,4}$

${ }^{1}$ Programa de Pós-graduação em Atividade Física e Saúde pela Universidade Federal do Paraná (UFPR), Curitiba/PR Brasil, ${ }^{2}$ Programa de Pós-graduação em Desempenho Esportivo pela Universidade Federal do Paraná (UFPR), Curitiba/PR Brasil, ${ }^{3}$ Universidade Campos de Andrade, Curitiba/PR, ${ }^{4}$ Departamento de Fisioterapia da Universidade Federal do Paraná (UFPR), Curitiba/PR

\section{Email: brunayamaguchi@hotmail.com}

Introdução: O ambiente aquático (AA) é amplamente utilizado. No entanto, pouco é descrito sobre comportamentos motores funcionais em imersão. Isso é necessário para aprimorar as estratégias utilizadas para o movimento neste ambiente e para possíveis transferências para o solo. Objetivos: O objetivo deste estudo é descrever qualitativamente comportamentos motores aquáticos para indivíduos hígidos. Em um segundo momento, intenta-se relacionar tais padrões com os existentes no ambiente terrestre e, por meio da perspectiva biopsicossocial fundamentada na Classificação Internacional de Funcionalidade, Incapacidade e Saúde (CIF), com os domínios de atividades e participação desta Classificação. Métodos: Utilizou-se pesquisa-ação que aborda de forma observacional e descritiva comportamentos motores na água com sistematização pelas fases de Israel, Aquatic Functional Assessment Scale (AFAS), efeitos aquáticos no corpo imerso, relação com o movimento funcional no solo e CIF. Partiu-se numa primeira fase para busca de estudos teóricos sobre comportamentos motores funcionais. Depois, realizada uma prática para exploração aquática pelas próprias pesquisadoras durante uma vivência em piscina terapêutica aquecida. Nesta ocasião os movimentos funcionais aquáticos foram filmados dentro e fora da água. $\mathrm{Na}$ terceira fase, as pesquisadoras categorizaram os comportamentos motores aquáticos de acordo com as seguintes as fases de Israel: ambientação, domínio do meio líquido, exercícios terapêuticos especializados e condicionamento orgânico global. Essa sistematização permitiu a adesão de novos comportamentos motores ainda não descritos na escala AFAS, contudo relevantes para ampliar as possibilidades de incentivar habilidades motoras. Em paralelo, foram elencados os principais efeitos do corpo em imersão no AA para cada comportamento descrito. Por fim, os comportamentos aquáticos foram discutidos com movimentos funcionais desempenhados no solo, baseados nos domínios de Atividade e Participação da CIF. Resultados: Resultados permitiram a sistematização do movimento aquático a partir das peculiaridades da água, relacionando-os com repercussões de atividades e participação do movimento funcional, sob visão biopsicossocial da CIF. A teoria biopsicossocial, traz a aprendizagem ocorrendo ao realizar atividades motoras, por meio da exploração do meio ambiente em que vive e ao protagonizar as atividades. Assim, podemos dizer que ao explorarmos o AA há respostas motoras aproveitadas para o AT, pois, como afirmou Morgan, os estímulos e as questões ligadas ao meio interferem diretamente no controle motor e na plasticidade cerebral de maneira a alterar o repertório motor. Conclusão: Este estudo possibilitou maior entendimento do movimento aquático sob a visão biopsicossocial da CIF, de forma que os comportamentos motores executados na água sejam entendidos de forma global, relacionado a padrões de funcionalidade humana no AT. Devemos considerar que essa sistematização permite que profissionais envolvidos no estudo do movimento humano em imersão compreendam a complexidade dessa abordagem e possam aprimorar suas decisões práticas, sejam elas de exercício físico ou terapêutico para a saúde. Palavras-chave: hidroterapia, classificação internacional de funcionalidade, incapacidade e saúde, exercício, atividade motora. 
A efetividade da Fisioterapia Aquática combinada à fisioterapia convencional versus fisioterapia convencional no equilíbrio de indivíduos pós-AVE: uma revisão sistemática e metanálise

\author{
Cavalcante VSP ${ }^{1}$, Missias AA ${ }^{1}$, Mendes $\mathrm{FAS}^{2,3}$, Carmo $\mathrm{AA}^{2}$, Leal $\mathrm{JC}^{2}$ \\ ${ }^{1}$ Universidade de Brasília (Faculdade de Ceilândia), Brasília/DF, ${ }^{2}$ Departamento de Fisioterapia, \\ Universidade de Brasília, Brasília/DF, ${ }^{3}$ Programa de Pós-Graduação em Ciências da \\ Reabilitação da UnB, Universidade de Brasília, Brasília/DF
}

Email: vitoria.s.pinho@hotmail.com

Introdução: Pacientes com Acidente Vascular Encefálico (AVE) frequentemente apresentam déficits de equilíbrio, uma vez que, esses indivíduos têm dificuldade em controlar seus movimentos devido a fraqueza muscular, alteração de tônus muscular e padrões de movimento anormais, o que reduz a quantidade de movimentos e os limites de estabilidade que podem interferir na mobilidade, aumentando o risco de quedas. A terapia aquática é comumente usada na reabilitação neurológica, pois tem potencial para facilitar a movimentação durante a transferência de peso e fornece segurança reduzindo o impacto de uma queda. As propriedades geradas pela água, como a pressão hidrostática e a flutuabilidade permitem que o exercício tenha várias vantagens em relação a um ambiente influenciado pela gravidade. Assim, o treinamento do equilíbrio, pode ser mais vantajoso quando realizado em um ambiente aquático. Embora a fisioterapia aquática seja amplamente utilizada na prática clínica, ainda existe uma lacuna em termos de evidências sobre a sua efetividade no equilíbrio de pessoas que sofreram AVE quando ela é combinada a terapia convencional no plano de tratamento dessa população. Objetivos: Sumarizar criticamente, a evidência atual através de Ensaios Clínicos Randomizados (ECRs) que avaliaram o desfecho equilíbrio em indivíduos com sequelas de AVE após intervenção com fisioterapia aquática combinada a fisioterapia convencional em comparação a estudos que utilizaram somente a fisioterapia convencional. Métodos: Foi realizada uma revisão sistemática com metanálise de ensaios clínicos randomizados. A revisão sistemática foi baseada nas recomendações PRISMA. Foram rastreados artigos que tivessem as palavras-chave pesquisadas no título ou resumo, publicados até maio de 2018 nas seguintes bases de dados: CENTRAL, CINAHL, Google Scholar, LILACS, PEDro, PubMed, Scielo, Scopus e Web of Science. As buscas foram realizadas por dois revisores de forma independente, obedecendo os critérios de elegibilidade e, posteriormente, comparadas. Todos os estudos selecionados foram avaliados metodologicamente utilizando-se a escala PEDro. Foi realizado um teste estatístico para avaliar a concordância inter-avaliador utilizando o teste de coeficiente Kappa (SPSS Statistics versão 20). Para a metanálise foi utilizado o software R 3.4.2. As diferenças médias (MD) e seus intervalos de confiança de 95\% (IC 95\%) foram utilizados para avaliar os desfechos de equilíbrio. Resultados: Um total de 356 estudos foram identificados através da busca em banco de dados e dois adicionais identificados em outras fontes. Seis estudos foram incluídos para análise qualitativa e 4 estudos foram incluídos na metanálise. Os resultados para medições da Escala de Equilíbrio de Berg (EEB) demonstraram uma heterogeneidade não significativa nos valores marcados após 2-6 semanas (MD: 1,85; IC 95\%: $(0,83 ; 2,87) ; p=0,98)$. A metanálise dos estudos que utilizaram o Teste de Alcance Funcional (TAF) demonstrou heterogeneidade não significativa após 2-6 semanas de tratamento (MD: 2,07; IC 95\% (1.01; 3.13); P= 0,79). Para os estudos que avaliaram com o Timed Up and Go Test (TUG) foi demonstrada heterogeneidade não significativa após 6 semanas de tratamento (MD: -2,43; IC 95\% $(-3,37 ;-1,48) ; P=0,80)$. Apesar de alguns estudos obterem resultados favoráveis aos grupos experimentais, no compilado dos resultados das metanálises não houve resultados que favorecessem o uso combinado da terapia aquática com a convencional. Os resultados encontrados auxiliam na decisão clínica em relação às possibilidades de intervenções para o tratamento do equilíbrio em sobreviventes do AVE no qual, a terapia aquática pode ser utilizada como uma terapia complementar à terapia convencional. Conclusão: Conclui-se que a fisioterapia aquática é benéfica no tratamento do equilíbrio em indivíduos no pós-AVE e que a adição da fisioterapia convencional não mostrou diferenças significativas quando comparada a fisioterapia convencional isoladamente.

Palavras-chave: AVE, hidroterapia, equilíbrio postural 
Efeitos da Fisioterapia Aquática no tratamento da dor e qualidade de vida de pacientes
com fibromialgia: uma revisão de literatura

Machado YA ${ }^{1}$, Araújo BN¹, Cardoso RAM¹, Ferreira APS ${ }^{1}$, Fontenele KLC ${ }^{1}$, Silva DV²

${ }^{1}$ Acadêmica de Fisioterapia da Universidade Federal do Piauí, Parnaíba/PI, ${ }^{2}$ Mestranda em Saúde da Mulher pela Universidade Federal do Piauí e Especialista em Fisioterapia Aquática pela UNINASSAU, Recife/PE

Email: yaramachado-@hotmail.com

Introdução: A fibromialgia é uma condição crônica caracterizada por dor musculoesquelética e sintomas secundários como rigidez articular, fadiga, distúrbios do sono e depressão. $O$ diagnóstico baseia-se na presença de dor crônica e difusa por mais de três meses e dor a palpação em no mínimo 11 dos 18 pontos específicos. Em consequência da dor, os indivíduos com fibromialgia apresentam diminuição da capacidade física, causando impacto negativo na qualidade de vida e nos aspectos pessoais, profissionais, familiares e sociais. O tratamento deve integrar abordagens farmacológicas e não farmacológicas com o objetivo de aliviar a dor e a fadiga, melhorar a qualidade do sono e o condicionamento físico. Nesse contexto, a fisioterapia aquática proporciona um ambiente onde as atividades podem ser executadas com maior facilidade, permitindo a reprodução de movimentos com impactos minimizados. Objetivo: $O$ objetivo desse estudo de revisão bibliográfica foi investigar a influência da fisioterapia aquática na dor, sono, condições emocionais e qualidade de vida de indivíduos diagnosticados com fibromialgia. Métodos: Foram utilizadas as bases de dados PubMed, Bireme, SciELO e BVS, com artigos do período de 2006 a 2017. As palavras-chave utilizadas na pesquisa foram: Fibromialgia, Hidroterapia, Qualidade de vida. Resultados: De acordo com os termos de busca pré-definidos foram encontrados 143 artigos. Com a utilização dos filtros, data e idioma (inglês e português), foram reduzidos para um total de 88 artigos. Destes, 53 foram excluídos por não serem compatíveis com o tema em questão e 35 foram selecionados para a leitura do resumo. Após a análise, 17 artigos foram selecionados para a leitura do texto completo por se enquadrarem no tema proposto, focando na fibromialgia, aspecto físicos e psicológicos dos pacientes e na atuação da fisioterapia aquática, finalizando em 17 artigos. Os protocolos de tratamento foram compostos por exercícios de alongamento muscular, exercícios aeróbicos, relaxamento, além do Watsu, técnica baseada em movimentos passivos do paciente. A efetividade dos tratamentos foi qualificada por meio da utilização de questionários avaliando a qualidade de vida, impacto da fibromialgia na funcionalidade, depressão e qualidade do sono. Conclusão: A fisioterapia aquática é uma modalidade de terapia efetiva no tratamento da fibromialgia, atuando na redução da sintomatologia, permitindo a participação ativa do paciente no seu tratamento, proporcionando melhoras significativas nos aspectos relacionados a saúde física e emocional, diminuição da sensibilidade à dor, aumento da tolerância ao exercício e melhora do condicionamento geral, contribuindo positivamente para a qualidade de vida desses pacientes.

Palavras-chave: fibromialgia, hidroterapia, qualidade de vida. 
Efeitos da Fisioterapia Aquática na promoção da qualidade de vida e redução de perda de equilíbrio em idosos: uma revisão sistemática

Araújo BN¹, Fontenele KLC ${ }^{1}$, Ferreira APS ${ }^{1}$, Melo LA ${ }^{2}$

${ }^{1}$ Universidade Federal do Piauí, Parnaíba/PI, ${ }^{2}$ Docente da Universidade Federal do Piauí, Parnaíba/PI

Email: bruna.silver0701@gmail.com

Introdução: O processo de envelhecimento é definido como a redução da capacidade de adaptação do ser humano no meio ambiente, tornando-o cada vez mais dependente. Com esse processo, alguns sistemas são afetados, e dentre estes os responsáveis pela manutenção do controle postural levando, consequentemente, ao aumento do risco de quedas, um fator de grande ressalto epidemiológico para a população idosa. A prática de atividade física promove uma minimização na degeneração causada pelo envelhecimento, levando a uma melhor qualidade de vida e independência. Entre as atividades indicadas para os idosos há um destaque para hidroterapia, um dos recursos fisioterapêuticos que promove tanto reabilitação quanto promoção da saúde por meio de exercícios aliados as propriedades físicas da água. Objetivos: Verificar a eficácia da hidroterapia no equilíbrio de idosos. Métodos: Para a pesquisa bibliográfica, foram realizadas buscas nas bases de dados SciELO, Pubmed e ScienceDirect por material literário publicado entre 2010 a 2017, utilizando os descritores "hidroterapia", "equilíbrio postural", e "idosos". Foram encontrados 17 artigos, dentre eles 07 foram excluídos e 10 encaixaram-se nos critérios da busca, tendo como critérios de inclusão: estudos que tivessem como temática efeitos da hidroterapia na qualidade de vida de idosos e de exclusão: inadequação a questão norteadora, artigos incompletos, monografias e teses. Resultados: De acordo com os artigos explanados, foi evidenciado a melhora do equilíbrio nos idosos submetidos aos diversos protocolos de treinamento, sendo estes com sequências de exercícios que variam entre treinos de propriocepção, fortalecimento muscular, exercícios para marcha e voltados ao sistema vestibular. As melhoras apontadas na prática dos exercícios em hidroterapia são relacionadas as propriedades da água, que oferecem maior resistência e deixam os movimentos mais lentos durante a sessão, fazendo com que os idosos tenham maior percepção sobre os momentos de desequilíbrio, possibilitando a eles um tempo de reação melhor para retornar à posição de equilíbrio, evitando assim as quedas. A temperatura utilizada nas sessões de hidroterapia gera um efeito analgésico, que também auxilia na manutenção do equilíbrio, pois muitas vezes os pacientes idosos sentem dores que interferem nesse processo. Conclusão: A partir dos resultados observados pode-se perceber a eficiência da hidroterapia no restabelecimento do equilíbrio em idosos, gerando melhoria na qualidade de vida dos mesmos pois proporciona maior independência e segurança a este público.

Palavras-chave: hidroterapia, equilíbrio postural, idosos.

Análise do índice de quedas em idosos submetidos à Fisioterapia Aquática: revisão literária

Nascimento $\mathrm{VH}^{1}$, Barbosa $\mathrm{KV}^{1}$, Gomes $\mathrm{TBN}^{1}$, Santos $\mathrm{PMM}^{1}$, Silva $\mathrm{AMM}^{1}$, Silva $\mathrm{MTP}^{1}$, Ferreira ATS $^{1}$, Silva AN ${ }^{1}$, Souza PHVA ${ }^{2}$

${ }^{1}$ Graduandos em Fisioterapia pelo Centro Universitário Tiradentes - UNIT/AL, ${ }^{2}$ Docente do Centro Universitário Tiradentes - UNIT/AL, Grupo de Pesquisa da Liga Acadêmica de Fisioterapia Aquática LAFA, Maceió/AL

Email: vittor.fisio@gmail.com

Introdução: Envelhecer e algo que vai além do ciclo biológico, algo complexo e próprio de todo ser vivo. O envelhecimento pode ser caracterizado pelo declínio da atividade motora e consequentemente da funcionalidade, contribuindo com a fraqueza muscular. Decorrente disso, 
essa população sofrerá com déficit de equilíbrio, perda de massa óssea e muscular, ocasionando maior prevalência de doenças crônico degenerativas e quedas. Objetivos: Este trabalho tem como objetivo analisar o efeito da fisioterapia aquática na prevenção de quedas em idosos. Metodologia: Foi realizado neste estudo um levantamento bibliográfico dos artigos publicados entre 2006 e 2017, nas seguintes bases dados PubMed, LILACS e SciELO utilizando os seguintes descritores: hidroterapia, idoso, queda. Os critérios de inclusão foram artigos publicados em português e inglês, considerando a metodologia dos artigos de ensaios clínicos, randomizados e experimentais. E os critérios de exclusão foram artigos não disponíveis na íntegra. Resultados: Após análise criteriosa do levantamento literário foram encontrados 44 artigos. Destes 39 foram excluídos por não estarem relacionados com o objetivo deste estudo, intervenção da fisioterapia aquática ou por não ser possível o acesso ao texto De acordo com resultados obtidos a fisioterapia aquática mostrou uma melhora no equilíbrio, diminuindo as quedas, interferindo positivamente na qualidade de vida do idoso. Conclusão: De acordo com o que foi visto é notório que a fisioterapia aquática tem influência na redução de quedas em pessoas acima dos 60 anos, apresentando uma melhora no equilíbrio e proporcionando uma melhor qualidade de vida aos idosos.

Palavras-chave: idoso, hidroterapia, queda.

Os efeitos da Fisioterapia Aquática em relação ao equilíbrio em idosos: uma revisão de literatura

Lopes $\mathrm{TS}^{1}$, Silva $\mathrm{RL}^{1}$, Carvalho $\mathrm{KF}^{1}$, Oliveira $\mathrm{FA}^{1}$ Costa BC ${ }^{1}$, Souza $\mathrm{ATS}^{1}$, Gouveia GPM${ }^{2}$, Sousa $\mathrm{LM}^{2}$

${ }^{1}$ Universidade Federal do Piauí, Parnaíba/PI, ${ }^{2}$ Grupo de Pesquisa em Fisioterapia Avaliativa e Terapêuticas - GPFAT, Parnaíba/PI

Email: thamireslopes674@gmail.com

Introdução: A senescência é considerada como um processo natural, dinâmico e progressivo, em que acarreta várias alterações morfológicas e funcionais, a perca de equilíbrio e modificações na postura, por exemplo. Para o atraso ou evitar que essas alterações sejam atenuantes é indicado a realização de atividades física, no qual a fisioterapia aquática se torna importante por conta das propriedades físicas da água somadas aos exercícios. As manifestações dos distúrbios do equilíbrio corporal têm grande impacto para os idosos, podendo levá-los à redução de sua autonomia social, uma vez que acabam reduzindo suas atividades de vida diária, trazendo sofrimento, instabilidade corporal, medo de cair e altos custos com o tratamento Objetivos: Analisar por meio de uma revisão de literatura os efeitos da fisioterapia aquática em relação ao equilíbrio dos idosos. Métodos: Este trabalho foi elaborado a partir de uma revisão da literatura, realizada mediante o uso da base de dados SciELO, Bireme, PubMed. Os descritores foram selecionados a partir da Biblioteca Virtual em Saúde (BVS), usados no idioma inglês, sendo eles aquatic physiotherapy, equilibrium, seniors. Como critério de inclusão foram selecionados os artigos originais do período de 2010 a 2018 e que eram relevantes para o estudo e como critérios de exclusão, os artigos de relato caso e revisões de literatura. Resultados: A fisioterapia aquática é um dos recursos usados no tratamento de pacientes pois melhora desordens músculos esqueléticas, espasticidade, e consequentemente o equilíbrio dos mesmos. Foram encontrados 20 artigos, destes, 9 foram relevantes à revisão mostrando resultados significativos em relação ao equilíbrio e diminuição do risco de quedas nos idosos. Conclusão: Diante dos achados, concluiu-se que a fisioterapia aquática é eficaz no aumento do equilíbrio e na redução de quedas em idosos, porém faz se necessário ser realizadas mais pesquisas nessa temática para a obtenção de mais dados.

Palavras-chave: fisioterapia aquática, equilíbrio, idosos. 
Efeitos da Fisioterapia Aquática na qualidade do sono e capacidade funcional de indivíduos com doenças crônicas degenerativas

Cardeira $\mathrm{CSF}^{1}$, De Araújo $\mathrm{MGR}^{2}$, De Amorim EM${ }^{1}$, De Mattos $\mathrm{RM}^{2}$, De Oliveira AIS ${ }^{1}$, Figueirêdo $\mathrm{BBRS}^{2}$, Rodrigues FTM², Ferreira APL ${ }^{2}$

${ }^{1}$ Universidade Federal de Pernambuco, Recife/PE, ${ }^{2}$ Departamento de Fisioterapia, Universidade Federal de Pernambuco, Recife/PE

Email: ferreiracaroline251@gmail.com

Introdução: Estima-se que $60 \%$ dos problemas de saúde do mundo estão relacionados às doenças crônico degenerativas que na maioria dos casos afetam a qualidade do sono e capacidade funcional dos pacientes. Objetivo: Verificar os efeitos da Fisioterapia Aquática sobre a qualidade do sono e capacidade funcional de indivíduos com doenças crônico degenerativas. Pressupõe-se que a Fisioterapia Aquática possa contribuir para uma melhor qualidade do sono e incremento da capacidade funcional. Métodos: Trata-se de um estudo do tipo série de casos, foram incluídos indivíduos de ambos os sexos com diagnóstico de doenças crônico degenerativas (neurológicas, reumatológicas e cardiovasculares) com relato positivo de má qualidade do sono e dificuldades para realizar as funções físicas cotidianas. Para avaliar a qualidade do sono foi utilizado o Questionário de Qualidade do Sono de Pittsburgh e para avaliar a capacidade funcional foram utilizados: o teste Timed Up \& Go (TUG), Teste de Caminhada de 10 metros e escala de percepção do esforço. O trabalho foi realizado no setor de Fisioterapia Aquática da Clínica Escola de Fisioterapia da UFPE, durante 4 meses, 2 vezes por semana, sessões com duração de 50 minutos. Foram realizados procedimentos de cinesioterapia aquática com e sem o auxílio de flutuadores, métodos de Halliwick, Bad Ragaz e Watsu, e massagens subaquáticas. O estudo foi aprovado pelo comitê de ética da UFPE, parecer CAAE 83398118.8.0000.5208/2018. Resultados: Foram analisados 44 indivíduos (34 do sexo feminino e 10 do sexo masculino), com média de idade de 44,13 \pm 15,8 e IMC médio de 25,15 $\pm 2,9$. Houve melhora quanti e qualitativa do sono de pobre (escore médio 14?0,6) para ótimo (escore médio $4,13 \pm 0,8$ ), o teste de caminhada de 10 metros revelou mudança na velocidade da marcha de $0,72 \pm 0,24 \mathrm{~m} / \mathrm{s}$ para $2,3 \pm 0,44 \mathrm{~m} / \mathrm{s}$ com maior frequência das passadas, melhora qualitativa no sincronismo do movimento dos braços e diminuição da rotação pélvica. A percepção do esforço foi reduzida de 9 para 7 pontos. As experiências provocadas pela água podem estimular a potencialidade plástica do sistema nervoso central por meio de estímulos sensitivos e motores, favorecendo um maior controle motor, reações de equilíbrio além de promover o máximo de independência funcional em indivíduos com doenças crônico degenerativas. Conclusão: a Fisioterapia Aquática contribuiu para melhorar a qualidade do sono e a capacidade funcional de indivíduos com doenças crônico degenerativas. Esse resultado aponta para o fato que outros pacientes com o mesmo diagnóstico possam se beneficiar do tratamento no meio aquático.

Palavras-chave: doença crônico degenerativa, hidroterapia, capacidade funcional.

\section{A importância da hidrocinesioterapia na paralisia cerebral do tipo tetraparesia espástica - relato de experiência}

Bento AKO, Almeida GKO1, Escórcio AS, Cerqueira WF, Ferreira Neto JM, Pereira MLS, Teixeira BBS

Graduandos em Fisioterapia pela Universidade Federal do Piauí - UFPI, Parnaíba/PI

Email: anikeli0424@hotmail.com

Introdução: O termo paralisa cerebral (PC) é definido como uma desordem do movimento e da postura devido a uma lesão no cérebro imaturo. É uma patologia não progressiva e provoca debilitações variáveis na coordenação da ação muscular, com resultante incapacidade em manter posturas e realizar movimentos normais, sendo que a gravidade das alterações depende 
do tipo, extensão e localização da lesão. A PC do tipo tetraparética espástica representa a forma clínica mais grave das paralisias cerebrais. Em sua maioria, as crianças apresentam retardo mental, crises convulsivas e grave comprometimento motor. Dessa forma, a Fisioterapia tem um papel reabilitador, visando a melhora do controle de movimento e prevenção da fraqueza muscular decorrentes dos danos ao desenvolvimento motor atípico. A hidroterapia ou hidrocinesioterapia é uma modalidade de reabilitação da Fisioterapia que possui uma longa história. A piscina terapêutica oferece oportunidades estimulantes para os movimentos mais difíceis e complexos, pois forças diferentes agem na água. Os efeitos de flutuabilidade, metacentro e das rotações fornecem campo para as técnicas especializadas e ainda, os efeitos terapêuticos trazem benefícios como a manutenção ou aumento da amplitude de movimento das articulações; fortalecimento dos músculos enfraquecidos e aumento na sua tolerância aos exercícios; reeducação dos músculos paralisados; melhoria da circulação; encorajamento das atividades funcionais e melhoria da coordenação motora. Objetivo: Verificar a importância da hidroterapia no tratamento da paralisia cerebral do tipo tetraparética espástica para a manutenção e/ou melhora do quadro clínico. Métodos: Trata-se de um estudo de caráter observacional sobre o atendimento fisioterapêutico a um paciente diagnosticado com paralisia cerebral, realizado de março a maio de 2018, na Clínica Escola de Fisioterapia da Universidade Federal do Piauí - UFPI. Os atendimentos eram realizados durante 2 vezes por semana, com duração de 60 minutos, com exercícios de alongamentos passivos, treino de Bad Ragaz, modulação de tônus e treino de marcha. $O$ estudo baseou-se nos princípios éticos, onde todos os envolvidos foram esclarecidos do objetivo do estudo e assinado o termo de consentimento livre e esclarecido. Resultados: Paciente S.F.R., sexo masculino, nascido no dia 11/02/1992, parto prematuro ao sexto mês de gravidez, após o nascimento permaneceu 3 meses na incubadora e posteriormente diagnosticado com encefalopatia crônica não progressiva. A avaliação fisioterapêutica diagnosticou um quadro de tetraparesia espástica, associado à hiporreflexia dos membros superiores e joelho, hipertonia nos membros superiores. Visando minimizar a evolução dos comprometimentos a fisioterapia tem papel fundamental para melhorar e/ou manter trofismo, minimizar a fraqueza muscular, bem como alongar as estruturas envolvidas. A literatura demonstra que a reabilitação neuromotora aquática foi descrita como um precursor útil para os programas tradicionais de reabilitação de lesão cerebral. $\mathrm{O}$ tratamento de um paciente com distúrbios neurológicos na água oferece uma grande variedade de opções em um ambiente altamente dinâmico. A meta de uma reabilitação é tornar o indivíduo mais independente possível, melhorando sua funcionalidade e qualidade de vida. Conclusão: Verificou-se que o programa de tratamento realizado duas vezes por semana no ambiente aquático é eficaz, visto que houve melhoras em relação a marcha subaquática, bem como para o relaxamento muscular, redução de espasmos musculares e espasticidade, melhora da musculatura respiratória, melhora do equilíbrio e da amplitude de movimento, sendo os princípios físicos da água auxiliares no processo de tratamento.

Palavras-chave: hidroterapia, paralisia cerebral.

\title{
Os benefícios da Fisioterapia Aquática para pacientes com diagnóstico de fibromialgia: revisão de literatura
}

\author{
Barbosa $\mathrm{CCG}^{1}$, Da Silva $\mathrm{ACCN}{ }^{1}$, De Paula $\mathrm{TB}^{1}$, Junior $\mathrm{ETL}^{1}$, Mendes $\mathrm{JPS}^{1}$, Peixoto $\mathrm{MMF}^{2}$ \\ ${ }^{1}$ Centro Universitário Maurício de Nassau, Recife/PE, ${ }^{2}$ Graduação pela Faculdade São Miguel, \\ Programa de Pós-Graduação, Faculdade Redentor, Recife/PE
}

Email: mariliapeixoto17@gmail.com

Introdução: A fibromialgia é uma síndrome dolorosa crônica que se caracteriza pela existência de pontos dolorosos à palpação de regiões específicas do corpo. Seus principais sintomas são dor, alterações do sono, cefaleia, fadiga, depressão que são considerados essenciais para o estabelecimento de seu diagnóstico. E uma síndrome que atinge cerca de $2 \%$ da população adulta, com maior incidência entre as mulheres e sua etiologia permanece incerta. A fisioterapia se apresenta como um recurso de suma importância, uma vez que os exercícios preservam a mobilidade, mantendo a atividade muscular, minimizando e retardando a evolução da patologia 
além de melhorar a qualidade de vida do paciente Objetivos: O objetivo desse estudo é analisar os benefícios da fisioterapia aquática para pacientes com diagnóstico de fibromialgia. Métodos: Este estudo trata-se de uma revisão integrativa da literatura envolvendo publicações científicas sobre a fibromialgia e hidroterapia. A pesquisa foi realizada em abril de 2017, com artigos publicados de 2010 a 2017 conforme o enfoque temático. Resultados: Verificamos que a fibromialgia é uma doença de etiologia ainda incerta, com um diagnóstico consideravelmente subjetivo e com tratamento em constante evolução. A sua prevalência depende dos métodos usados para considerar o diagnóstico como positivo e varia entre 2 e $8 \%$. Dentre os sintomas em casos mais graves podemos encontrar problemas de raciocínio ou de memória, fraqueza muscular, cefaleia, dor ou cólicas no abdómen, dormência ou formigueiro, tonturas, insónias, dor no abdome superior, náusea, nervosismo, dor torácica, visão turva, febre, diarreia, xerostomia, prurido, fenômeno de Raynaud, urticária, zumbido, vômitos, pirose, aftas, disgeusia ou ageusia, convulsões, xeroftalmia, dispneia, perda de apetite, exantema, sensibilidade à exposição solar, dificuldades auditivas, equimose fácil, perda de cabelo, aumento da frequência urinária, disúria e espasmos da bexiga. A melhor forma de tratamento seria a conjugação do farmacológico com o não farmacológico como a prática de exercícios físicos, exercícios aeróbicos, fisioterapia e hidroterapia que auxiliam na diminuição e retardamento dos sintomas. Conclusão: Contudo conclui-se que são diversos os benefícios da fisioterapia aquática para os pacientes com diagnóstico de fibromialgia dentre eles destacam-se atuação na dor, na rigidez, capacidade funcional, fadiga, função social, estado de humor, alterações do sono, ansiedade, depressão, além de promover o bem-estar e melhora na qualidade de vida.

Palavras-chave: fibromialgia, fisioterapia, qualidade de vida, fisioterapia aquática, sintomas.

Fisioterapia Aquática como recurso de readaptação da corrida em maratonista amadora pós politraumatismo coxofemoral: relato de caso

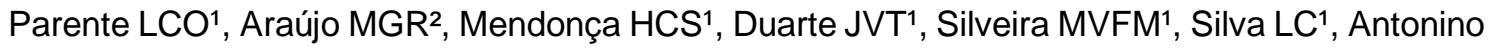
$\mathrm{GB}^{3}$, Ferreira $\mathrm{APL}^{2}$

${ }^{1}$ Acadêmico de Fisioterapia, Universidade Federal de Pernambuco, Recife/PE, ${ }^{2}$ Docente do Departamento de Fisioterapia, Universidade Federal de Pernambuco, Recife/PE, ${ }^{3}$ Programa de Pós-Graduação em Fisioterapia, Universidade Federal de Pernambuco, Recife/PE

Email: luanaparente00@gmail.com

Introdução: O politraumatismo do quadril apresenta sequelas funcionais que tornam difícil o retorno à atividade esportiva. Hipotetiza-se que a Fisioterapia aquática pode ser considerada um recurso terapêutico importante no retorno da corrida por possibilitar a descarga de peso precoce sobre o membro comprometido. Objetivos: Verificar os efeitos da Fisioterapia Aquática como recurso de readaptação da corrida em maratonista amadora com histórico de politraumatismo coxofemoral. Métodos: Relato de caso, paciente do sexo feminino, 46 anos, IMC $26,2 \mathrm{~kg} / \mathrm{m}^{2}$, representante comercial, sofreu fratura cominutiva de hemipelve e quadril. Durante avaliação cinético funcional relatou fraqueza dos músculos periarticulares do quadril, sensação de peso e dificuldade para aumentar o ritmo da marcha e realizar a transição marcha-corrida. $O$ trabalho foi iniciado após 4 meses de intervenção cirúrgica (osteossíntese complexa com placa e parafusos para pelve e fêmur). O tratamento foi realizado no setor de Fisioterapia Aquática da Clínica Escola de Fisioterapia da UFPE, durante 3 meses, 2x/semana, sessões com duração de 50 minutos. Foram realizados procedimentos de cinesioterapia aquática com e sem o auxílio de flutuadores, método de Bad Ragaz, Watsu e massagens subaquáticas, Deep Running e corrida em circuito. O estudo foi aprovado pelo comitê de ética da UFPE, parecer CAAE: 83398118.8.0000.5208/2018. Para avaliar a capacidade de readaptação da corrida foram utilizados: teste de força muscular para o quadril (TFM; KgF) com célula de carga da marca Miotec $\AA$, Teste funcional de corrida (Shuttle Run Test), escala de percepção do esforço e com o uso de um relógio com GPS, frequencímetro e sensor de acelerometria foi possível verificar a frequência cardíaca, velocidade e ritmo da deambulação e corrida, além do tempo de transição marcha-corrida. Resultados: Foi verificado incremento médio de $20 \%$ da força muscular, Teste funcional (Shuttle Run Test) demonstrou maior velocidade da corrida (de estágio 3 para estágio 
7) com boa recuperação no quinto minuto de repouso. A percepção do esforço diminuiu de 9 (muito difícil) para 2 (fácil) pontos na escala visual, houve aumento na velocidade e ritmo de deambulação com adaptação e otimização do tempo para transição marcha-corrida. A Fisioterapia Aquática permite a mobilização precoce com redução do impacto podendo favorecer ganhos consideráveis sobre o desempenho da corrida e sobre a capacidade cardiorrespiratória contribuindo assim para a readaptação do esporte pós-trauma. Conclusão: A Fisioterapia Aquática contribuiu para readaptação da corrida em maratonista amadora promovendo ganhos consideráveis na performance da corrida.

Palavras-chave: corrida, aptidão cardiorrespiratória, exercício.

\section{Contribuição da acelerometria na quantificação de carga durante o exercício aquático}

Pereira RAA ${ }^{1}$, Silva $\mathrm{CM}^{1}$, Conceição $\mathrm{AM}^{1}$, Souza $\mathrm{MCP}^{1}$, Inocencio $\mathrm{AVM}^{1}$, Esteves $\mathrm{GRP}^{1}$, Silva $\mathrm{MBC}^{1}$, Rodrigues MAB ${ }^{1}$

\section{${ }^{1}$ Grupo de Pesquisa em Engenharia Biomédica, UFPE, Recife/PE}

Email: rogerioantunespereira10@gmail.com

Introdução: A utilização da água como recurso para a atividade física e principalmente como meio terapêutico é muito antiga. Atualmente, é muito utilizada para reabilitação de pacientes nas diversas áreas da saúde, bem como em atividades físicas e nos esportes em geral. O exercício na água vem apresentando uma grande lacuna no que diz respeito a mensuração da carga (esforço) durante o exercício. Segundo os princípios da hidrodinâmica (mecânica de fluidos), o esforço do indivíduo durante o exercício dentro da água é alterado por alguns fatores como: o sentido do movimento do corpo, aumento da resistência frontal pela área de arrasto, bem como o aumento da força contra o sentido do exercício diretamente proporcional a velocidade na execução dele. Com relação a aceleração esta é trabalhada, no campo da fisioterapia aquática, de forma empírica por não haver um equipamento aquático que correlacione o esforço à velocidade e à possível carga que o indivíduo está utilizando durante o exercício aquático. A quantificação da velocidade por ser realizada por acelerômetros, que são componentes eletromecânicos sensíveis a aceleração do corpo e que transformam a informação em sinais digitais que poderá ser lido por computadores ou celulares. Através da acelerometria pode se calcular e identificar a velocidade durante o exercício aquático. A representação da velocidade pode ser dada através de sinais luminosos, associando-os com a velocidade. Objetivo: Desenvolver um equipamento capaz de representar o sinal de acelerometria através de luz (LEDs RGB), associando a escala de cores com o nível de velocidade do movimento do paciente (leve, moderada e intensa), durante o exercício aquático. Métodos: $\mathrm{O}$ desenvolvimento do equipamento baseia-se em três grandes etapas: a primeira foi a definição de um circuito de controle eletrônico que utiliza um acelerômetro triaxial (monitoração dos três eixos cartesianos $X, Y, Z$ ), após foi interligado um conjunto de LEDs RGB, isto é, que possibilitam mudar a sua cor de acordo com a programação do circuito de controle. Essa representação torna possível a realização de uma relação luminosa em tempo real da velocidade do movimento (exercício) que é executado no meio aquático. A segunda etapa foi a calibração do sistema, que é realizada diretamente através do firmware (programa) do equipamento, onde é associado o tempo de ativação e a cor do LED de acordo com o movimento. Essa fase associa a força do movimento e a velocidade do movimento a ser realizado dentro da água com a intensidade e a cor da luz que deve ser apresentada ao fisioterapeuta. A terceira etapa foi o desenvolvimento em uma impressora 3D de um dispositivo do tipo pulseira, capaz de ser colocado no braço ou na perna do paciente, de forma que esse não ocasione nenhum problema de oposição ao movimento dentro da água. Resultados: Os resultados obtidos em laboratório demonstram que o equipamento desenvolvido é capaz de relacionar a velocidade do movimento com indicadores luminosos que são controlados através do equipamento. $O$ consumo do equipamento é extremamente baixo em torno de $19 \mathrm{~mA}$ no modo de alto desempenho. Conclusão: Para validação desse equipamento foram realizados testes em laboratório e dentro da água, demostrando a viabilidade do sistema. A dificuldade encontrada no projeto foi a relação da velocidade do movimento com a representação luminosa, que tem que levar em consideração o 
tipo de exercício a ser realizado e as limitações do paciente. Outra dificuldade encontrada é a utilização de um equipamento dentro da água, totalmente vedado, para que a água não afete os circuitos eletrônicos. Após todos os testes realizados verificou-se que o equipamento através da acelerometria, pode calcular e identificar a velocidade durante o exercício aquático podendo, podendo ser adaptado (configurado) para qualquer tipo de exercício na água.

Palavras-chave: hidroterapia, medição de velocidade, acelerometria.

\section{Impactos da Fisioterapia Aquática na fibromialgia: uma revisão integrativa}

Teixeira BBS ${ }^{1}$, Bento $\mathrm{AKO}^{1}$, Almeida $\mathrm{GKO}^{1}$, Ferreira Neto $\mathrm{JM}^{1}$, Monteiro MGT ${ }^{2}$, Silva PJC ${ }^{1}$, Cerqueira WF ${ }^{1}$, Cerqueira $\mathrm{WF}^{1}$,

${ }^{1}$ Graduando em Fisioterapia pela Universidade Federal do Piauí - UFPI, ${ }^{2}$ Mestranda em Ciências Biomédicas pelo Laboratório de Mapeamento Cerebral e Funcionalidade (LAMCEF), Universidade Federal do Piauí - UFPI, Parnaíba/PI

Email: brunabeatriiz18@gmail.com

Introdução: A síndrome da fibromialgia (SFM) é uma das doenças reumatológicas mais frequentes, caracterizada por dor musculoesquelética difusa e crônica, com pontos sensíveis (tender points) nos músculos ou na junção miotendinosa. São 18 tender points situados em locais distintos do corpo e seu caráter crônico, causa impacto negativo na qualidade de vida de seus portadores, pois além da dor e da sensibilidade dos tender points, os pacientes também apresentam irregularidades no sono, fadiga, rigidez matinal, diminuição da capacidade funcional, ansiedade e depressão, que reduzem a capacidade do paciente de realizar as tarefas domésticas básicas. Todos esses sintomas prejudicam a vida social e profissional do fibromiálgico. Estimase que a prevalência na população geral é de $2 \%$ a $5 \%$ e a fisiopatologia é multicausal. As opções terapêuticas para o tratamento da fibromialgia incluem medicações para reduzir a dor e melhorar - sono, programas de exercícios para fortalecer a musculatura e melhorar a aptidão cardiovascular, técnicas de relaxamento para combater a tensão muscular e programas educativos para ajudar a entender e manejar a fibromialgia. Assim, a fisioterapia tem um importante papel na melhora do controle da dor e no aumento ou na manutenção das habilidades funcionais do paciente em casa ou no trabalho. Dentre os recursos fisioterapêuticos a hidroterapia consiste em um recurso abrangente que utiliza os exercícios aquáticos para ajudar na reabilitação de várias patologias e está bem indicada para pacientes com SFM, sendo importante para a melhoria de qualidade do sono, capacidade funcional, situação profissional, distúrbios psicológicos e sintomas físicos da síndrome, além dos efeitos relacionados a alívio da dor, diminuição dos espasmos, relaxamento muscular, aumento da amplitude de movimento, aumento da circulação sanguínea, fortalecimento muscular, aumento da resistência muscular e melhora na autoestima. Objetivo: Analisar os benefícios da Fisioterapia Aquática em pacientes com fibromialgia. Métodos: Revisão integrativa de estudos indexados nas bases de dados SciELO e Pubmed, sobre publicações que utilizavam os termos "Fibromialgia", "Hidroterapia" e "Tratamento" nos idiomas português e inglês. Como critério de inclusão: estudos que tivessem como temática os efeitos da hidroterapia na fibromialgia, artigos originais e ensaios clínicos publicados entre 2009 e 2018. Como exclusão foram: revisões bibliográficas, artigos incompletos, monografias e teses. Resultados: Foram encontrados 53 estudos, dos quais, 5 foram utilizados por atenderem os critérios de inclusão. Os efeitos fisiológicos da hidrocinesioterapia advêm de uma combinação dos efeitos físicos da água (térmicos/mecânicos) com os efeitos do exercício, proporcionando grande alívio dos sintomas da fibromialgia, pois os movimentos na água são lentos e dão suporte às estruturas corporais permitindo maior mobilidade e, consequentemente, alongamentos mais eficientes, além dos benefícios da imersão do paciente em água aquecida, em torno de $30^{\circ} \mathrm{C}$ a $34^{\circ} \mathrm{C}$, favorecendo o relaxamento muscular e diminuindo a dor e a rigidez. Conclusão: Os estudos mostraram que o exercício na água tem uma utilidade imediata a curto prazo e deve ser considerada como uma opção para o tratamento da dor da SFM. Portanto, a hidrocinesioterapia, além de permitir o relaxamento muscular por meio da água aquecida, proporciona aos fibromiálgicos um tratamento com melhora da autoconfiança e evolução mais rápida e uma melhora significativa da qualidade de vida. 
Palavras-chave: hidroterapia, fisioterapia, fibromialgia.

\section{Análise dos efeitos da Fisioterapia Aquática no equilíbrio de idosos: uma revisão sistemática}

Cerqueira WF ${ }^{1}$, Ferreira Neto $\mathrm{JM}^{1}$, Teixeira BBS ${ }^{1}$, Almeida GKO1, Bento AKO ${ }^{1}$, Cerqueira WF${ }^{1}$, Nery CVF ${ }^{1}$, Monteiro MGT ${ }^{2}$

${ }^{1}$ Graduando em Fisioterapia pela Universidade Federal do Piauí - UFPI, Parnaíba, PI, Brasil, ${ }^{2}$ Mestranda em Ciências Biomédicas pelo Laboratório de Mapeamento Cerebral e Funcionalidade (LAMCEF/UFPI), Parnaíba/PI

Email: walanyfontcerq@gmail.com

Introdução: No Brasil, segundo dados de 2002 (Instituto Brasileiro de Geografia e Estatística IBGE), até o ano de 2020 a população idosa será de 31,8 milhões de pessoas. Com o envelhecimento ocorre o comprometimento da habilidade do sistema nervoso central em realizar o processamento dos sinais vestibulares, visuais e proprioceptivos responsáveis pela manutenção do equilíbrio corporal, bem como diminui a capacidade das reações adaptativas, tendo a instabilidade postural um dos principais fatores que limita as atividades de vida diárias do idoso. Nesse contexto, as quedas se tornaram um dos maiores problemas de saúde pública em idosos, sendo o tipo de acidente mais frequente e suas complicações, a principal causa de morte naqueles com mais de 65 anos. Assim, com o envelhecimento populacional tem se buscado, por meio de diferentes tipos de exercícios, melhorar o equilíbrio, prevenindo assim as quedas e suas consequências, pois para o idoso, ter saúde é ter autonomia e independência. Dentre os recursos, a água é mais uma opção para o tratamento, sendo certamente um meio diferenciado e bastante apropriado, pois as propriedades físicas da água, somadas aos exercícios, podem cumprir com a maioria dos objetivos físicos propostos num programa de reabilitação. Sendo o meio aquático seguro e eficaz na reabilitação do idoso, pois a água atua simultaneamente nas desordens musculoesqueléticas e melhora o equilíbrio. Objetivo: Avaliar através de uma revisão sistemática, os efeitos de programas de Fisioterapia Aquática no equilíbrio de idosos. Métodos: Revisão sistemática de estudos indexados nas bases de dados SciELO, Pubmed, Scopus sobre publicações que utilizavam os termos: "Hidroterapia", "equilíbrio postural" e "idoso" nos idiomas português e inglês. Como critério de inclusão: estudos que tivessem como temática os efeitos da prática da Fisioterapia aquática no equilíbrio em pacientes idosos, artigos originais e ensaios clínicos publicados entre 2008 a 2018. Como exclusão, foram: revisões bibliográficas, artigos incompletos, monografias e teses. Resultados: Foram selecionados 17 estudos, dos quais, 6 foram utilizados por atenderem os critérios de inclusão. Os autores são unânimes quanto à indicação de exercícios aquáticos para indivíduos com medo e risco de queda, uma vez que reduzem o risco de quedas em idosos devido ao aumento da coordenação e equilíbrio, aumento de recrutamento de motoneurônios, aumento da resistência à fadiga muscular e hipertrofia, principalmente, de fibras tipo II. Os exercícios físicos somadas as propriedades físicas da água podem cumprir com a maioria dos objetivos físicos propostos num programa de reabilitação, permitindo criar situações de instabilidade com utilização dos efeitos da turbulência, fornecendo grande quantidade de informações sensoriais, promovendo melhora nas reações de equilíbrio corporal. Conclusão: De acordo com os estudos foi verificado que programas de exercícios de fisioterapia aquática são capazes de influenciar os sistemas sensoriais responsáveis pelo controle da postura, proporcionando um aumento do equilíbrio e redução do risco de quedas na população idosa. Prevenindo assim, os efeitos indesejados decorrentes de tais quedas que causam restrições das atividades e comprometem severamente a qualidade de vida.

Palavras-chave: hidroterapia, equilíbrio postural, idoso. 


\section{Efeitos da hidroterapia na fibromialgia: relato de experiência}

Almeida $\mathrm{GKO}^{1}$, Araújo $A E P^{1}$, Bento $\mathrm{AKO}^{1}$, Cerqueira $\mathrm{WF}^{1}$, Ferreira Neto $\mathrm{JM}^{1}$, Pereira $\mathrm{MLS}{ }^{1}$, Teixeira BBS ${ }^{1}$, Melo LA ${ }^{2}$

${ }^{1}$ Graduando em Fisioterapia pela Universidade Federal do Piauí - UFPI, Parnaíba/PII, ${ }^{2}$ Docente do Curso de Fisioterapia na Universidade Federal do Piauí - UFPI, Parnaíba/PI

Email: giok.oliveira1@gmail.com

Introdução: A Organização Mundial de Saúde (OMS), define saúde como o conjunto de bemestar físico, mental e social. O que leva os profissionais da saúde a se preocuparem com as repercussões das doenças nas diversas dimensões da vida dos indivíduos. Dessa forma, A fibromialgia é definida como uma síndrome dolorosa de etiologia ainda desconhecida que acomete em sua maioria mulheres, caracterizada também pela presença de dores musculares difusas crônicas e sítios dolorosos específicos, relacionados frequentemente a distúrbios do sono, fadiga, cefaleia crônica, distúrbios psíquicos e intestinais funcionais. Os portadores de fibromialgia se beneficiam com a realização de atividade física, pois esta prática contribui para a melhora da dor, da qualidade do sono, da fadiga, da ansiedade e de outros sintomas, permite ainda uma socialização, dependendo de circunstâncias, e influencia positivamente alguns aspectos psicológicos. A hidroterapia, geralmente praticada em água aquecida entre $32^{\circ}$ e $34^{\circ} \mathrm{C}$, é fortemente indicada para o tratamento da fibromialgia, seu objetivo principal no tratamento da fibromialgia é aumentar a tolerância do indivíduo ao exercício e o nível de resistência física, melhorando o condicionamento geral. Dentre os principais efeitos terapêuticos da água estão à promoção do relaxamento muscular pela redução da tensão, a diminuição dos espasmos musculares pela temperatura aquecida da água e a redução da sensibilidade à dor. Durante a imersão, os estímulos sensoriais competem com os estímulos dolorosos, interrompendo o ciclo da dor. Outro importante efeito terapêutico é o aumento da facilidade na execução dos movimentos articulares. A flutuação na água contrapõe-se à gravidade aliviando o peso corporal e reduzindo as forças de compressão sobre as articulações. Objetivo: Verificar os efeitos da Hidroterapia no tratamento do paciente com fibromialgia, na manutenção ou melhora do caso clínico. Métodos: Trata-se de um estudo de caráter observacional sobre o atendimento fisioterapêutico à um paciente diagnosticado com fibromialgia, realizado de agosto de $2017 \mathrm{a}$ abril de 2018, na Clínica Escola de Fisioterapia da Universidade Federal do Piauí - UFPI. Os atendimentos eram realizados durante 2 vezes por semana, com duração de 60 minutos, com caminhada dentro da piscina, treino respiratório, alongamento de MMII e MMSS, exercícios resistidos e mobilização articular. O estudo baseou-se nos princípios éticos, onde todos os envolvidos foram esclarecidos do objetivo do estudo e assinado o termo de consentimento livre e esclarecido. Resultados: Paciente L.F.S.M, 59 anos, sexo feminino, relatou que há 10 anos começou a sentir dores pelo corpo, que limitam suas atividades de vida diária, e ao procurar o reumatologista recebeu o diagnóstico de fibromialgia. Durante a avaliação fisioterapêutica a paciente relatou novamente muita dor acompanhada de falta de equilíbrio quando está em crise. A fisioterapia tem um importante papel na melhora do controle da dor e no aumento ou na manutenção das habilidades funcionais do paciente em casa ou no trabalho. A hidroterapia consiste em um recurso terapêutico abrangente que utiliza os exercícios aquáticos para ajudar na reabilitação de várias patologias. Esse recurso proporciona grande alívio dos sintomas da fibromialgia, pois os movimentos na água são lentos e dão suporte às estruturas corporais permitindo maior mobilidade e, consequentemente, alongamentos mais eficientes. Conclusão: Nesse sentido, conclui-se que o programa de tratamento realizado duas vezes por semana no ambiente aquático, é um recurso eficaz para o tratamento de pacientes acometidos por fibromialgia, uma vez que houve melhora em aspectos referentes à amplitude de movimento, força muscular e qualidade de vida.

Palavras-chave: hidroterapia, fibromialgia. 
Fisioterapia Aquática na doença de Strümpell-Lorrain: uma revisão de literatura

Carvalho KF${ }^{1}$, Silva MGS ${ }^{1}$, Silva FIP ${ }^{1}$, Gouveia $\mathrm{GPM}^{2}$, Silva RL ${ }^{1}$, Lopes $\mathrm{TS}^{1}$, Souza ATS ${ }^{1}$, Magalhães FEX ${ }^{1}$

${ }^{1}$ Universidade Federal do Piauí, Parnaíba/PI, ${ }^{2}$ Grupo de Pesquisa em Fisioterapia Avaliativa e Terapêuticas - GPFAT, Parnaíba/PI

Email: jkananda07@gmail.com

Introdução: A paraparesia espástica hereditária ou doença de Strümpell-Lorrain é uma doença neurodegenerativa, caracterizada por fraqueza muscular e espasticidade lentamente progressiva dos membros inferiores. A sintomatologia da doença é expressa pelas formas pura e complicada, sendo as puras classificadas especialmente pela degeneração progressiva do trato corticoespinal e das fibras do fascículo grácil resultando no comprometimento motor e sensitivo dos membros inferiores. Já na forma complicada o envolvimento adicional de múltiplas partes do sistema nervoso faz com que o paciente também apresente manifestações associadas como neuropatia, ataxia, amiotrofia, epilepsia, declínio cognitivo, entre outras. A fisioterapia aquática é um dos métodos terapêuticos mais antigos utilizados para o gerenciamento de disfunções físicas. As propriedades de suporte, assistência e resistência da água favorecem os fisioterapeutas e os pacientes na execução de programas voltados para melhora da amplitude de movimento, recrutamento muscular, exercícios de resistência e no treinamento de deambulação e do equilíbrio. Objetivo: Analisar, por meio de uma revisão de literatura, as informações existentes relacionadas à utilização da fisioterapia aquática em pacientes com paraparesia espástica hereditária. Métodos: Procedeu-se uma revisão, usando as bases de dados: PUBMED e Science Direct, PLOS ONE, SciELO, PeDRO e Bireme. Foram utilizados os seguintes descritores: "Aquatic Physiotherapy" e "Hereditary Spastic Paraparesis" e seus respectivos descritores em português, utilizando busca booleanas "or, and". Para análise, os critérios de inclusão foram: artigos de pesquisa, estudos de caso, dissertações e teses, escritos em língua inglesa e portuguesa, publicados de 2000 a 2018. Os critérios de exclusão foram: inadequação a questão norteadora e artigos incompletos. Resultados: A busca somou-se em 3 artigos que se adequavam ao tema e foram introduzidos no trabalho. A fisioterapia aquática é um recurso fisioterapêutico que utiliza os efeitos físicos e fisiológicos advindos da imersão do corpo em piscina aquecida, como recurso para a reabilitação ou na prevenção de alterações funcionais. É comprovado os benefícios do ambiente aquático para o tratamento de pacientes com lesões neurológicas que cursam com espasticidade, porém há divergências quanto à abordagem terapêutica específica a ser utilizada e seu embasamento científico. A fisioterapia aquática pode ser um importante método auxiliar, a ponto de permitir a redução da dose de medicação necessária para o controle da espasticidade. As propriedades da água promovem efeitos benéficos como o relaxamento muscular e diminuição do espasmo, redução da sensibilidade à dor, além da sensação de independência e bem-estar. A viscosidade e a flutuação favorecem a melhora do equilíbrio e auxiliam na deambulação. Técnicas cinesioterapêuticas estão sendo empregadas em ambiente aquático, tais manobras utilizam posturas e exercícios, visando à introdução de padrões funcionais, com objetivos de adequação tônica, fortalecimento da musculatura, manutenção das amplitudes de movimentos articulares e estimulação sensorial e proprioceptiva. Conclusão: Apesar da fisioterapia aquática ser considerada benéfica no tratamento de pacientes com paraparesia espástica, faltam evidências experimentais da sua eficácia. As evidências existentes na literatura quanto aos benefícios da fisioterapia aquática quando aplicada aos pacientes com espasticidade são escassas. Devendo, dessa forma, serem realizados novos estudos.

Palavras-chave: fisioterapia aquática, paraparesia espástica, reabilitação. 
Efetividade da Fisioterapia Aquática no equilíbrio de indivíduos pós-AVE: uma revisão sistemática e metanálise

\author{
Missias $\mathrm{AA}^{1}$, Cavalcante VSP${ }^{1}$, Mendes $\mathrm{FAS}^{2,3}$, Carmo $\mathrm{AA}^{2}$, Leal $\mathrm{JC}^{2}$ \\ ${ }^{1}$ Universidade de Brasília - UnB - Faculdade de Ceilândia - FCE, Brasília/DF, ${ }^{2}$ Departamento de \\ fisioterapia, Universidade de Brasília - Faculdade de Ceilândia, Brasília/DF, ${ }^{3}$ Programa de Pós- \\ Graduação em Ciências da Reabilitação, Universidade de Brasília, Brasília/DF
}

Email: aliny.missias@gmail.com

Introdução: O controle do equilíbrio é fundamental para a capacidade de deambulação, sendo necessário na abordagem de reabilitação dos pacientes com acidente vascular encefálico (AVE), por ser uma doença que causa limitações relacionadas à locomoção do indivíduo devido ao déficit no controle motor que contribui nessas desordens e podem aumentar o risco de quedas por interferir na mobilidade e equilíbrio devido fraqueza, alteração de tônus muscular. $O$ treinamento do equilíbrio quando realizado em um ambiente aquático, pode ser benéfico pelas propriedades geradas pela água proporcionarem uma força de suporte nas articulações, uma redução da força gravitacional e facilitar a movimentação durante a transferência de peso. Porém, existe uma escassez nas evidências sobre a efetividade da fisioterapia aquática em comparação à terapia convencional, ambas de forma isolada, no equilíbrio de pessoas que sofreram AVE. Objetivo: Avaliar criticamente a evidência atual através de ensaios clínicos randomizados que avaliaram o desfecho equilíbrio em indivíduos com sequela de AVE após intervenção com fisioterapia aquática versus terapia convencional. Métodos: Trata-se de uma revisão sistemática com metanálise de ensaios clínicos randomizados, baseadas nas recomendações PRISMA. Foram rastreados artigos que tivessem as palavras-chave pesquisadas no título ou resumo publicados até maio de 2018 nas seguintes bases de dados: CENTRAL, CINAHL, Google Scholar, LILACS, PEDro, PubMed, Scielo, Scopus e Web of Science. Foram incluídos estudos que utilizaram como desfecho o equilíbrio estático ou dinâmico em indivíduos que sofreram AVE. As buscas foram realizadas por dois revisores de forma independente, obedecendo os critérios de elegibilidade e, posteriormente, comparadas. Todos os estudos selecionados foram avaliados metodologicamente utilizando-se a escala PEDro. Foi realizado um teste estatístico para avaliar a concordância inter-avaliador utilizando o teste de coeficiente Kappa. O software R 3.4.2 foi usado para a meta-análise e o teste de heterogeneidade para os estudos foi baseado no $Q$-test e $I^{2}$ statistic. Resultados: Um total de 356 estudos foram identificados através da busca em banco de dados e dois identificados em outras fontes. Oito estudos foram incluídos para análise qualitativa e 5 estudos foram incluídos na metanálise. Nessa revisão sistemática, nos estudos incluídos a fisioterapia aquática se mostrou melhor ou igual para os ambos os grupos, ou seja, em nenhum deles obteve resultados inferiores à terapia convencional. Os resultados demonstraram heterogeneidade significativa na Escala de Equilíbrio de Berg após 4-8 semanas de terapia aquática (MD: 1,29; IC 95\%: $(-0,60 ; 3,18)$; $P<0.01)$ e no Teste de Alcance Funcional após 4-6 semanas de terapia aquática (MD: 3,09; IC 95\%: $(-1,88 ; 8,07)$; $P<0.01)$. Na metanálise dos estudos que utilizaram o $\mathrm{O}$ Timed Up and Go Test, foi demonstrada heterogeneidade não significativa após 4-6 semanas de terapia aquática (MD: -1,40; IC 95\%: $(-2,07 ;-0,74)$; $P=0,53)$. A metanálise confirma um maior benefício no ganho de equilíbrio após a intervenção com a terapia aquática em comparação à convencional, pelo ambiente aquático ser capaz de facilitar o movimento controlado enquanto se faz a transferência de peso e auxiliar no controle do equilíbrio postural durante a realização da atividade. A terapia aquática pode melhorar o equilíbrio estático e dinâmico, que são os principais fatores de risco de quedas quando ocorre redução deles. Conclusão: A terapia aquática é capaz de melhorar o equilíbrio nessa população e contribuir para prevenção de quedas, uma vez que os estudos que utilizaram como desfecho a EEB e TAF, obtiveram benefícios no tratamento com a terapia aquática quando comparada à terapia convencional. Esses resultados podem auxiliar na decisão clínica em relação às possibilidades de intervenções para o tratamento do equilíbrio em sobreviventes do AVE.

Palavras-chave: hidroterapia, acidente vascular cerebral, equilíbrio postural. 


\title{
A Fisioterapia Aquática como intervenção na lombalgia gestacional
}

\author{
Santos KNA ${ }^{1}$, Oliveira LS ${ }^{1}$, Rocha FS², Teixeira $\mathrm{SS}^{3}$ \\ ${ }^{1}$ Programa de Pós-graduação em Ciências Biomédicas, Universidade Federal do Piauí, \\ Parnaíba/PI, ${ }^{2}$ Universidade Federal do Piauí, Parnaíba/PI, ${ }^{3}$ Departamento de Fisioterapia, \\ Universidade Federal do Piauí, Parnaíba, Pl, Brasil
}

\section{Email: kyvianaysis@gmail.com}

Introdução: Durante o período gestacional, o corpo da mulher passa por importantes adaptações musculoesqueléticas para permitir o crescimento e desenvolvimento do feto. No entanto, tais adaptações provocam sobrecarrega ao organismo, fazendo com que aproximadamente $50 \%$ das gestantes se queixem de algum desconforto durante este período. A lombalgia é uma das principais queixas durante a gestação, sendo responsável por inúmeras repercussões negativas na qualidade de vida da grávida. Sabendo das propriedades terapêuticas da fisioterapia aquática, que proporcionam alívio de dores, instigou-se a utilização da mesma como meio de tratamento para dores lombares que acomete gestantes. Objetivos: Analisar a fisioterapia aquática como intervenção na lombalgia gestacional. Métodos: Revisão literária, desenvolvida com artigos coletados na base eletrônica SCielo, na qual foram encontrados 31 artigos, usando os decritores "Gestante", "Fisioterapia aquática", "Hidroterapia", "Lombalgia". Foram excluídos 27 trabalhos devido a não atenderem a proposta de estudo. Ao final, totalizou para a revisão 4 artigos. Os critérios de inclusão foram: artigos originais, que usassem a fisioterapia aquática como protocolo de tratamento aplicado para lombalgia gestacional. Os critérios de exclusão foram: artigos de revisão, que usassem outros protocolos de intervenção ou outro público alvo e que analisassem os efeitos terapêuticos da fisioterapia aquática para outras finalidades em grávidas. Resultados: Nos quatro estudos analisados, os pesquisadores usaram protocolos parecidos, que envolveram exercícios de aquecimento, alongamento, fortalecimento; atividade aeróbica; relaxamento com exercícios respiratórios; massoterapia. O período gestacional compreendido foi da $15^{\underline{a}}$ a $36^{\underline{a}}$ semana, sendo que as gestantes foram submetidas de 5 a 12 atendimentos de fisioterapia aquática. Das 12 pacientes envolvidas nas pesquisas, 10 obtiveram melhora da dor e 2 relataram o agravamento do quadro álgico. Há uma alta prevalência de lombalgia em grávidas, sendo fundamental o emprego de medidas educativas, preventivas e reabilitadoras no período gestacional. Exercícios aquáticos tem melhores resultados em relação ao solo no alívio das dores e dos desconfortos, pelo fato da água permitir que ação da gravidade atue de forma menos intensa, aliviando o peso corporal, além de corrigir a postura. Quando aquecida, a água também reduz a sensibilidade das terminações nervosas sensitivas, diminuindo o tônus e espasmos musculares, favorecendo o relaxamento. $O$ meio aquático ainda proporciona diminuição do estresse articular devido ao empuxo e aumento da circulação local. Conclusão: A fisioterapia aquática é eficaz na prevenção e no tratamento da lombalgia gestacional, sendo um método seguro e acessível para o alívio da dor. Entretanto, existem poucos estudos sobre a temática abordada, sendo necessária a realização de novas pesquisas relacionadas.

Palavras-chave: lombalgia, gestação, hidroterapia. 


\title{
A aplicabilidade da Fisioterapia Aquática em pacientes com fibromialgia: uma revisão integrativa
}

Ferreira ATS ${ }^{1}$, Nascimento $\mathrm{VH}^{1}$, Silva $\mathrm{AMM}^{1}$, Silva MTP${ }^{1}$, Barbosa $\mathrm{KV}^{1}$, Gomes TBN ${ }^{1}$, Santos $\mathrm{PMM}^{1}$, Souza PHVA ${ }^{2}$

${ }^{1}$ Graduandos em Fisioterapia pelo Centro Universitário Tiradentes - UNIT Maceió/AL, ${ }^{2}$ Docente do Centro Universitário Tiradentes - UNIT Maceió/AL, Grupo de Pesquisa da Liga de Fisioterapia Aquática L.A.F.A, Maceió/AL

Email: aryanno.fisio@hotmail.com

Introdução: A fibromialgia é uma síndrome clínica dolorosa crônica de etiologia desconhecida, caracterizada por um quadro clínico de dor muscular difusa relacionada com a presença de fadiga, alteração do sono e de caráter psicológico. Essas disfunções podem ocasionar limitações na capacidade funcional, como também, na qualidade de vida dos indivíduos acometidos pela fibromialgia. Uma intervenção baseada em exercícios terapêuticos na água pode, através das propriedades físicas da água, proporcionar efeitos fisiológicos para o sistema musculoesquelético e para o aspecto psicológico. Objetivo: Realizar uma revisão integrativa sobre a aplicabilidade da Fisioterapia Aquática em paciente com fibromialgia. Metodologia: Foi realizado neste estudo um levantamento bibliográfico dos artigos publicados entre 2008 e 2013, nas seguintes bases dados PubMed, Lilacs e SciELO. Os critérios de inclusão foram artigos publicados em português e inglês, considerando a metodologia dos artigos de ensaios clínicos, randomizados e experimentais. E os critérios de exclusão foram artigos não disponíveis na íntegra. Resultados: Após análise criteriosa do levantamento bibliográfico foram encontrados 80 artigos. Destes 74 foram excluídos por não especificarem os efeitos fisiológicos da intervenção da fisioterapia aquática ou por não ser possível o acesso ao texto completo do artigo. De acordo com resultados obtidos a fisioterapia aquática mostrou uma melhora na qualidade do sono e na redução da dor muscular, conferindo uma otimização na flexibilidade. Conclusão: Diante do que foi relatado acima foi possível observar que a fisioterapia aquática é eficaz no tratamento de pacientes portadores de fibromialgia e apresenta diversos benefícios, dentre eles a redução do espasmo muscular com conseguinte diminuição do quadro álgico.

Palavras-chave: fibromialgia, hidroterapia, intervenção.

\section{Os efeitos da Fisioterapia Aquática no equilíbrio e no risco de quedas em idosos: uma revisão integrativa}

\author{
Ferreira ATS ${ }^{1}$, Farias $\mathrm{DH}^{1}$, Nascimento $\mathrm{VH}^{1}$, Oliveira $\mathrm{AN}^{1}$, Souza $\mathrm{PHVA}^{2}$ \\ ${ }^{1}$ Graduandos em Fisioterapia pelo Centro Universitário Tiradentes - UNIT Maceió/AL, ${ }^{2}$ Docente \\ do Centro Universitário Tiradentes - UNIT Maceió/AL, Grupo de Pesquisa da Liga de Fisioterapia \\ Aquática L.A.F.A, Maceió/AL
}

\section{Email: Aryanno.fisio@hotmail.com}

Introdução: O envelhecimento pode ser compreendido como um conjunto de alterações estruturais e funcionais, dentre estas alterações encontra-se o comprometimento da habilidade do sistema nervoso central em realizar o processamento das informações provenientes do sistema vestibular, visual e proprioceptivo. E, quando ocorrem disfunções dessas informações, podem desencadear déficits no desempenho de habilidades motoras e adaptações do indivíduo. Os estímulos sensoriais podem ser favorecidos com a prática de exercícios terapêuticos na água por ser um meio instável, favorecendo os estímulos sensoriais através dos efeitos fisiológicos de suas propriedades, como também, pode ser considerada a presença da força de flutuabilidade possibilitando maior amplitude para os movimentos e, consequentemente, maior mobilidade. Objetivo: Realizar uma revisão de literatura integrativa sobre os efeitos da Fisioterapia Aquática no equilíbrio e no risco de quedas em idosos. Metodologia: Foi realizado um levantamento 
bibliográfico nas bases de dados PubMed, SciELO e Lilacs, tendo como critério de inclusão artigos publicados na língua portuguesa e inglesa nos últimos 10 anos, correspondendo ao período de janeiro de 2008 a janeiro de 2018, considerando a metodologia dos artigos de ensaio clínico, randomizados e experimentais. E como critério de exclusão artigos que não abordavam a temática e que não estavam disponíveis na integra. Resultados: Foram encontrados 506 artigos, apresentando potencial de inclusão 6 artigos que corroboravam com o objetivo deste estudo. Os Programas terapêuticos, utilizando os recursos da fisioterapia aquática, apresentam uma boa adesão para população idosa, uma vez que os exercícios obtiveram um ganho do equilíbrio considerável, diminuindo o índice de queda e melhorando as atividades de vida diárias. Conclusão: Os programas de fisioterapia aquática se mostraram eficazes no ganho da força muscular e na restauração do equilíbrio, sendo uma possível intervenção fisioterapêutica para a prevenção de quedas em idosos, podendo reduzir os efeitos indesejados decorrentes das quedas.

Palavras-chave: hidroterapia, idosos, equilíbrio postural.

\title{
Efeitos da Fisioterapia Aquática no tratamento de pacientes com doença pulmonar obstrutiva crônica: uma revisão integrativa
}

\author{
Kreitlow A , Araújo LMC'1 , Junior ES 1 \\ ${ }^{1}$ Faculdade Paranaense - FAPAR, Curitiba/PR \\ Email: line_krei@hotmail.com
}

Introdução: A Doença Pulmonar Obstrutiva Crônica (DPOC) se caracteriza por ser uma doença incapacitante e irreversível, porém evitável, e uma das principais causas de morbidade, mortalidade e custos de saúde em todo o mundo. Ela deve se tornar a terceira principal causa de morte e incapacidade em todo o mundo até o ano 2020 e acaba não afetando somente a parte respiratória do indivíduo, mas também a força e resistência dos músculos, composição corporal, aptidão física e a qualidade de vida. O treinamento físico baseado em água, que é um conceito relativamente novo no manejo de pessoas com DPOC e mostra resultados positivos. Objetivo: Avaliar os efeitos da Fisioterapia Aquática como forma de tratamento para indivíduos com DPOC. Metodologia: Este trabalho se trata de uma revisão integrativa, através de estudos experimentais retirados das bases de dados SciELO, PubMed, UpToDate, PEDro, LILACS e MEDLINE. Os dados encontrados foram analisados mediante sistematização de alguns elementos, utilizando critérios de data, relevância e qualidade metodológica. Resultados: Após a aplicação dos critérios de inclusão e exclusão, foram selecionados 10 artigos para leitura. Os efeitos da Fisioterapia Aquática analisados foram função pulmonar, aceitabilidade, qualidade de vida, força muscular inspiratória e expiratória, composição corporal e aptidão física. Os exercícios aquáticos trazem uma melhora significativa da força muscular inspiratória e expiratória, melhora da circulação sanguínea, diminuição no impacto nas articulações, além de melhorar a aptidão física, composição corporal e qualidade de vida. Conclusão: Conclui-se que a Fisioterapia Aquática, apesar de representar uma modalidade terapêutica relativamente nova para portadores de DPOC, esta produz resultados positivos, trazendo benefícios em diversos aspectos relacionados à saúde do indivíduo, como maior força e resistência muscular periférica durante a respiração, acarretando em menor comorbidade e melhora na qualidade de vida do paciente, sendo portanto benéfica, viável, segura e bem aceito. Em relação à função pulmonar, não houve diferenças significativas.

Palavras-chave: fisioterapia aquática, dpoc, reabilitação pulmonar. 


\title{
Aplicabilidade da Fisioterapia Aquática em pacientes com osteoartrite de joelho
}

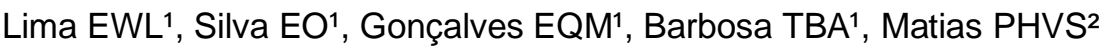 \\ 1Discente do Centro Universitário Tiradentes - UNIT, Maceió/AL, ${ }^{2}$ Docente do Curso de \\ Fisioterapia do Centro Universitário Tiradentes - UNIT, Maceió/AL
}

Email: lizi.olliveira@gmail.com

Introdução: A osteoartrite do joelho $(\mathrm{OA})$ é uma doença degenerativa crônica de natureza inflamatória que se caracteriza por alterações na cartilagem articular, presença de áreas de fibrilação e rachaduras e espessamento do osso subcondral. Clinicamente, está associado à dor, rigidez, deformidade e perda de capacidade funcional. Aproximadamente $10 \%$ da população com mais de 60 anos é afetada pela OA; $80 \%$ desta população têm restrições de movimento e $25 \%$ têm limitações funcionais que comprometem o desempenho das atividades diárias. A fisioterapia aquática pode ser considerada uma intervenção segura e eficaz no tratamento da OA do joelho, uma vez que a imersão em água diminui a sobrecarga articular e, consequentemente, a sintomatologia da dor, possibilitando uma melhora na mobilidade e funcionalidade dos pacientes. Objetivos: Realizar uma revisão de literatura integrativa sobre os efeitos da Fisioterapia Aquática em paciente com osteoartrite de joelho. Métodos: Foi realizado uma revisão de literatura integrativa nas bases de dados SciELO, Lilacs, PEDro e Pubmed através dos seguintes descritores: Hidroterapia e Osteoartrite. Os critérios de inclusão desta pesquisa foram artigos publicados em inglês, entre os anos de 2008 a 2018, considerando artigos do tipo ensaios clínicos, randomizados e experimentais sobre a aplicabilidade da fisioterapia aquática no tratamento da osteoartrite $(\mathrm{AO})$ de joelho. Os critérios de exclusão foram artigos que não estavam disponíveis na íntegra e que não abordavam o tem em questão. Resultados: Foram encontrados um total de 28 estudos através do cruzamento dos descritores. Os artigos selecionados incluíram ensaios clínicos que aplicaram ou analisaram intervenções que envolveram exercícios aquáticos para indivíduos com osteoartrite (AO) de joelho. Após leitura crítica dos artigos, 9 atenderam os critérios de inclusão, sendo demonstrado pelos estudos realizados que a fisioterapia aquática melhorou significativamente em curto prazo a qualidade de vida, dor, incapacidade e funcionalidade em pessoas com OA de joelho, quando comparada com outras intervenções similares em terra. Entre os achados foi salientado que realização de exercícios terapêuticos na água pode possibilitar o relaxamento muscular, redução da dor e melhora da mobilidade do paciente Conclusão: O exercício aquático pode ser eficaz no tratamento de pessoas com OA de joelho, considerando que as intervenções propostas podem resultar em redução da dor, incapacidade, melhora na funcionalidade e melhoria na qualidade de vida.

Palavras-chave: hidroterapia, joelho e osteoartrite.

\section{Melhora da funcionalidade do assoalho pélvico pelo método Bad Ragaz: revisão sistemática}

Costa $B C^{1}$, Sousa $\mathrm{LM}^{2}$, Gouveia $\mathrm{GPM}^{2}$, Silva $A \mathrm{~A}^{1}$, Costa $\mathrm{RF}^{1}$, Oliveira $\mathrm{FA}^{1}$, Lopes $\mathrm{TS}^{1}$, Silva $\mathrm{RL}^{1}$

${ }^{1}$ Universidade Federal do Piauí, Parnaíba/PI, ${ }^{2}$ Grupo de Pesquisa em Fisioterapia Avaliativa e Terapêuticas - GPFAT, Parnaíba/PI

\section{Email: brunocunha09@hotmail.com}

Introdução: O assoalho pélvico é formado por músculos, ligamentos e fáscias, que agem de maneira conjunta para prover suporte e sustentação às vísceras pélvicas. Os músculos do assoalho pélvico são formados por fibras estriadas esqueléticas e inervados pelo nervo pudendo. Essa musculatura atua fornecendo suporte aos órgãos pélvicos e abdominais. Estes componentes envolvem, suspendem e conectam os órgãos pélvicos ao suporte muscular e ósseo da pelve, mantendo-os dentro da sua posição anatômica. O método Bad Ragaz, quando 
realizados utilizando as características físicas da água, especialmente, pressão hidrostática, flutuação, viscosidade e efeitos térmicos, a combinação destes, aos efeitos do exercício em imersão resulta nas respostas fisiológicas do exercício na água. Objetivos: Analisar o efeito do método Bad Ragaz na funcionalidade da musculatura do assoalho pélvico (MAP). Métodos: $O$ estudo trata-se de uma revisão sistemática, desenvolvida mediante uma busca bibliográfica nas bases de dados eletrônicas Lilacs, SciELO, além de pesquisa em capítulos de livros e revistas. Os descritores foram selecionados a partir da Biblioteca Virtual em Saúde. Foram selecionados os títulos que se enquadravam para o fortalecimento do assoalho pélvico. Resultados: A busca somou-se em 17 títulos, desses, 9 foram utilizados, sendo 4 artigos originais e 5 livros. Os estudos apontam para uma melhora positiva quanto ao fortalecimento e conscientização do assoalho pélvico. Conclusão: O método Bad Ragaz, aliado aos efeitos físicos da água tem sido eficaz na melhora da qualidade vida dos indivíduos que apresentaram fraqueza da MAP, quanto ao aumento da força da MAP e percepção dela.

Palavras-chave: assoalho pélvico, fisioterapia aquática, bad ragaz.

Impacto do método Bad Ragaz no controle motor e nos biomarcadores de estresse oxidativo em idosos diabéticos tipo 2, Parnaíba/PI: ensaio clínico randomizado

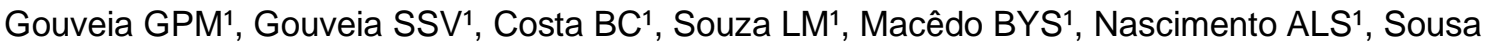
JRS ${ }^{1}$, Vasconcelos $\mathrm{PRL}^{2}$, Hissa $\mathrm{MN}^{2}$

${ }^{1}$ Universidade Federal do Piauí - UFPI, Grupo de Pesquisa em Fisioterapia Avaliativa e Terapêuticas - GPFAT, Curso de Fisioterapia, '2Universidade Federal do Ceará - UFC, Departamento de curso Stricto Sensu em Ciências Médico-Cirúrgicas - UFC

Email: gpfatufpi@gmail.com

Introdução: O envelhecimento é um processo dinâmico e progressivo, que associado a diabetes potencializa a perda de funcionalidade sistêmica. A diabetes tipo 2 é uma enfermidade crônica que gera inflamação endotelial e injúria oxidativa, perceptível pelas alterações nos valores de malondialdeído e glutationa. Diversos são os tratamentos que minimizam as complicações oriundas desta patogenia, dentre eles destaca-se a fisioterapia aquática. Esta visa à melhoria do controle motor, equilíbrio e força muscular respiratória. Objetivo: Analisar o impacto do Método Bad Ragaz na funcionalidade, no sistema respiratório e nos biomarcadores de estresse oxidativo em idosos diabéticos tipo 2, por meio de um ensaio clínico randomizado. Métodos: Estudo randomizado controlado, realizado na Universidade Federal do Piauí, no período de janeiro a dezembro de 2017. O estudo constituiu-se de 60 idosos diabéticos tipo 2, alocados em dois grupos com 30 cada: grupo Intervenção e Grupo Controle. Foram analisados dados de características sociodemográficas, estabilometria, controle glicêmico, controle motor e estresse oxidativo. O treinamento no Gl foi realizado com o método dos anéis de Bad Ragaz, com frequência de dois atendimentos semanais, totalizando oito com média de 35 minutos cada, enquanto o controle foi realizado flutuação com mesma frequência e tempo do grupo de intervenção. Utilizou-se o teste ANOVA com post hoc de Bonferroni com nível de significância de $5 \%$ e intervalo de confiança $95 \%$, por meio do SPSS 21.0. Resultados: Obteve-se idade média de $67 \pm 4$ anos, sendo a maioria do gênero feminino $(61,7 \%)$ com índice de massa corporal de $27,99 \pm 4,56 \mathrm{~kg} / \mathrm{m}^{2}$. Ao verificar os efeitos dos protocolos na glicemia, antes e após os protocolos, encontrou-se diferença significante no grupo de intervenção $(p<0,001)$. Dados relacionados à estabilometria apontam uma diferença para o grupo de intervenção com $p<0,05$. Em relação ao controle motor, houve diferença significativa em todos os músculos $(p<0,05)$ exceto no grande dorsal. Todavia, em relação à concentração de malondialdeído e glutationa, não foi percebida diferença significativa com p de 0,143 e 0,623, respectivamente. Conclusão: Conclui-se que o método Bad Ragaz promoveu melhorias do controle motor e do equilíbrio, enquanto reduziu o nível glicêmico, a pressão arterial e a frequência cardíaca. O seu efeito no estresse oxidativo não foi estatisticamente significante, apesar de ter ocorrido uma redução dos valores de malondialdeído e aumento da glutationa.

Palavras-chave: saúde do idoso, diabetes mellitus tipo 2, fisioterapia, biomarcadores. 
Impacto do método Bad Ragaz na variabilidade autonômica cardíaca e força muscular respiratória em idosos diabéticos tipo 2, Parnaíba/PI: ensaio clínico randomizado

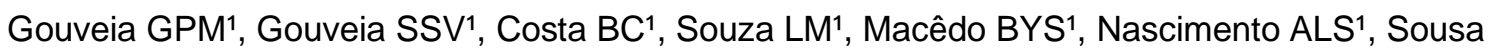
JRS 1 , Vasconcelos $\mathrm{PRL}^{2}$, Hissa $\mathrm{MN}^{2}$

${ }^{1}$ Universidade Federal do Piauí - UFPI, Grupo de Pesquisa em Fisioterapia Avaliativa e Terapêuticas - GPFAT. Curso de Fisioterapia, '2Universidade Federal do Ceará - UFC, Departamento de curso Stricto Sensu em Ciências Médico-Cirúrgicas - UFC

Email: gpfatufpi@gmail.com

Introdução: O envelhecimento é um processo dinâmico e progressivo, que associado a diabetes potencializa a perda de funcionalidade sistêmica. A diabetes tipo 2 é uma enfermidade crônica que gera inflamação endotelial e injúria oxidativa, perceptível pelas alterações nos valores de malondialdeído e glutationa. Diversos são os tratamentos que minimizam as complicações oriundas desta patogenia, dentre eles destaca-se a fisioterapia aquática. Esta visa à melhoria do controle motor, equilíbrio e força muscular respiratória. Objetivo: Analisar o impacto do Método Bad Ragaz na funcionalidade, no sistema respiratório e nos biomarcadores de estresse oxidativo em idosos diabéticos tipo 2, por meio de um ensaio clínico randomizado. Métodos: Estudo randomizado controlado, realizado na Universidade Federal do Piauí, no período de janeiro a dezembro de 2017. O estudo constituiu-se de 60 idosos diabéticos tipo 2, alocados em dois grupos com 30 cada: grupo Intervenção e Grupo Controle. Foram analisados dados de características sociodemográficas, estabilometria, controle glicêmico, controle motor e estresse oxidativo. O treinamento no Gl foi realizado com o método dos anéis de Bad Ragaz, com frequência de dois atendimentos semanais, totalizando oito com média de 35 minutos cada, enquanto o controle foi realizado flutuação com mesma frequência e tempo do grupo de intervenção. Utilizou-se o teste ANOVA com post hoc de Bonferroni com nível de significância de $5 \%$ e intervalo de confiança $95 \%$, por meio do SPSS 21.0. Resultados: Obteve-se idade média de $67 \pm 4$ anos, sendo a maioria do gênero feminino $(61,7 \%)$ com índice de massa corporal de $27,99 \pm 4,56 \mathrm{~kg} / \mathrm{m}^{2}$. Ao verificar os efeitos dos protocolos na pressão arterial, observou-se uma queda significante de 15,1 $\mathrm{mmHg}$ na sistólica de repouso no grupo de intervenção $(p=0,02)$ e 9,5 $\mathrm{mmHg}$ na média da diastólica $(p=0,033)$. Em relação às variações da frequência cardíaca, antes e após os protocolos, houve diferença significativa $(p<0,001)$ para o grupo de intervenção, como também na saturação de oxigênio $(p=0,021)$. Quanto à glicemia, antes e após os protocolos, encontrou-se diferença significante no grupo de intervenção $(p<0,001)$. Ao inferir a variabilidade da frequência cardíaca percebeu-se que não houve diferença significativa na modulação autonômica entre os grupos. Ao verificar os efeitos dos protocolos na força muscular respiratória nos grupos em estudo, observou-se diferença significativa na variação média do percentual de Pimáx e Pemáx no grupo de intervenção $(p<0,05)$. Conclusão: Conclui-se que o método Bad Ragaz promoveu melhorias da saturação de oxigênio, autonomia cardíaca e força muscular respiratória, enquanto reduziu o nível glicêmico, a pressão arterial e a frequência cardíaca. $O$ seu efeito no estresse oxidativo não foi estatisticamente significante, apesar de ter ocorrido uma redução dos valores de malondialdeído e aumento da glutationa.

Palavras-chave: saúde do idoso, diabetes mellitus tipo 2, fisioterapia, biomarcadores. 
Influência da hidroterapia na reabilitação de portadores de sequelas de acidente vascular encefálico: uma revisão

\author{
Araújo BN ${ }^{1}$, Fontenele KLC ${ }^{1}$, Ferreira APS ${ }^{1}$, Cardoso RAM1, Machado YA1, Melo LA² \\ ${ }^{1}$ Universidade Federal do Piauí, Parnaíba/PI, ${ }^{2}$ Docente da Universidade Federal do Piauí, \\ Parnaíba/PI
}

Email: Ifontenele89@gmail.com

Introdução: O Acidente Vascular Encefálico (AVE) está entre as maiores causas de mortes no Brasil e no mundo, sendo o principal gerador de incapacidades adquiridas em adultos. É causado pela obstrução ou rompimento de uma ou mais artérias, gerando falta de circulação sanguínea em uma região do encéfalo e assim repercutindo em implicações da função neurológica, danos ao sistema motor, respiratório, sensitivo, de percepção e linguagem. Para uma melhor qualidade de vida dos portadores de sequelas do AVE, têm se chamado muita atenção para a hidroterapia, devido aos efeitos e propriedades físicas da água que auxiliam no tratamento desses pacientes, contribuindo para um maior relaxamento, sustentação parcial de peso do corpo e assim favorecer uma mobilização de articulações com menor esforço do paciente. Objetivos: Verificar a atuação da hidroterapia na reabilitação de sequelados de AVE. Métodos: Para a pesquisa bibliográfica, foram realizadas buscas nas bases de dados SciELO, Revista de neurociências e ScienceDirect por material literário publicado entre 2011 a 2017, utilizando os descritores "hidroterapia", "reabilitação", e "acidente vascular encefálico". Foram encontrados 17 artigos, dentre eles 05 foram excluídos e 12 encaixaram-se nos critérios da busca, tendo como critérios de inclusão: estudos que tivessem como temática influência da hidroterapia na reabilitação de portadores de sequelas pós ave e de exclusão: inadequação a questão norteadora, artigos incompletos, monografias e teses. Resultados: A partir da análise dos artigos selecionados, evidenciou-se a importância da hidroterapia nas sequelas decorrentes do AVE. A principal e mais comum repercussão ocasionada pelo AVE é a espasticidade, uma desordem motora caracterizada pela hiperexcitabilidade do reflexo de estiramento, aumento dos reflexos profundos e do tônus muscular. Algumas das manifestações clínicas resultantes da espasticidade incluem dores e espasmos musculares, posturas anormais, déficits na marcha e resistência exacerbada ao movimento. Os benefícios da hidroterapia nesse público são resultantes das propriedades da água que proporcionam uma atenuação dos sintomas nesses pacientes. A temperatura a que são submetidos os pacientes ocasiona a diminuição tônus muscular e consequentemente da espasticidade, além de promover aumento da circulação sanguínea, diminuição de dores e relaxamento muscular. Esses fatores auxiliam na manutenção e ganho de amplitude de movimento. A resistência da água é usada para ganho de força muscular e com os movimentos mais lentos há um aumento da percepção corporal, proporcionando melhora no equilíbrio dinâmico e estático e na propriocepção, gerando uma melhora na capacidade funcional da marcha. Conclusão: A partir de resultados obtidos, foi constatado que a hidroterapia pode influenciar de forma positiva e satisfatória na reabilitação de portadores de sequelas de AVE dando uma melhor qualidade de vida a essas pessoas após as sessões, diminuição de dores, além de propiciar maior independência para os mesmos.

Palavras-chave: hidroterapia, reabilitação, acidente vascular encefálico. 
A eficácia da Fisioterapia Aquática para funcionalidade e qualidade de vida em pacientes com insuficiência cardíaca: uma revisão integrativa

\author{
Nascimento $\mathrm{VH}^{1}$, Matos $\mathrm{LAD}^{1}$, Ferreira ATS ${ }^{1}$, Rocha $\mathrm{RM}^{1}$, Calles $A C N^{2}$, Souza PHVA² \\ ${ }^{1}$ Graduandos em Fisioterapia pelo Centro Universitário Tiradentes - UNIT/AL, ${ }^{2}$ Docentes do \\ Centro Universitário Tiradentes - UNIT/AL, Grupo de Pesquisa da Liga Acadêmica de \\ Fisioterapia Aquática L.A.F.A, Maceió/AL
}

Email: vittor.fisio@gmail.com

Introdução: A insuficiência cardíaca (IC) é definida como uma síndrome comum, porém complexa, caracterizada por sinais e sintomas secundários à função cardíaca anormal, pode ser resultado de uma variedade de disfunções e condições que prejudicam e/ou sobrecarregam o coração. Com isso, pode ocorrer um impacto na funcionalidade e na qualidade de vida desses pacientes. A intervenção fisioterapêutica no paciente com IC é importante para o restabelecimento das suas funções, sendo assim, podem ser considerados os exercícios terapêuticos aquáticos de acordo com os efeitos fisiológicos da água no sistema cardiovascular, auxiliando na reabilitação e/ou prevenção de alterações funcionais. Objetivo: Realizar uma revisão integrativa de literatura científica sobre a eficácia da fisioterapia aquática para funcionalidade e qualidade de vida em pacientes com IC. Metodologia: Foi realizado um levantamento bibliográfico das bases de dados PubMed, LILACS e SciELO, publicados no período de 2008 a 2018, utilizando os seguintes descritores: hidroterapia, insuficiência cardíaca e qualidade de vida. Os critérios de inclusão foram artigos científicos publicados em português e inglês, considerando artigos do tipo ensaios clínicos, randomizados e experimentais. $\mathrm{E}$, como critérios de exclusão, foram não compatíveis com o tema e não disponíveis na íntegra. Após leitura e análise criteriosa dos estudos, os estudos foram descritos de acordo com a metodologia, resultados e conclusões. Resultados: Foram encontrados 9 artigos, sendo que 4 estavam de acordo com os critérios de inclusão. Os recursos terapêuticos aquáticos podem ser utilizados para o desenvolvimento e capacidade funcional, melhorando assim a qualidade de vida dos indivíduos. Conclusão: Sabe-se que a intervenção aquática é eficaz no tratamento dos pacientes diagnosticado com IC estável, sendo uma terapia tolerável pelos indivíduos, assim, ocorrendo uma boa adesão ao tratamento melhorando a funcionalidade e a qualidade de vida.

Palavras-chave: hidroterapia, insuficiência cardíaca, qualidade de vida.

\title{
A eficácia da hidroterapia na qualidade de vida de portadores de artrite reumatóide: uma revisão da literatura
}

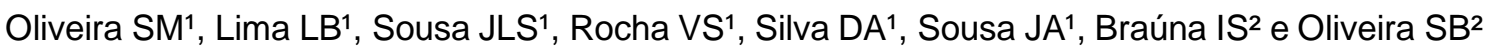

'Universidade Federal do Piauí, Parnaíba/PI, 2Programa de Pós-Graduação em Ciências Biomédicas, Universidade Federal do Piauí, Parnaíba/PI

Email: sabmarques76@gmail.com

Introdução: A Artrite Reumatoide (AR) é uma doença crônica, autoimune e de etiologia desconhecida, causada pela inflamação da membrana sinovial e que acomete as articulações em virtude da destruição da cartilagem e da erosão óssea. O paciente com AR apresenta manifestações sistêmicas e desenvolve alterações físicas funcionais, podendo levá-lo ao estado de incapacidade para a realização de suas atividades. A hidroterapia é um recurso muito utilizado no processo de reabilitação especialmente em pacientes reumáticos, uma vez que diminui os efeitos da gravidade, resultando em uma menor compressão nas articulações, além de possuir efeitos fisiológicos propiciados pelo meio aquático. Objetivo: Verificar a eficácia da utilização da hidroterapia na qualidade de vida de portadores de AR. Métodos: Trata-se de uma revisão de literatura, cujos trabalhos estão indexados nas bases de dados SciELO, PubMed e Lilacs. Foram utilizados os descritores "Hidroterapia", "Artrite Reumatoide" e "Reabilitação". Como critérios de 
inclusão foram selecionados artigos publicados no período entre 2012 e 2017, nos idiomas inglês e português, ensaio randomizado, estudos de caso e outros materiais complementares. Os artigos excluídos foram os incompletos, bem como aqueles que fugiam da temática buscada, sendo estes referentes à balneoterapia no tratamento. Resultados: Após a pesquisa, foram encontrados 14 artigos, dos quais apenas 7 foram selecionados. Observou-se que o tratamento aquático quando comparado com aquele realizado em solo mostra-se superior. Essas melhoras funcionais se devem aos princípios físicos da água, que contribuem para o aumento da ADM através da força de flutuação que atua facilitando o movimento articular. Além disso, a piscina quando aquecida contribui para a diminuição da dor e ajuda no relaxamento muscular. Conclusão: Nesse sentido, a hidroterapia pode beneficiar os portadores de AR, proporcionando o aumento da sua funcionalidade e uma melhora na qualidade de vida. Recomenda-se que esses pacientes sejam estimulados a iniciar o tratamento precocemente para a obtenção de melhores resultados. Contudo, são poucos os estudos comprovando a sua efetividade, portanto, sugere-se que novas pesquisas sejam realizadas para a comprovação da terapêutica abordada.

Palavras-chave: hidroterapia, artrite reumatoide, reabilitação.

\title{
Efeitos da Fisioterapia Aquática na hipertensão arterial: revisão de literatura
}

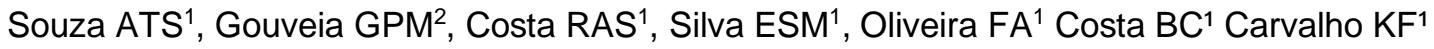 \\ ${ }^{1}$ Universidade Federal do Piauí, Parnaíba/PI, ${ }^{2}$ Grupo de Pesquisa em Fisioterapia Avaliativa e \\ Terapêuticas - GPFAT, Parnaíba/PI
}

Email: souzatainara906@yahoo.com

Introdução: A hipertensão arterial (HA) é uma condição clínica multifatorial que afeta quase $20 \%$ da população mundial, sendo caracterizada pela elevação dos níveis pressóricos sistólicos $\geq 140 \mathrm{mmHg}$ e/ou diastólicos $\geq 90 \mathrm{mmHg}$. Sabe-se que a imersão em água aquecida, juntamente com seus efeitos físicos e terapêuticos acarretam repercussões fisiológicas nos sistemas cardiovascular e renal. Com relação às alterações hemodinâmicas e dos sistemas reguladores, o sistema cardiovascular sofre aumento de $700 \mathrm{ml}$ de volume sanguíneo no seu compartimento, interferindo no aumento de volume sistólico e débito cardíaco, diminuição da resistência vascular periférica, pressão arterial e frequência cardíaca. Tal quadro clínico sendo possível sob um protocolo de intervenção em ambiente aquático a longo prazo. Objetivos: Identificar os efeitos da fisioterapia aquática (FA) em pacientes com hipertensão arterial. Métodos: $\mathrm{O}$ estudo trata-se de uma revisão sistemática, desenvolvida mediante uma busca bibliográfica nas bases de dados eletrônicas Pubmed, PEDro, Lilacs e SciELO. Os descritores foram selecionados a partir da Biblioteca Virtual em Saúde (BVS), usados no idioma inglês, sendo eles physiotherapy, hydrotherapy, hypertension e heated Water. Foi realizado a análise e leitura dos artigos, sendo selecionados aqueles que se enquadram, utilizando a FA no tratamento a longo prazo, na melhora da hipertensão arterial nas populações adulta e em processo de senescência. Resultados: Totalizou-se ao todo 10 títulos, desses 8 foram selecionados, sendo uma revisão e sete artigos originas. Os artigos norteavam o uso de FA e, em água aquecida em treinamento prolongado favorece uma redução da hipertensão arterial, atuando positivamente em pacientes com hipertensão arterial. Conclusão: Com os exercícios da FA, ocorre a promoção de hipotensão pós-exercício, evidenciando uma queda na pressão arterial em pacientes com hipertensão arterial e assim, melhorando a qualidade de vida e controle da HA.

Palavras-chave: fisioterapia, hidroterapia, hipertensão. 


\title{
Efeitos da Fisioterapia Aquática para os pacientes com doença de Parkinson: uma revisão
} integrativa

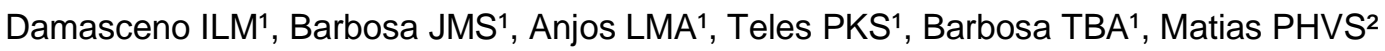 \\ ${ }^{1}$ Discente do Centro Universitário Tiradentes - UNIT, Maceió, Alagoas, Brasil, ${ }^{2}$ Docente das \\ disciplinas recurso cinesioterapêutico e funcional, fisioterapia aquática e administração em \\ fisioterapia do curso de fisioterapia do Centro Universitário Tiradentes - UNIT, Maceió/AL
}

Email: isis_larissa96@outlook.com

Introdução: A Doença de Parkinson (DP) é uma disfunção neuro degenerativa que pode causar tremor, rigidez muscular, instabilidade postural e bradicinesia em diferentes intensidades, podendo ocasionar interferência no nível de capacidade funcional e qualidade de vida dos indivíduos que apresentam esse diagnóstico clínico. Entre os recursos de tratamento existentes voltados para pacientes parkinsonianos, a fisioterapia aquática busca minimizar as sequelas motoras através dos efeitos causados pelas propriedades da água favorecendo a reabilitação funcional. Objetivos: Realizar uma revisão integrativa da literatura científica sobre os efeitos da fisioterapia aquática para os pacientes com Doença de Parkinson. Métodos: Foi realizada busca bibliográfica nas bases de dados SciELO, Lilacs, PEDro e Pubmed, utilizando os seguintes descritores: Doença de Parkinson, fisioterapia e hidroterapia. Os critérios de inclusão desta pesquisa foram artigos publicados em português e inglês, durante os anos de 2008 a 2018. Os artigos que não estavam disponibilizados na íntegra e que não apresentavam a Fisioterapia Aquática como tratamento foram excluídos desta pesquisa. Resultados: Inicialmente foi realizada uma busca dos artigos, sendo encontrado um total de 18 estudos através do cruzamento dos descritores. Após leitura crítica dos resumos, 9 atenderam aos critérios de inclusão e foram analisados na íntegra. Os estudos demonstraram que a fisioterapia aquática pode ser uma intervenção utilizada, principalmente, no início da Doença de Parkinson, podendo auxiliar no equilíbrio, marcha, qualidade de vida e capacidade funcional dos indivíduos acometidos pela Doença de Parkinson. Considerações finais: A Fisioterapia Aquática pode favorecer a melhora do equilíbrio postural estático e dinâmico, podendo melhorar a capacidade funcional e a qualidade de vida do paciente com Doença de Parkinson.

Palavras-chave: Doença de Parkinson, fisioterapia, hidroterapia.

\section{Análise da força e pico de fluxo respiratório em idosos submetidos a exercícios resistidos em piscina aquecida}

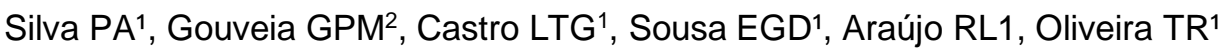

${ }^{1}$ Grupo de Pesquisa em Fisioterapia Avaliativa e Terapêuticas- GPFAT, Universidade Federal do Piauí, Parnaíba, PI, Brasil, ${ }^{2}$ Coordenador do Grupo de Pesquisa em Fisioterapia Avaliativa e Terapêuticas- GPFAT

\section{Email: priandrade@outlook.com}

Introdução: O envelhecimento traz consigo diversas alterações no sistema pulmonar, entre elas a redução do calibre das vias aéreas, que interferem na mecânica respiratória, ocasionando diminuição nos valores de PImáx e PEmáx. A prática de exercícios resistidos, em piscina aquecida, visa atenuar tais alterações, melhorando a força muscular respiratória. Objetivo: avaliar a força dos músculos respiratórios e o pico de fluxo expiratório em idosos submetidos a exercícios resistidos em piscina aquecida. Métodos: O presente trabalho tratou-se de um estudo intervencionista, descritivo, transversal de caráter quantitativo, contemplando 13 voluntários residentes no município de Parnaíba-PI e aprovado pelo Comitê de Ética da Universidade Federal do Piauí/PI, com parecer número 2.379.589. Foi realizado avaliação de manovacuometria e de pico de fluxo expiratório (PFE). O programa de exercícios em ambiente aquático constituiu-se alongamento, exercícios de aquecimento, resistência, equilíbrio e 
relaxamento, executados durante uma hora, duas vezes por semana, durante seis semanas. Para a análise estatística realizou-se a verificação de normalidade dos dados com o teste de Shapiro-Wilk, distribuição de frequência simples das variáveis de interesse do estudo e teste $t$ de student para amostras pareadas. Resultados: Obteve-se significância estatística para as variáveis pico de fluxo $(\mathrm{p}=0,018)$ e força muscular expiratória $(\mathrm{p}=0,014)$, apontando para a eficácia do protocolo no sistema pulmonar, enquanto na força muscular inspiratória não houve interferência significativa $(p=0,490)$. Conclusão: O protocolo realizado de exercícios resistidos em piscina aquecida influenciou na melhoria do pico de fluxo, promovendo também melhoras da musculatura expiratória em pacientes idosos. Porém, na força muscular inspiratória não houve evolução significativa.

Palavras-chave: idoso, fisioterapia, exercício.

\title{
Análise autonômica cardíaca domínio auto regressivo em idosos antes e após atividades aquáticas
}

\author{
Silva PA¹, Gouveia GPM², Castro LTG ${ }^{1}$, Sousa EGD¹, Araújo RL1, Oliveira TR \\ ${ }^{1}$ Grupo de Pesquisa em Fisioterapia Avaliativa e Terapêuticas- GPFAT, Universidade Federal do \\ Piauí, Parnaíba/PI, ${ }^{2}$ Coordenador Grupo de Pesquisa em Fisioterapia Avaliativa e Terapêuticas- \\ GPFAT
}

\section{Email:priandrade@outlook.com}

Introdução: A Frequência Cardíaca é modulada por uma ação conjunta dos ramos simpático e parassimpático do Sistema Nervoso Autônomo. Uma das mudanças adaptativas na regulação neural produzida pelo exercício físico é aumento da modulação vagal, observado pelo aumento da variabilidade da frequência cardíaca (VFC). A hidrocinesioterapia utiliza as propriedades físicas da água e sua capacidade térmica para promover bem-estar físico e mental, elevação da temperatura corpórea, vasodilatação e melhora do condicionamento cardiovascular. Objetivo: Analisar a influência da prática de exercícios fisioterapêuticos em piscina aquecida no tônus vagal cardíaco e VFC. Métodos: O presente trabalho tratou-se de um estudo intervencionista, descritivo, transversal de caráter quantitativo. Estiveram envolvidos 12 sujeitos com idade média de 67,77士5,94 (60 - 78) anos, residentes no município de Parnaíba/PI, sob aprovação do Comitê de Ética da Universidade Federal do Piauí-PI, com parecer número 2.379.589. Verificou-se a VFC domínio frequência em 12 voluntários, sendo monitorada por um frequencímetro Polar Rs800x® antes e após cada intervenção, utilizando-se da técnica de análise espectral da variabilidade cardíaca. O programa de exercícios em ambiente aquático constituiu-se de um protocolo com alongamentos, exercícios resistidos com série para membros superiores e inferiores, equilíbrio, propriocepção e relaxamento, executados durante uma hora, duas vezes por semana em dias alternados, durante seis semanas. Para análise estatística realizou-se teste descritivo e o de normalidade de Shapiro-Wilk que confirmou uma distribuição normal para as variáveis em estudo, obtendo $p>0,05$, sendo, portanto, utilizado o teste T pareado. Resultados: Ao inferir os dados da variabilidade da frequência cardíaca, antes e após, o protocolo de exercícios aquáticos resistidos, quanto às variáveis $L F, H F$ e a relação LF/HF do auto regressivo, por meio do teste t pareado, não obteve significância estatística para as referidas variáveis, apresentando valores de $p=0,116 ; 0,259$ e 0,147, respectivamente. Conclusão: Conclui-se que o protocolo realizado em idosos não refletiu na redução do tônus vagal cardíaco. De acordo com a análise dos resultados obtidos pelo domínio frequência (auto regressivo) o protocolo de hidrocinesioterapia estudado não promove alterações da frequência cardíaca.

Palavras-chave: frequência cardíaca, exercícios, hidroterapia. 
Reabilitação neurofuncional de uma idosa com sequelas de acidente vascular cerebral em ambiente aquático: relato de caso

Conceição $\mathrm{AM}^{1}$, Ferreira $K R C^{1}$, Souza $\mathrm{CCB}^{1}$, Souza, $\mathrm{MCP}^{1}$, Rodrigues MAB ${ }^{1}$, Macedo $\mathrm{LP}^{2}$

${ }^{1}$ Grupo de Pesquisa Engenharia Biomédica, UFPE, Recife/PE, ${ }^{2}$ Fisioterapeuta, Graduada FSM, Recife/PE

Email:amanda.1fisio@hotmail.com

Introdução: O Acidente Vascular Cerebral (AVC) é um déficit neurológico focal ou global, ocasionado por uma interrupção abrupta do fluxo sanguíneo cerebral, onde os sintomas persistem por mais de 24 horas, ou que leve o indivíduo à morte. A grande maioria dos indivíduos que sobrevivem ao AVC evoluem com sequelas motoras, sensoriais e cognitivas. Objetivo: Relatar o caso de uma idosa com sequelas neuromotoras decorrentes de um AVC que foi submetida a fisioterapia aquática. Métodos: Trata-se de um relato de caso, onde a paciente analisada é uma idosa, cujas iniciais são S. M. M. C., com 62 anos, residente na cidade do Recife-PE, com diagnóstico clínico de AVC e histórico prévio de hipertensão arterial sistêmica (HAS). Foi realizada a avaliação funcional, onde verificou-se tônus, edema, sensibilidade superficial e profunda, equilíbrio estático e dinâmico, atividades motoras, atividades de vida diária e reações de proteção. Observou-se que a paciente apresentava um quadro de rigidez relevante em membro superior esquerdo (MSE), déficit de equilíbrio, de sensibilidade, espasticidade em MSE e marcha claudicante com auxílio de órtese. Posteriormente foi realizado o Diagnóstico fisioterapêutico (Hemiparesia em hemicorpo esquerdo), plano de tratamento, objetivos e condutas. Segundo informações colhidas pela própria paciente a mesma realizou fisioterapia em solo em outra clínica, tendo sido no total 51 sessões, posteriormente foi encaminhada para fisioterapia aquática. As intervenções com a fisioterapia aquática ocorreram duas vezes por semana, com duração de 45 minutos cada sessão, por um período de seis meses, na Clínica Escola de Fisioterapia da Faculdade São Miguel, em Recife/PE. Resultados: As condutas eleitas para a presente paciente foram: Estimulação sensorial, propriocepção, mobilização neural, treino de alcance, treino de marcha, fortalecimento muscular, alongamentos e relaxamento em flutuação. Em decorrência dos efeitos fisiológicos e das propriedades físicas da água, tais como o auxílio da temperatura, a fisioterapia aquática mostrou-se eficaz no que diz respeito a diminuição da rigidez e da espasticidade do MSE, além disso, verificou-se também uma melhora no padrão da marcha e no equilíbrio, possibilitando a paciente realizar a caminhada sem auxílio da órtese, com relação a sensibilidade não houve melhora significante. Acredita-se que as propriedades da água concomitantemente a um plano de tratamento adequado agem no sistema nervoso central, atenuando as sequelas do AVC e favorecendo a neuroplasticidade. Conclusão: Diante do exposto, constatou-se que a fisioterapia aquática proporcionou uma melhora relevante do quadro clínico. Foi possível observar uma evolução na qualidade e na perspectiva de vida da paciente, possibilitando um retorno mais rápido para as suas atividades da vida diária, tornandoa o mais funcional possível.

Palavras-chave: hidroterapia, acidente vascular cerebral, idoso. 


\section{Benefícios da hidrocinesioterapia na recuperação do equilíbrio e na prevenção de quedas} em idosos: uma revisão

Rodolfo dos Santos Diniz' ${ }^{1}$, Joedna de Brito Silva1 ${ }^{1}$ Natália Alexandre Lima1, Roberta Mariana Silva ${ }^{1}$, Ana Paula Pereira Silva ${ }^{1}$, Eduardo Antônio Costa Silva ${ }^{2}$, Leonardo Felix Santos ${ }^{2}$

${ }^{1}$ Acadêmicos do Curso de Fisioterapia, UNESC Faculdades, Campina Grande/PB, ${ }^{2}$ Docentes UNESC Faculdades, Campina Grande/PB

Email: rodo_fo_007@hotmail.com

Introdução: O envelhecimento caracteriza-se por um conjunto de alterações morfológicas, fisiológicas, bioquímicas e psicológicas. Com essas alterações, o indivíduo pode apresentar perda progressiva da capacidade de adaptação ao meio ambiente, surgir doenças, alterações das habilidades motoras e cognitivas. As quedas estão relacionadas à limitação funcional, aumento da idade, fraqueza muscular, uso de medicamentos psicotrópicos, riscos ambientais, sexo feminino e déficit visual. A hidrocinesioterapia é um recurso fisioterapêutico que busca a reabilitação humana através dos princípios da aplicação de exercícios físicos aliado às propriedades físicas da água. Objetivo: Este artigo objetivou investigar os benefícios da hidrocinesioterapia na recuperação do equilíbrio e prevenção de quedas em idosos, além de mostrar a importância de se realizar novos estudos com o mesmo tema. Metodologia: Tratou-se de um estudo exploratório com abordagem bibliográfica, elaborado a partir de artigos e material disponibilizado nas bases de dados: SciELO, Lilacs, Bireme, PEDro. Resultados: Essa pesquisa mostra que a hidrocinesioterapia tem resultados positivos, na recuperação e prevenção de quedas em idosos. Conclusão: A fisioterapia aquática no geral e em específico a hidrocinesioterapia tem demonstrado ser um importante aliado na recuperação do equilíbrio e minimizando os fatores de risco de quedas.

Palavras-chave: hidrocinesioterapia, equilíbrio, queda.

\section{Eficácia da hidroterapia em crianças com encefalopatia crônica não progressiva da infância: uma revisão}

Rodolfo dos Santos Diniz ${ }^{1}$, Joedna de Brito Silva ${ }^{1}$, Natália Alexandre Lima ${ }^{1}$, Ana dos Santos Dantas $^{1}$, Roberta Mariana Silva ${ }^{1}$, Ana Paula Pereira Silva ${ }^{1}$, Eduardo Antônio Costa Silva ${ }^{2}$, Leonardo Felix Santos ${ }^{2}$

${ }^{1}$ Acadêmicos do Curso de Fisioterapia, UNESC Faculdades, Campina Grande/PB, ${ }^{2}$ Docentes UNESC Faculdades, Campina Grande/PB

Email:rodo_fo_007@hotmail.com

Introdução: Atualmente, a Paralisia Cerebral é conceituada como Encefalopatia Crônica Não Progressiva da Infância e definida como qualquer desordem caracterizada por alteração na estrutura e função do corpo, atividade e participação por causa de lesão não progressiva do cérebro em desenvolvimento. Existem várias técnicas fisioterapêuticas para reabilitação de indivíduos com essa patologia, entretanto, nenhuma técnica se destaca como mais eficaz na literatura. A utilização da abordagem hidroterapêutica torna-se viável em vários aspectos estruturais, funcionais e sociais no processo de reabilitação. Objetivos: Avaliar, por meio da seleção e análise criteriosa de artigos, as evidências da eficácia da hidroterapia em crianças e/ou adolescentes com encefalopatia crônica não progressiva da infância com idade inferior a 17 anos. Metodologia: Foi realizada pesquisa na Biblioteca Virtual em Saúde nas bases de dados bibliográficos da Lilacs, Medline, Scielo, Biblioteca Cochrane e busca ativa em periódicos nacionais e internacionais. Resultados: Os bancos de dados localizaram apenas dois artigos de revisão sistemática sobre o tema abordado, pelos quais foi possível localizar, por busca ativa, seis artigos científicos. Esses trabalhos foram analisados de acordo com os critérios de inclusão e, por fim, apenas cinco artigos compuseram o estudo, os quais foram avaliados quanto à 
qualidade. Conclusão: Houve limitada evidência dos efeitos da abordagem hidroterapêutica nessa população. Assim sendo, estudos futuros do tipo ensaio clínico aleatório fazem-se necessário para a conduta clínica e para comunidade científica.

Palavras-chave: fisioterapia, hidroterapia, encefalopatia crônica.

\title{
Protocolo de Fisioterapia Aquática com ênfase no equilíbrio e na função motora grossa de crianças com paralisia cerebral: ensaio clínico randomizado
}

\author{
Oliveira $\mathrm{LMM}^{1}$, Silva $\mathrm{BST}^{2}$, Braga $\mathrm{DM}^{3}$, Castro CRA4, Oliveira $\mathrm{LC}^{5}$, Goes MFT ${ }^{6}$
}

1,5Fisioterapeutas referência da clínica de Paralisia Cerebral do setor da Fisioterapia Aquática da Associação de Assistência à Criança Deficiente - AACD, São Paulo/SP, ${ }^{2,6}{ }^{2}$ Fisioterapeutas aprimorandas da AACD em 2017, São Paulo/SP, ${ }^{3}$ Fisioterapeuta supervisor do setor da Fisioterapia Aquática da $A A C D$, São Paulo/SP, ${ }^{4}$ Fisioterapeuta referência da clínica de Pósoperatório na Paralisia Cerebral do setor da Fisioterapia Aquática da AACD, São Paulo/SP

Email: lucianammag@hotmail.com

Introdução: A Paralisia Cerebral (PC) é um grupo heterogêneo de alterações clínicas de caráter não progressivo do encéfalo em desenvolvimento ou imaturo, que levam a uma série de alterações, dentre elas distúrbios motores, sensoriais, posturais e de equilíbrio, que geram limitações funcionais. O tratamento na PC é multidisciplinar, no qual a fisioterapia aquática faz parte do processo de reabilitação, em que as propriedades hidrodinâmicas têm mostrado bons resultados no tratamento. Objetivo: Avaliar os efeitos de um protocolo de fisioterapia aquática com ênfase no equilíbrio e na função motora grossa de crianças com PC diparética espástica classificadas no nível III do Gross Motor Function Classification System (GMFCS). Métodos: Trata-se de um ensaio clínico controlado, randomizado, longitudinal, estratificado, cego, de caráter descritivo-analítico, qualitativo e quantitativo, sendo realizado na AACD, Unidade Ibirapuera, São Paulo, SP, Brasil. Foi previamente aprovado pelo Comitê de Ética em Pesquisa da AACD (parecer oㅜ 68545917.1.0000.0085) em conformidade com a Resolução 466/12 do Conselho Nacional de Saúde do Brasil. Foram triados 65 prontuários dos quais 19 crianças foram incluídas e 12 finalizaram o estudo. Dentre os critérios de inclusão, incluem-se: PC do tipo diparesia espástica, classificadas no nível III do GMFCS, com idade entre 4 e 8 anos e 11 meses. Foram excluídos pacientes incapazes de compreender as atividades propostas, submetidos à cirurgia ortopédica a menos de 12 meses e a bloqueios periféricos a menos de 6 meses e que apresentaram intercorrências clínicas. As crianças foram alocadas em grupo controle (GC), que realizou terapias convencionais e grupo intervenção (Gl) que realizou o protocolo de exercícios aquáticos. Os grupos foram avaliados pré e pós-intervenção através das escalas e instrumentos: Escala Visual Analógica (EVA), Medida da Função Motora Grossa (GMFM-88), Escala de Equilíbrio Funcional Pediátrica (EEP), Dynamic Gait Index (DGI), Time Up and Go (TUG), Teste de Caminhada de 10 metros (10-MWT), Child Health Questionaire (CHQPF-50) e Anamnese. Para análise estatística foram utilizados os testes qui-quadrado, Manova, Mann-Whitney e o teste de Wilcoxon. Foi considerado um intervalo de confiança (IC) de 95\%, o nível de significância de $p<0,05$. Foram utilizados os softwares SPSS V.2.1, Minitab 16 e Excel Office 2010. Resultados: Foi encontrado melhora do GMFM total somente no $\mathrm{Gl}(\mathrm{p}=0,028)$, enquanto na dimensão $\mathrm{E}$ ambos os grupos apresentaram melhora, $G I(p=0,026)$ e $G C(p=0,046)$. No teste 10 MWT o GI diminuiu o tempo para a distância total percorrida, com valor significativo de $(p=0,028)$ comparado ao $\mathrm{GC}(\mathrm{p}=0,463)$. Também foi observado significante melhora no equilíbrio dinâmico do $\mathrm{GI}(p=0,041)$ após intervenção segundo a escala DGI. Não houve resultados significativos na TUG e EEP após aplicação do protocolo. Discussão: Notou-se déficit no equilíbrio dinâmico e estático durante as atividades avaliadas nesta população. Crianças com PC diparéticas espásticas, nível III, apresentam o equilíbrio prejudicado e este interfere na realização das atividades funcionais, pois o equilíbrio é fundamental para se recuperar de situações de instabilidade. O protocolo foi elaborado de acordo com os parâmetros utilizados na literatura, sendo realizado 16 sessões de fisioterapia aquática, com frequência de 2 vezes por semana e duração de 35 minutos para cada sessão. Os exercícios do protocolo foram elaborados para estimular a criança. A atividade na água promove o aumento da confiança e tem caráter 
desafiador, além do processo ensino- aprendizado. Apesar das terapias serem aplicadas no meio líquido, o objetivo era que estes ganhos funcionais fossem transferidos para o solo. Conclusão: O protocolo de equilíbrio na fisioterapia aquática aplicado em crianças com PC nível III do GMFCS, proporcionou melhora na função motora grossa, na velocidade da marcha, no equilíbrio e na qualidade de vida, mostrando a fisioterapia aquática um importante meio de reabilitação.

Palavras-chave: paralisia cerebral, balance postural, hidroterapia, fisioterapia.

Influência da Fisioterapia Aquática funcional na simetria da descarga de peso na passagem de sentado para em pé em hemiparéticos pós AVC

\author{
Gouvêa JXM, Magalhães DRC, Baccaro VM, Braga DM, Lourenço MA \\ Departamento de Fisioterapia Aquática, Associação de Assistência à Criança Deficiente (AACD) \\ - Unidade Ibirapuera, São Paulo/SP
}

Email: jgouvea@aacd.org.br

Introdução: Um dos movimentos mais executados na vida diária é a passagem de sentado para em pé, sendo este um pré-requisito para a estabilidade e mobilidade na postura ortostática. Dentre as abordagens da reabilitação no tratamento de Acidente Vascular Cerebral (AVC), a Fisioterapia Aquática Funcional é uma das alternativas que se destaca. Objetivo: Avaliar a influência da Fisioterapia Aquática Funcional na simetria da descarga de peso entre os membros inferiores durante a passagem de sentado para em pé em pacientes com hemiparesia pós AVC, e sua provável interferência na ativação dos músculos reto e bíceps femoral, relacionando essas medidas com parâmetros de funcionalidade e qualidade de vida. Métodos: Estudo aprovado pelo Comitê de Ética em Pesquisa da Associação de Assistência à Criança Deficiente (1.739.217/2016). Estudo clínico controlado, cego, de caráter descritivo-analítico. Participaram do estudo 18 indivíduos hemiparéticos (média de tempo pós AVC: 18,77 meses) que foram alocados em dois grupos: Grupo Experimental (GE), composto por 10 indivíduos (média de idade: 43,2 anos), submetidos a um protocolo de Fisioterapia Aquática Funcional composto por 11 exercícios com foco na ativação muscular de membros inferiores (reto e bíceps femoral); e Grupo Controle (GC), composto por 8 indivíduos (média de idade: 52,9 anos), submetidos apenas a fisioterapia em solo. Ambos os grupos realizaram 14 sessões individuais, 2 vezes por semana, por 35 minutos; foram também recrutados 18 indivíduos saudáveis (média de idade: 47,9) para comparar a simetria da descarga de peso nos membros inferiores. Os grupos foram avaliados antes e após o período de intervenção. Dados sobre a ativação muscular de reto e bíceps femoral foram coletados por meio da eletromiografia de superfície e os dados sobre a análise de simetria, por meio de uma plataforma de força; estes resultados foram relacionados a escalas de funcionalidade e qualidade de vida (Escala de Qualidade de Vida Específica para AVC, Medida de Independência Funcional e Escala de Equilíbrio de Berg). O software utilizado na análise dos dados foi o SPSS v.21. Para a estatística descritiva utilizou-se tabela de frequências com o teste qui-quadrado, e a correção do teste exato de Fisher quando apropriado. Para análise da variância entre os grupos no momento pré-tratamento utilizou-se ANOVA de uma via e o teste de KruskallWallis para quando não havia normalidade ou homogeneidade entre os grupos. Para avaliar os efeitos dos tipos de tratamento utilizou-se um modelo linear geral de medidas repetidas. Para a comparação entre os grupos foi utilizado a média e os intervalos de confianças, e os valores de significância apresentados referem-se ao efeito de interação entre grupo de tratamento e o tempo $(\mathrm{p}<0,05)$. Resultados: Ambos os grupos mostraram melhora na independência, funcional, equilíbrio e qualidade de vida, demonstrada através das escalas funcionais (MIF: $p=0,025$; BERG: $p=0,001 ; p=0,040$ ), entretanto, sem diferença significativa entre os grupos. A correlação negativa moderada entre a ativação de reto femoral e bíceps femoral esquerdos e o pico máximo de Força Vertical de Reação ao Solo na plataforma esquerda sugere que, quanto menor a ativação desses músculos, maior a descarga de peso na plataforma esquerda e, considerando que $70 \%$ dos indivíduos do GE eram hemiparéticos à esquerda, sugere-se, assim, que houve influência do protocolo na melhora do equilíbrio entre essas duas musculaturas, possibilitando a diminuição da assimetria durante a passagem de sentado para em pé, sugerindo que houve mudança na eficiência da musculatura, visto que houve maior descarga de peso com uma menor necessidade 
de recrutamento muscular. Houve diferença na razão de simetria da descarga de peso em membros inferiores entre indivíduos saudáveis $(p=0,001)$. Conclusão: A Fisioterapia Aquática Funcional exerceu influência na simetria da descarga de peso em membros inferiores no grupo que realizou o protocolo, com reflexo positivo na funcionalidade e qualidade de vida. Ambos os tratamentos foram efetivos nos parâmetros avaliados, e o grupo que realizou Fisioterapia Aquática apresentou uma diminuição da razão de simetria da descarga de peso, sugerindo melhora da simetria em membros inferiores durante a passagem de sentado para em pé.

Palavras-chave: acidente vascular cerebral, hidroterapia, paresia.

\title{
Importância da Fisioterapia Aquática no equilíbrio de idosos
}

\author{
Correia Filha $\mathrm{MJ}^{1}$, Melo $\mathrm{IGL}^{2}$, Moreno $\mathrm{GMM}^{3}$ \\ ${ }^{1}$ Faculdades Integradas da Vitória de Santo Antão (Faintvisa), Vitória de Santo Antão/PE, \\ ${ }^{2}$ Departamento de Fisioterapia, Faintvisa, Vitória de Santo Antão/PE
}

Email: mariajcorreiaf@gmail.com

Introdução: O processo de envelhecimento e suas alterações fisiológicas têm recebido atenção crescente da comunidade científica devido ao aumento significativo desta parcela da população, bem como do importante impacto socioeconômico que têm seus processos de adoecimento. No curso do processo de envelhecimento o desempenho de habilidades motoras como o equilíbrio é comprometido secundariamente à degenerações sensoriais gradativas no sistema nervoso com comprometimento principalmente dos sistemas visual, vestibular e somato-sensorial. $\mathrm{O}$ déficit de equilíbrio é responsável pelo aumento do risco de quedas em idosos, que tem relação direta com diversas comorbidades, diminuição da qualidade de vida, aumento do número de internamentos e mortes de idosos. Nesse contexto a busca de estratégias terapêuticas capazes de promover melhoras nessa função merecem especial atenção, especialmente àquelas não invasivas e não farmacológicas, dadas as fragilidades desse grupo da população. A fisioterapia aquática se propõe a utilizar as propriedades físicas da água para auxiliar na implementação de programas de atividades cinesioterapêuticas, cognitivas e sensoriais para a recuperação e manutenção de equilíbrio. Objetivo: Descrever a importância da hidroterapia como terapêutica para melhor capacidade do equilíbrio para uma melhor qualidade de vida de idosos. Identificar os benefícios adquiridos com a prática da hidroterapia na melhora do equilíbrio para o público idoso. Métodos: Trata-se de uma revisão integrativa descritivo-exploratória. Os critérios de inclusão foram artigos cujos objetivos fossem avaliar a hidroterapia como principal terapêutica para melhor qualidade de vida para idosos que apresentem déficit de equilíbrio, publicados em língua portuguesa, com texto completo, disponíveis de forma gratuita eletronicamente, indexados na Biblioteca Virtual em Saúde (BVS), nas bases Literatura Latino Americana y del Caribe em Ciências de La Salud (LILACS), Medical Literature Analysis and Retrieval System Online (MEDLINE) Scientific Eletronic Library Online (SciELO) no período 2008 a 2018 e que contivessem os descritores utilizados na busca no seus título, resumo ou assunto. Excluíram-se os artigos em outros idiomas, que não apresentavam texto completo, que não se enquadravam no recorte temporal estabelecido, além de outros documentos como livros, monografias, dissertações, teses e editoriais. Foram encontrados 21 artigos, dos quais apenas 06 responderam à questão norteadora: como a hidroterapia pode melhorar o equilíbrio e evitar futuras complicações em pacientes idosos? Resultados: Devido à resistência que a água promove na prática desta terapia, foi observada uma melhora significativa na força muscular e potência na maioria dos músculos, as melhoras partiram desde a realização de movimentos que simulavam atividades funcionais como durante o treino de marcha' ${ }^{1}$. Os benefícios são evidentes na literatura, pois relata uma melhor mobilidade adquirida por pacientes idosos que fazem da hidroterapia seu recurso de tratamento para uma melhor qualidade de vida e melhora de equilíbrio. Conclusão: Com a melhora da qualidade de vida deste público, é notável que a marcha e a diminuição no risco de quedas fiquem bem evidentes, mas são necessários novos estudos que abordem as mudanças do equilíbrio após o tratamento na hidroterapia.

Palavras-chave: hidroterapia, idosos, equilíbrio postural. 
Avaliação da Fisioterapia Aquática no tratamento da doença de Parkinson: revisão de literatura

\author{
Araujo ASML' ${ }^{1}$ Mendes $\mathrm{LS}^{2}$, Rocha JCT ${ }^{2}$ \\ ${ }^{1}$ Universidade Federal do Piauí, Parnaíba/PI, ${ }^{2}$ Departamento de Fisioterapia, Universidade \\ Federal do Ceará, Fortaleza/CE \\ Email: tatmatsu@gmail.com
}

Introdução: A Doença de Parkinson (DP) é uma afecção crônica neurodegenerativa de lenta progressão que ocorre devido à perda neuronal de células dopaminérgicas na via negro-estriatal do cérebro. Caracteriza-se pela presença de bradicinesia, hipocinesia, acinesia, tremor e rigidez, além de déficits de equilíbrio e na marcha. Além disso, os pacientes podem apresentar depressão, distúrbios autonômicos e demência. A fisioterapia aquática é um recurso terapêutico que utiliza os efeitos físicos, fisiológicos e cinesiológicos resultante da imersão do corpo em piscina aquecida para auxiliar no tratamento e na prevenção de alterações funcionais. Objetivos: Avaliar a utilização da fisioterapia aquática no paciente com Doença de Parkinson. Métodos: Trata-se de um estudo descritivo, do tipo avaliativo. Utilizou-se de artigos publicados na Biblioteca Virtual em Saúde (BVS), no período de 2014 a 2018, em inglês e português, com os seguintes descritores: Parkinson AND physiotherapy. Utilizou-se como critério de exclusão todos os artigos que não fossem correlatos a fisioterapia aquática. Resultados: Utilizando o Parkinson's Disease Questionnaire (PDQ-39), observou-se que pacientes que praticam a hidroterapia possuem maior conforto corporal em comparação àqueles que não praticam. Após a realização de fisioterapia aquática, pacientes com DP reduziram escores do PDQ-39 indicando melhoria na qualidade de vida. Quando comparada a fisioterapia aquática com a fisioterapia convencional, usando a escala Timed Up and Go (TUG), o Teste de Alcance Funcional (TAF), o teste de Caminhada de 10 metros (TC10), o Dynamic Gait Index (DGl) e a escala Falls Efficacy Scale (FES), notou-se que os dois métodos são eficientes na melhora do equilíbrio e da função da marcha e na redução do risco de quedas e incapacidade funcional. Utilizando um protocolo de tratamento de Terapia Aquática que consistia em 4 fases: aquecimento (1), alongamento (2),exercícios ativos e proprioceptivos (3) e relaxamento (4), obteve-se melhora na amplitude de movimento nos movimentos de flexão de ombro $\left(150^{\circ}-170^{\circ}\right)$, abdução de ombro $\left(160^{\circ}-170^{\circ}\right)$, flexão de cotovelo $\left(110^{\circ}-120^{\circ}\right)$ e em membros inferiores: flexão de quadril $\left(105^{\circ}-115^{\circ}\right)$ e flexão de joelho $\left(110^{\circ}\right.$ $120^{\circ}$ ), além de ganho no grau de força muscular. Conclusão: A fisioterapia aquática é um importante recurso utilizado para a reabilitação de pacientes parkinsonianos, resultando em maior conforto corporal, melhora na qualidade de vida, no equilíbrio e da função da marcha, reduz o risco de quedas e a incapacidade funcional, melhora amplitude de movimento e aumenta o grau de força muscular.

Palavras-chave: Parkinson, fisioterapia, hidroterapia.

Aplicação da Fisioterapia Aquática com uso do método Halliwick em pacientes pósacidente vascular encefálico: revisão de evidências

\author{
Araujo ASML', Mendes LS², Peixoto $\mathrm{KS}^{2}$ \\ ${ }^{1}$ Universidade Federal do Piauí, Parnaíba/PI, ${ }^{2}$ Departamento de Fisioterapia, Universidade \\ Federal do Ceará, Fortaleza/CE
}

Email: tatmatsu@gmail.com

Introdução: O Acidente Vascular Encefálico (AVE) é caracterizado como um déficit neurológico transitório ou definitivo em uma área cerebral secundário a lesão vascular que corresponde a um grupo de afecções que apresentam manifestações clínicas semelhantes, porém etiologias diversas. Por sua vez, a fisioterapia aquática é um recurso terapêutico que favorece a reabilitação utilizando os efeitos físicos, fisiológicos e cinesiológicos da imersão do corpo em piscina 
aquecida. O Tratamento de sequelas pós-AVE com os recursos biohídricos é tema relevante de debate e evidências ao longo dos anos. Objetivos: Identificar na literatura o uso do método Halliwick na fisioterapia aquática em indivíduos pós-acidente vascular encefálico. Métodos: Trata-se de uma revisão integrativa da literatura composta de artigos. Utilizou-se de artigos publicados na Biblioteca Virtual em Saúde (BVS), no período de 2014 a 2018, em inglês, com os seguintes descritores: Aquatic AND Stroke. Utilizou-se como critério de exclusão todos os artigos que não fossem correlatos a fisioterapia aquática e o método Halliwick. Resultados: Foram encontrados 58 artigos, após a leitura de títulos e resumos apenas 2 artigos foram selecionados por serrem correlacionados com a fisioterapia aquática. O método Halliwick é uma técnica da hidroterapia que consiste nos princípios de adaptação ambiental, restauração do equilíbrio, inibição, e facilitação utilizado no tratamento de diferentes alterações de desenvolvimento e disfunções neurológicas. No primeiro estudo participaram da pesquisa 15 indivíduos com distúrbios de equilíbrio pós-AVE; no segundo estudo fizeram parte 14 pessoas no grupo de intervenção e 16 no grupo controle, ambos na fase pós-aguda de reabilitação do quadro de AVE. Os resultados das duas pesquisas mostraram uma evolução considerável no quadro dos pacientes após a aplicação da fisioterapia aquática utilizando-se do método de Halliwick. Conclusão: Observou-se que o uso dos recursos de hidroterapia em pacientes com sequelas pós-AVE foi aceitável e relevante em seus respectivos tratamentos. Constatou-se também que a aplicação do método de Halliwick foi significativamente importante para a obtenção dos resultados positivos. Entretanto, em alguns indivíduos a aplicação unicamente do método e da própria fisioterapia aquática pode não mostrar benefícios significativos para a qualidade de vida destes; necessitando, portanto, de complementação no tratamento.

Palavras-chave: acidente vascular encefálico, stroke, hidroterapia.

\section{A efetividade da hidroterapia na prevenção de quedas em idosos: uma revisão}

Joedna de Brito Silva, Rodolfo dos Santos Diniz, Natália Alexandre Lima, Jéssica dos Santos Ferreira, Roberta Mariana Silva, Ana Paula Pereira Silva, Dilermando da Silva Noblat, Eduardo Antônio Costa Silva, Leonardo Felix Santos

\section{Curso de Fisioterapia, UNESC Faculdades, Campina Grande/PB}

Email: joedna21@gmail.com

Introdução: O envelhecimento é descrito como um processo multifatorial e progressivo, que resulta na diminuição da velocidade de contração muscular, causando alterações nos reflexos de proteção, na coordenação e no equilíbrio, o que torna idosos mais vulneráveis aos riscos ambientais. A causa das quedas é multifatorial, que depende tanto de fatores intrínsecos, como os aspectos fisiológicos. A hidroterapia é um recurso que utiliza os efeitos físicos, fisiológicos e cinesiológicos, resultante da imersão do corpo em piscina aquecida, que auxilia na reabilitação ou prevenção de alterações funcionais. Objetivo: Verificar a efetividade da hidroterapia na prevenção de quedas em idosos. Metodologia: Tratou-se de um estudo exploratório, de caráter qualitativo, a partir de uma revisão bibliográfica, realizada através de uma análise de conteúdo dos resultados encontrados. Foram considerados artigos em idioma português e inglês, utilizando 20 artigos de periódicos pelas bases de dados nacionais e internacionais como: Lilacs, Bireme, PubMed, SciELO e Google Scholar nos últimos 15 anos. Resultados: Do estudo desenvolvido temos como resultado que, a hidroterapia influência na capacidade funcional e no equilíbrio em idosos. Sendo assim considerada uma técnica eficaz para a diminuição do risco de queda em idosos. Conclusão: Esse estudo demonstrou que a hidroterapia pode melhorar o equilíbrio dinâmico e estático em idosos, como também minimizar os fatores de risco das quedas, pois houve resultados estatisticamente significativos.

Palavras-chave: hidroterapia, envelhecimento, quedas. 
A efetividade da hidrocinesioterapia na redução das dores em pacientes com fibromialgia: revisão de literatura

Joedna de Brito Silva ${ }^{1}$, Rodolfo dos Santos Diniz' ${ }^{1}$, Natália Alexandre Lima ${ }^{1}$, Roberta Mariana Silva ${ }^{1}$, Ana Paula Pereira Silva ${ }^{1}$, Dilermando da Silva Noblat ${ }^{1}$, Eduardo Antônio Costa Silva ${ }^{2}$, Leonardo Felix Santos ${ }^{2}$

${ }^{1}$ Acadêmicos do Curso de Fisioterapia, UNESC Faculdades, Campina Grande/PB, ${ }^{2}$ Docentes UNESC Faculdades, Campina Grande/PB

Email: joedna21@gmail.com

Introdução: A fibromialgia é uma patologia reumatologia, crônica e sistêmica, tendo como principal característica dor musculoesquelética difusa. Acomete preferencialmente o gênero feminino, com incidência entre os 40 e 60 anos de idade e a prevalência mundial é de $2 \%$. A hidrocinesioterapia é bastante indicada para o tratamento de pacientes com fibromialgia, sendo praticada em água aquecida entre $32^{\circ} \mathrm{C}$ e $33^{\circ} \mathrm{C}$. No tratamento, durante a imersão, os estímulos sensoriais competem com os estímulos dolorosos, interrompendo o ciclo da dor. Objetivo: Este artigo objetivou avaliar a efetividade da hidrocinesioterapia na redução das dores em pacientes com fibromialgia. Metodologia: Tratou-se de um estudo exploratório, descritivo com abordagem bibliográfica, elaborado a partir de artigos e material disponibilizado nas bases de dados: SciELO, Lilacs, Bireme, PEDro. A partir dos seguintes descritores: Fibromialgia, Hidroterapia, Hidrocinesioterapia. Resultados: Nessa pesquisa, os resultados encontrados apontam que a hidrocinesioterapia e outros métodos também contribuem de forma positiva no tratamento de pacientes com fibromialgia. Mesmo demostrando a escassez de produção literária sobre o tema. Conclusões: A fisioterapia de maneira geral e em específico a hidrocinesioterapia tem demonstrado um importante papel na busca da qualidade de vida dos pacientes e tendo como meta, reduzir a dor e melhorar o condicionamento físico, evitando a perpetuação do ciclo vicioso: dor, inatividade e limitação funcional. Tornando-se a terapia mais agradável e lúdica.

Palavras-chave: fibromialgia, hidroterapia, hidrocinesioterapia.

Análise comparativa do equilíbrio em idosos após a prática de exercícios resistidos em ambiente aquático

Sousa EGD¹, Gouveia GPM², Castro LTG ${ }^{1}$, Silva PA ${ }^{1}$, Araújo RL ${ }^{1}$, Oliveira TR

${ }^{1}$ Grupo de Pesquisa em Fisioterapia Avaliativa e Terapêuticas- GPFAT, Universidade Federal do Piauí, Parnaíba/PI, ${ }^{2}$ Coordenador do Grupo de Pesquisa em Fisioterapia Avaliativa e Terapêuticas- GPFAT

\section{Email:laryssatheodora@hotmail.com}

Introdução: O envelhecimento é um fenômeno natural da vida humana que ocasiona mudanças fisiológicas. A senescência provoca alterações que vão interferir no equilíbrio. O exercício é reconhecido como aliado no processo de envelhecimento, assim, exercícios de resistência muscular podem ser realizados em ambiente aquático e terrestre, porém, exercícios aquáticos criam situações de instabilidade, fornecendo mais informações sensoriais. Objetivo: Analisar a utilização dos exercícios resistidos no ambiente aquático na melhora do equilíbrio de idosos por meio da análise da plataforma de força e com a eletromiografia de superfície. Métodos: Trata-se de um estudo intervencionista, descritivo, transversal de caráter quantitativo, no qual as variáveis utilizadas foram avaliadas antes e após o programa de treinamento. A pesquisa contemplou 13 anciãos do município de Parnaíba-PI. O programa de exercícios resistidos em ambiente aquático constituiu-se de exercícios de resistência muscular, equilíbrio e relaxamento, executados durante uma hora, duas vezes por semana em dias alternados, durante seis semanas. Resultados: Em relação à análise estabilométrica houve melhoria do centro de gravidade e controle motor dos integrantes. Ao inferir os dados da eletromiografia dos músculos estudados, obteve-se 
significância estatística para cada variável, apontando eficácia do protocolo no controle motor destes músculos. Conclusão: O protocolo proposto é eficaz no controle motor e equilíbrio de idosos, reduzindo o risco de quedas e promovendo melhoria da capacidade funcional.

Palavras-chave: idoso, equilíbrio, funcionalidade.

\section{Efeitos da Fisioterapia Aquática na força muscular e flexibilidade de indivíduos com deficiência visual}

Silva BTP ${ }^{1}$, Lenci $S^{1}$, Shimano SGN $^{2}$

${ }^{1}$ Universidade Federal do Triângulo Mineiro, Uberaba/MG, ${ }^{2}$ Departamento de Fisioterapia Aplicada, Universidade Federal do Triângulo Mineiro, Uberaba/MG

Email: bianca22-@hotmail.com

Introdução: A deficiência visual é definida como a condição de saúde em que o indivíduo é privado parcialmente ou totalmente da capacidade de ver. A força e a flexibilidade são qualidades físicas e motoras que definem o nível de aptidão física do indivíduo, porém, a diminuição destes componentes pode afetar o equilíbrio, a postura e o desempenho funcional, além de aumentar o risco de quedas, diminuir a velocidade da marcha e dificultar as atividades da rotina diária. Assim sendo, a fisioterapia aquática através de suas propriedades atua melhorando a qualidade de vida, além de melhorar a força, a flexibilidade e o equilíbrio do indivíduo, estimulando sua independência, e melhorando a percepção sobre suas relações sociais e com seu meio. Objetivos: Avaliar os efeitos da fisioterapia aquática adaptada na força muscular e flexibilidade de deficientes visuais em diferentes momentos: avaliação inicial, 6 e 12 semanas de intervenção. Métodos: Trata-se de um estudo longitudinal, de intervenção, série de casos, quantitativo, obedecendo aos princípios éticos para pesquisa envolvendo seres humanos sob parecer $\mathrm{n}^{\circ}$ 2.496.643, realizado no Instituto de Cegos do Brasil Central (ICBC), composto por 4 voluntários que possuíam deficiência visual (baixa visão grave ou cegueira), entre 18 e 45 anos. $\mathrm{Na}$ intervenção foram realizados exercícios de fisioterapia aquática para ganho de equilíbrio, força e flexibilidade, com uso de halteres, espaguetes, e alongamentos, aumentando a intensidade progressivamente de acordo com o desenvolvimento de cada um. Os testes utilizados para avaliação foram: Teste de alcance funcional, Teste de força do músculo gastrocnêmio e Dinamometria de preensão palmar. Resultados: no Teste de alcance funcional obteve-se melhora de $6,26 \%$ ao término da $6^{\text {a }}$ semana e $11,75 \%$ ao término da $12^{2}$ semana. Teste de força do músculo gastrocnêmio: obteve-se melhora de $37,83 \%$ ao término da $6^{\underline{a}}$ semana e $8,14 \%$ ao término da $12^{\mathrm{a}}$ semana. Dinamometria de preensão palmar: na mão direita houve aumento de força de 6,43\% com 6 semanas e 9,87\% com 12 semanas, já na mão esquerda houve declínio de $5,8 \%$ com 6 semanas e $4,3 \%$ com 12 semanas. Nos 3 testes, os ganhos foram maiores principalmente ao término da $12^{\underline{a}}$ semana, quando os voluntários já apresentavam maior domínio e compreensão dos exercícios propostos. Conclusão: A fisioterapia aquática traz contribuições positivas para a melhora e manutenção da força muscular e flexibilidade quando é associada a mudança de hábitos de vida. Quando realizada com deficientes visuais se torna um desafio, pois é um ambiente novo e desconhecido, mas, é perceptível a grande capacidade e força de vontade deles quando comparados os resultados antes e após as intervenções na água.

Palavras-chave: hidroterapia, transtornos da visão, força muscular. 
Aqua Lymphatic Therapy (ALT) no linfedema pós mastectomia radical: relato de caso

\author{
da Silva LS ${ }^{1}$, Correia DF ${ }^{1}$, De Amorim KCS², Fonseca $\mathrm{PHS}^{3}$ \\ ${ }^{1}$ Graduanda(o) em Fisioterapia da Universidade Federal de Pernambuco (UFPE), Recife/PE, \\ ${ }^{2}$ Mestrando em Fisioterapia pela UFPE, Recife/PE, ${ }^{3}$ Docente do Departamento de Fisioterapia \\ da UFPE, Recife/PE
}

Email: laviniasbs@hotmail.com

Introdução: A Aqua Lymphatic Therapy (ALT) é um método de tratamento composto por exercícios suaves e de baixa resistência que combinam automassagem, cinesioterapia aquática, cuidados com a pele e compressão relacionada a? pressão hidrostática. Objetivos: Verificar os efeitos da ALT como recurso hipoalgésico e de melhora da capacidade funcional de uma paciente com linfedema pós- mastectomia radical. A terapia complexa desobstrutiva (TCD) tem sido considerada o padrão ouro de tratamento do linfedema, hipotetiza-se que a ALT possa apresentar resultados ainda mais promissores na hipoalgesia e melhora da capacidade funcional. Métodos: Relato de caso, paciente do sexo feminino, 42 anos, IMC 23,7, cobradora de transporte coletivo. Realizou procedimento cirúrgico 1 ano após receber diagnóstico de carcinoma ductal nível 2. Iniciou ALT 8 meses após mastectomia radical, com linfedema Grau II, referindo queixas de dores na região cérvico-torácica posterior e axilar esquerda, fraqueza no membro superior esquerdo e dor na área da cicatriz cirúrgica. $O$ tratamento foi realizado no setor de Fisioterapia Aquática da Clínica escola de Fisioterapia da UFPE, durante 4 meses, 2x semana, sessões com duração de 50 minutos. Foram realizados procedimentos de ALT que incluíram cinesioterapia aquática, exercícios suaves e de baixa resistência e automassagens em profundidade para potencializar os efeitos hidrostáticos. O estudo foi aprovado pelo comitê de ética da UFPE, parecer 1.759.097/2016. Para avaliar a intensidade da dor foi utilizada a escala visual analógica (EVA) e para avaliar a capacidade funcional do membro superior foram realizadas avaliações goniométricas e de força do ombro (de acordo com os critérios de Kendall). Além disso, foi aplicado o Questionário Shoulder Pain and Disability Index (SPADI). Resultados: Foi verificado redução da intensidade dolorosa de 73 para $28 \mathrm{~mm}$, ADM (flx. antes 640/depois 98 o; ext antes 32 o/depois $48 \mathrm{o}$; abd antes 36 o/depois 128 o; rot.int antes 27 o/depois 83 o; rot. ext. antes 23 o /depois 81 o). Força muscular (flx antes 3/depois 4; ext antes 4 /depois 5; abd antes 3/depois 5; rot.int antes 4/depois 5; rot. ext.3 antes /depois4) e Shoulder Pain and Disability Index (antes 79 /depois31 pontos). A Fisioterapia Aquática diminui o efeito da gravidade e aumenta 0 bombeamento linfático contribuindo para melhora das funções e redução das dores de indivíduos com linfedemas 1-3. Conclusão: Os resultados encontrados apontam que a Fisioterapia Aquática através do método ALT configura um procedimento complementar a? Terapia Complexa Descongestiva na hipoalgesia e melhora da capacidade funcional em paciente com linfedema pós mastectomia radical.

Palavras-chave: mastectomia, linfedema, fisioterapia.

\title{
Efeito de uma sessão de imersão em crianças com síndrome congênita relacionada ao vírus Zika
}

Silva $\mathrm{LS}^{1}$, Monteiro $\mathrm{MG}^{2}$, Jayse $\mathrm{A}^{1}$, de Melo $M F^{1}$, Maranhão $\mathrm{R}^{1}$, Wiesiolek $\mathrm{CC}^{3}$, Ferraz $\mathrm{KM}^{3}$

${ }^{1}$ Graduanda em Fisioterapia da Universidade Federal de Pernambuco (UFPE), Recife/PE, ${ }^{2}$ Mestre em Fisioterapia pela UFPE, Recife/PE, ${ }^{3}$ Docente do Departamento de Fisioterapia da UFPE, Recife/PE

Email: laviniasbs@hotmail.com

Introdução: Crianças com Síndrome Congênita relacionada à infecção pelo vírus Zika (SCZ) apresentam como queixas clínicas principais o comportamento irritável e as alterações de tônus muscular. Diante disso, a terapia em ambiente aquático pode ser um recurso adjuvante à 
reabilitação na SCZ por ser uma terapia prazerosa e benéfica para crianças. Objetivo: O objetivo desse estudo foi avaliar o efeito em curto prazo de uma sessão de imersão sobre o sono e o tônus muscular de crianças com microcefalia/SCZ. Métodos: Uma série de casos, aprovada pelo Comitê de Ética e Pesquisa da UFPE (CAAE: 60111416.6.0000.5208), foi realizada no Laboratório de Estudos em Pediatria (LEPED) do Departamento de Fisioterapia da Universidade Federal de Pernambuco (UFPE). A população do estudo foi constituída por crianças com microcefalia/SCZ, entre 3-24 meses de idade, sem crises convulsivas, refluxo gastroesofágico, artrogripose ou luxação congênita do quadril e com mais de 6 meses de aplicação de toxina botulínica. Para avaliação do sono, foi aplicado um questionário semiestruturado que abordava aspectos do sono (duração, qualidade e frequência de interrupções noturnas) no dia anterior e seguinte à sessão; o tônus muscular foi avaliado pela Escala Modificada de Tardieu (EMT), analisando-se o grau de tônus muscular e a ganho de amplitude articular (ADM) dos grupos musculares flexores e extensores das articulações do cotovelo e quadril. A sessão consistiu na imersão da criança em bacia (diâmetro de $85 \times 45 \mathrm{~cm}$ e profundidade de $40 \mathrm{~cm}$ ), com contenção flexora seguida por movimentos de deslizamento látero-lateral e ântero-posterior, lentos e ritmados, durante 15 minutos. Para análise estatística, utilizou-se o software SPSS (versão 20.0) para verificar normalidade dos dados pelo Teste de Shapiro-Wilk; os testes T pareado e Wilcoxon para análise antes e depois. Resultados: Foram avaliadas dez crianças (idade média em meses: $23,9+3,97 ; 58,7 \%$ do sexo feminino), das quais todas apresentavam algum grau de irritabilidade que, de acordo com as genitoras, estava relacionado à privação de sono $(100 \%)$. Foi observado após a sessão diminuição na frequência de interrupções noturna $(p=0,05)$ e melhora da qualidade do sono $(p=0,01)$, redução do grau de tônus muscular dos músculos extensores de cotovelo $(p=0,03)$ e joelho $(p=0,04)$. Tais resultados refletem os efeitos da terapia em ambiente aquático promovendo melhora do tônus muscular e do comportamento, demonstrando que as crianças experimentaram uma sensação de relaxamento. Tais efeitos podem auxiliar na reabilitação na SCZ visto que crianças com disfunções neurológicas tendem a apresentar distúrbios do sono além de sofrerem as consequências a longo prazo da hipertonia, como as deformidades e contraturas musculares. Conclusão: A sessão de imersão em ambiente restrito apresentou benefícios em curto prazo às crianças com microcefalia/SCZ da nossa amostra. Deve-se enfatizar que o protocolo aplicado foi de baixo custo e fácil aplicação, tornando-se replicável em ambiente domiciliar ou locais que não possuem piscina, além da possibilidade de ser uma técnica viável e não farmacológica no acompanhamento terapêutico destas crianças. $A$ experiência do fisioterapeuta deve guiar a escolha do protocolo adequado para cada criança, respeitando as suas particularidades.

Palavras-chave: Zika vírus, microcefalia, hidroterapia.

\section{Efeitos da Fisioterapia Aquática sobre a capacidade funcional em paciente com linfedema de membro inferior: relato de caso}

De Santana $\mathrm{TM}^{1}$, Araújo MGR ${ }^{2}$, De Morais NR${ }^{1}$, Da Silva KD¹, Andrade $\mathrm{MA}^{2}$, Maia $\mathrm{JN}^{2}$, Pedrosa $\mathrm{BCS}^{2}$, Ferreira $\mathrm{APL}^{2}$

${ }^{1}$ Universidade Federal de Pernambuco, Recife/PE, ${ }^{2}$ Departamento de Fisioterapia, Universidade Federal de Pernambuco, Recife/PE

Email: thaynamoura15@gmail.com

Introdução: O linfedema constitui uma doença crônica, grave e progressiva, caracterizado pelo déficit no equilíbrio das trocas de fluidos no espaço intersticial levando ao acúmulo tecidual de líquidos e macromoléculas no espaço intersticial, decorrentes de deficiências no sistema linfático. Os efeitos da Fisioterapia Aquática nessa doença são pouco explorados. Objetivos: Verificar os efeitos da Fisioterapia Aquática no linfedema de membro inferior. Hipotetiza-se que haverá redução volumétrica do membro e melhora da capacidade funcional. Métodos: Relato de caso, paciente de 47 anos, com diagnóstico de linfedema crônico grau III no membro inferior esquerdo diagnosticado aos 25 anos. Durante avaliação cinético funcional relatou sensação de peso, cansaço e dificuldade para deambular. $O$ trabalho foi realizado no setor de Fisioterapia Aquática da Clínica escola de Fisioterapia da UFPE, durante 4 meses, 2 vezes por semana, sessões com 
duração de 50 minutos. Foram realizados procedimentos de cinesioterapia aquática com e sem o auxílio de flutuadores, método de Bad Ragaz e massagens subaquáticas. O estudo foi aprovado pelo comitê de ética da UFPE, parecer 1.759.097/2016. A capacidade funcional foi avaliada através de: medida do volume do membro a partir da perimetria, amplitude de movimento com sensor inercial, mobilidade funcional através do Timed Up and Go (TUG) e o questionário Lymphoedema Funtioning Disability and Health Questionnaire for Limb Lymphoedema (Lymph-ICF-LL). Resultados: Foram observadas mudanças volumétricas antes e depois do tratamento $(4,30,5$ para $3,90,6)$; melhora da amplitude de movimento de dorsiflexão (12,4 para 16,2) e flexão plantar (34,8 para 37,7); TUG 13,8" para 9,88") e escore médio do Lymph-ICF-LL de 4,6 para 3,2). Embora tenha sido evidenciada discreta mudança na perimetria, o aumento da amplitude de movimento do tornozelo contribuiu para o melhor desempenho do TUG e do escore Lymph-ICF-LL. Segundo a literatura, a redução do volume do membro e consequentemente, do peso dos mesmos contribui para a menor limitação dos movimentos articulares diminuindo sobrecargas que influenciam diretamente na mobilidade e funcionalidade dos indivíduos. Conclusão: a Fisioterapia Aquática contribuiu para melhorar a capacidade funcional da paciente. Esse resultado aponta para o fato que outros pacientes com o mesmo diagnóstico podem se beneficiar do tratamento no meio aquático, sobretudo pelos efeitos positivos da pressão hidrostática imposta que favorece a aquisição de melhores resultados funcionais no linfedema.

Palavras-chave: linfedema, hidroterapia, funcionalidade.

\title{
Fisioterapia aquática no lúpus eritematoso sistêmico associado aos sintomas da Chikungunya: um estudo de caso
}

Douglas Pereira Silva ${ }^{1}$, Ygor Dias Ferreira Lisboa², Carla Patrícia Novaes Santos Fechine ${ }^{3}$, Ulissis Freire Ayres Lima ${ }^{3}$

\author{
${ }^{1}$ Associação Paraibana de Ensino Renovado (ASPER), João Pessoa/PB, ${ }^{2}$ Departamento de \\ Fisioterapia Faculdades Asper, João Pessoa/PB, ${ }^{3}$ Curso de Bacharelado em Fisioterapia \\ Faculdades Asper, João Pessoa/PB
}

Email: fisioterapiadouglas@gmail.com

Introdução: Lúpus Eritematoso Sistêmico é uma doença autoimune, onde acomete diversos órgãos, pois o sistema imunológico ataca as células do próprio corpo, gerando inflamações principalmente nas articulações, no sistema nervoso central e renal. Assim como no Lúpus, a Chikungunya atinge também as articulações, e seus principais sintomas são: febre alta, cefaleia e mialgia. E a longo prazo, essas patologias podem desencadear outras complicações, como: anorexia, artrites e até depressão. Objetivos: Reduzir o quadro álgico, ganhar amplitude de movimento, melhorar o equilíbrio e a postura. Métodos: Trata-se de um estudo de caso, de caráter quantitativo, realizado com uma paciente com o diagnóstico do Lúpus associados aos sintomas da Chikungunya, na cidade de João Pessoa, onde o levantamento de dados foi obtido através da aplicação de um questionário semiestruturado. Os instrumentos utilizados foram a escala visual analógica para o nível da dor e a escala de equilíbrio de Berg. O tratamento consistiu em sessões da fisioterapia aquática, com duração de uma hora, duas vezes na semana, durante dezesseis semanas. Após a coleta de dados, os mesmos foram armazenados em uma planilha do Windows Microsoft Excel 2016, e foram analisadas estatísticas descritivas variáveis (caracterização da saúde, escala visual analógica da dor, amplitude de movimento e déficit de equilíbrio) e posteriormente distribuído em formato de tabelas. Número de aprovação do Parecer Comitê de ética em Pesquisa: 2.315.138. Resultados: O tratamento consistiu em atendimentos da fisioterapia aquática em sessões de uma hora, duas vezes na semana, durante dezesseis semanas. Analisamos que a paciente relata que sua saúde atual está excelente em comparação há um ano. A paciente também relatou interferências nas suas atividades sociais e interferências causadas por seus problemas emocionais em boa parte do tempo, problemas estes causados pelas doenças. Diante dos resultados apontados, a fisioterapia aquática apresenta uma melhora significativa no quadro álgico, amplitude de movimento e déficit de equilíbrio. É necessário um programa de tratamento que deve ser iniciado de preferência assim que o diagnóstico for confirmado, o tratamento deve ser realizado individualmente para cada paciente após sua 
avaliação visto que quanto mais rápida a iniciação do tratamento, melhor será o seu prognóstico. Conclusão: Diante dos resultados, podemos observar que o programa de fisioterapia aquática trouxe benefícios a paciente, mostrando melhora do quadro álgico, melhora na flexibilidade muscular, equilíbrio, bem-estar geral, e, portanto, sua qualidade de vida.

Palavras-chave: lúpus eritematoso sistêmico, chikungunya, hidroterapia.

\title{
Fisioterapia Aquática na paralisia cerebral atáxica: estudo de caso
}

\author{
Fechine CPNS ${ }^{1}$, Araújo JS ${ }^{1}$, Dantas MAS ${ }^{1}$, Maciel MES ${ }^{1}$, Sousa SCD ${ }^{1}$, Barros CA $^{2}$
}

${ }^{1}$ Docente do curso de Fisioterapia do Centro Universitário de João Pessoa - UNIPÊ, João Pessoa/PB, ${ }^{2}$ Discente do curso de Fisioterapia do Centro Universitário de João Pessoa - UNIPÊ, João Pessoa/PB

\section{Email: carlafechine@hotmail.com}

Introdução: A paralisia cerebral (PC) é uma disfunção permanente que acomete o tônus muscular, postura e movimento interferindo na atividade e participação da criança. Pacientes com PC apresentam déficit no controle postural em virtude do comprometimento da função motora e sensorial, além da perda do controle da motricidade seletiva com consequente prejuízo na funcionalidade. Na PC atáxica, a criança apresenta base alargada, dismetria, déficit nas reações posturais e coordenação motora. Nesse sentido, a fisioterapia aquática torna-se uma alternativa no tratamento das disfunções causadas pela PC, visto que a água reduz o efeito da gravidade permitindo que as crianças realizem atividades que não podem ser executadas em terra. $A$ fisioterapia aquática é um recurso importante na reabilitação e treinamento físico de crianças com PC, acarretando melhorias, dentre as quais se destacam o aumento na força muscular, equilíbrio postural, flexibilidade e condicionamento cardiorrespiratório. Objetivo: Avaliar o equilíbrio estático e dinâmico pré e pós-intervenção da fisioterapia aquática em um paciente com paralisia cerebral atáxica. Métodos: Trata-se de uma pesquisa descritiva, exploratória do tipo estudo de caso, realizada na Clínica Escola de Fisioterapia de uma Instituição de ensino superior no município de João Pessoa-PB. O estudo foi realizado com um paciente do sexo masculino, 14 anos de idade, com diagnóstico de PC atáxica. Foram realizados 20 atendimentos em piscina aquecida à $32^{\circ}$, com duração de 50 minutos, duas vezes por semana. Foi utilizado como instrumento de pesquisa (pré e pós-intervenção), a Escala de Equilíbrio Pediátrica que avalia o equilíbrio funcional de crianças na faixa etária de 05 a 15 anos. É formada por 14 itens e, para cada item, utiliza-se a pontuação de 0 a 4 . A pontuação máxima da escala é 56 pontos, quanto maior o escore, melhor o equilíbrio. Também foi utilizado o teste Timed Up and Go (TUG) que quantifica em segundos o tempo que o indivíduo realiza a tarefa de levantar de uma cadeira, caminhar 3 metros, virar, voltar e sentar novamente. A conduta de tratamento consistiu em exercícios para trabalhar o equilíbrio estático e dinâmico, por meio das técnicas do Halliwick (com ênfase no programa de 10 pontos) e Hidrocinesioterapia (aquecimento, alongamento e fortalecimento muscular, reeducação da marcha associada à turbulência). O presente estudo foi aprovado pelo Comitê de Ética em Pesquisa da Instituição em 2016 sob o número CAAE: 57363516.0.0000.5185. Resultados: Na PC existe um desajuste no controle postural normal que formam a base para a realização de movimentos funcionais contra a gravidade. Portanto, a fisioterapia aquática teve como objetivo aprimorar o equilíbrio estático e dinâmico, melhorar o controle da ativação muscular e aumentar a flexibilidade dos membros inferiores. Após 20 atendimentos de fisioterapia aquática, houve aumento na pontuação dos testes de equilíbrio: Escala de Equilíbrio Pediátrica inicial de 48 pontos e final de 53 pontos; o Timed Up and Go (TUG) evoluiu de 20 segundos para 11 segundos pós intervenção. Conclusão: Houve melhora no controle postural, estabilidade, força muscular e mobilidade, repercutindo nas suas atividades funcionais e padrão de marcha. Nesse sentido, a fisioterapia aquática pode ser considerada um recurso benéfico, para o tratamento da PC atáxica, associando a utilização dos princípios físicos da água com as técnicas de tratamento. Portanto, novos estudos são necessários com uma amostra maior de crianças com paralisia cerebral, para que os resultados sejam melhor evidenciados.

Palavras-chave: paralisia cerebral, ataxia, equilíbrio, fisioterapia aquática 


\title{
Aumento da distância percorrida na marcha em crianças com paralisia cerebral após Fisioterapia Aquática
}

\author{
Vieira $S^{1}$, Santos $\mathrm{LF}^{1}$, Nascimento $\mathrm{KS}^{2}$, Caldas-Batista $\mathrm{TS}^{3}$, Schneiberg $\mathrm{S}^{4}$ \\ ${ }^{1}$ Egressos Fisioterapeutas, Departamento de Fisioterapia, Universidade Federal de Sergipe \\ (UFS) -Campus Lagarto, Lagarto ISE, ${ }^{2}$ Fisioterapeuta, Clínica Physiomed, Lagarto/SE, \\ ${ }^{3}$ Preceptora de Estágio, Departamento de Fisioterapia, Universidade Federal de Sergipe, \\ ${ }^{4}$ Docente, Universidade Federal de Sergipe (UFS) - Campus Lagarto, Lagarto/SE
}

Email: sheilaschneiberg@gmail.com

Introdução: Crianças com paralisia cerebral (PC) apresentam alteração na marcha com velocidade e padrões de movimentos atípicos. Apesar da fisioterapia aquática ser bastante utilizada no tratamento de crianças com PC, ainda não foi investigado o efeito de um protocolo de treino por tarefas orientadas adaptado à fisioterapia aquática na marcha dessas crianças. Objetivos: Investigar a eficácia de um protocolo de fisioterapia aquática baseado em tarefas orientadas na marcha de crianças com PC. Métodos: Trata-se de um estudo de eficácia com delineamento experimental $n$ de 1, com múltiplas avaliações, do tipo A1BA2, onde A1 são avaliações realizadas antes do tratamento, B - avaliações durante o tratamento e A2 avaliações após um mês de tratamento, nesse desenho o sujeito é seu próprio controle. O estudo foi aprovado no CEP da UFS (CAAE: 43225914.7.0000.5546). Os instrumentos utilizados para avaliação foram o Teste Timed "Up \& Go" (TUG), o Teste de Caminhada de 6 minutos (TC6) e a escala de percepção de fadiga de Borg. A intervenção consistiu de atividades realizadas na piscina terapêutica na clínica Physiomed, uma vez por semana, com duração de 50 minutos, totalizando 10 atendimentos. Dois métodos estatísticos foram utilizados: o método visual da banda formada pela média e por dois desvios padrão calculados no baseline e o método do cálculo do tamanho do efeito da terapia. Resultados: Participaram desse estudo três crianças, todas classificadas como hemiplégicas espásticas, GMFCS I e MACS I. Todas as crianças apresentaram melhora significativa no TUG $(p<0,05$ e tamanho de efeitos após terapia grandes a enormes $>0,80$ e 1,30). No TC6 a criança 1 e 3 tiveram uma melhora na distância da marcha percorrida após o tratamento, mas a criança 2 não melhorou durante o tratamento e após 0 tratamento teve uma redução na distância percorrida. Todas crianças não tiveram relatos de fadiga de acordo com a avaliação de BORG durante o TC6. Conclusão: O protocolo de fisioterapia aquática baseado em tarefas orientadas mostrou-se eficaz para aumento da velocidade da marcha em todas três crianças e aumentou a distância percorrida em apenas duas crianças.

Palavras-chave: crianças, paralisia cerebral; fisioterapia aquática; tarefas orientadas, marcha, ensaio experimental de sujeito único.

Tchibum! Fisioterapia Aquática neurofuncional: uma adaptação das teorias contemporâneas do controle motor ao meio aquático

Schneiberg $\mathrm{S}^{1}$, Vieira $\mathrm{SS}^{2}$, Santos $\mathrm{LF}^{2}$

${ }^{1}$ Docente, Universidade Federal de Sergipe (UFS) - Campus Lagarto, Lagarto/SE, ${ }^{2}$ Egressos Fisioterapeutas, Departamento de Fisioterapia, Universidade Federal de Sergipe (UFS) -Campus Lagarto, Lagarto/SE

Email: sheilaschneiberg@gmail.com

Introdução: Na tentativa de entender como os movimentos são controlados foram desenvolvidas diversas teorias de controle motor. As teorias contemporâneas mais aceitas afirmam que 0 movimento é controlado não apenas pelo cérebro, mas com a contribuição de diversos sistemas 
que influenciam o movimento humano através de parâmetros intrínsecos e extrínsecos. A fisioterapia aquática vai influenciar essencialmente o controle do movimento adicionando um fator extrínseco que é o meio aquático e suas propriedades físicas, logo, um movimento realizado na água, não tem os mesmos parâmetros de controle do que um movimento realizado fora d'água. Objetivo: O objetivo principal desse estudo é propor uma adaptação do treino por tarefas orientadas realizado na fisioterapia neurofuncional para a fisioterapia aquática. O método de treino por tarefas orientadas é baseado na teoria contemporânea de controle motor dos sistemas dinâmicos. Métodos: Cinco casos clínicos são apresentados para estabelecer protocolos de intervenção, os casos clínicos foram: Acidente Vascular Cerebral (AVC), Traumatismo Raquimedular (TRM), Parkinson, Ataxia cerebelar, Paralisia Cerebral (PC). Seguindo o guideline de planejamento terapêutico proposto pela American Physical Therapy Association (APTA) as incapacidades funcionais dos casos clínicos foram descritas de acordo com a Classificação Internacional de Funcionalidade (CIF). O diagnóstico fisioterapêutico foi determinado para cada caso e quatro objetivos SMART identificados, então, a partir desses objetivos atividades orientadas a tarefas funcionais foram desenvolvidas. Resultados: Através dos casos clínicos é possível entender que o processo de adaptação da fisioterapia neurofuncional no meio aquático segue princípios biomecânicos influenciados pela propriedade física d'água e a relação das incapacidades funcionais de cada caso no ambiente aquático. Especial atenção deve ser dada a relação entre densidade relativa dos seguimentos corporais $\mathrm{x}$ incapacidade funcional $\mathrm{x}$ eixo de rotação (centro de gravidade e centro de flutuação) para cada modelo de disfunção neurológica apresentado nos casos clínicos. Conclusão: A adaptação de métodos de tratamentos da fisioterapia neurofuncional no meio aquático requer um conhecimento integrado das incapacidades funcionais decorrentes de disfunções neurológicas e de como elas reagem as propriedades físicas d'água. Com essa interação de conhecimentos o fisioterapeuta pode facilitar ou desafiar determinada tarefa funcional realizada na piscina terapêutica.

Palavras-chave: fisioterapia aquática; fisioterapia neurofuncional, tarefas orientadas, cif, casos clínicos.

\title{
Fisioterapia Aquática na microcefalia por Zika vírus: estudo de caso
}

\author{
Barros $\mathrm{CA}^{1}$, Fechine $\mathrm{CPNS}^{2}$, Dantas $\mathrm{MAS}^{2}$, Sousa $\mathrm{SCD}^{2}$, Maciel MES ${ }^{3}$ \\ ${ }^{1}$ Discente do curso de Fisioterapia do Centro Universitário de João Pessoa - UNIPÊ, João \\ Pessoa/PB, ${ }^{2}$ Docente do curso de Fisioterapia do Centro Universitário de João Pessoa - UNIPÊ, \\ ${ }^{3}$ Coordenadora do curso de Fisioterapia do Centro Universitário de João Pessoa - UNIPÉ
}

\section{Email: c.azevedobarros@gmail.com}

Introdução: A microcefalia caracteriza-se por uma má-formação cerebral, em que o crânio do recém-nascido se desenvolve de maneira inadequada, podendo afetar o desenvolvimento neuropsicomotor (DNPM), causando alterações cognitivas, motoras, visuais e auditivas. A fisioterapia assume papel fundamental na avaliação e na escolha das condutas adequadas para proporcionar o estímulo necessário no desenvolvimento motor dessas crianças e proporcionar melhora na qualidade de vida. Nesse sentido, a fisioterapia aquática (FA) por meio dos princípios físicos e do calor da água proporciona um ambiente lúdico e com vários estímulos motores e sensoriais potencializando experiências que não são vivenciadas em solo. Objetivo: Avaliar os efeitos da Fisioterapia Aquática na microcefalia por Zika vírus (ZIKV). Métodos: Caracteriza-se como um estudo exploratório e descritivo, do tipo estudo de caso, com abordagem quantitativa, realizada com uma criança do sexo masculino, 3 anos de idade, com diagnóstico confirmado de microcefalia por ZIKV. O estudo foi realizado na Clínica Escola de uma Instituição de ensino superior no município de João Pessoa-PB. Inicialmente foi realizado um exame físico funcional, onde foi observado: quadriplegia espástica com hipertonia grau 2 nos membros inferiores e grau 3 nos membros superiores, GMFCS nível V, ausência dos padrões motores básicos e das reações de equilíbrio e proteção, encurtamento isquiostibiais (ângulo poplíteo de $74^{\circ}$ bilateral) e iliopsoas (Thomas $40^{\circ}$ bilateral), limitação na abdução do quadril bilateral (5), dorsiflexão do tornozelo $\left(0^{\circ}\right)$. A intervenção na FA foi realizada na piscina aquecida a $32^{\circ}$, duas vezes por semana, com duração de 40 minutos, perfazendo um total de 16 atendimentos. Foram utilizadas 
técnicas, tais como: conceito Halliwick (enfatizando as rotações transversa e sagital), Hidrocinesioterapia (alongamento, mobilização passiva) e o Conceito Bobath adaptado na água (adequação do tônus muscular com manuseios passivos e lentos, estimulação das reações de equilíbrio e controle do tronco no rolo e tapete flutuante visando à estimulação do desenvolvimento sensório-motor). O presente estudo foi aprovado pelo Comitê de Ética em Pesquisa da instituição em 2018 sob o número CAAE: 93514218.6.0000.5176. Resultados: O calor da água associada à diminuição da ação gravidade reduz as forças de compressão nas articulações, aliviando a dor, promovendo relaxamento muscular e adequando o tônus muscular. Portanto, o objetivo da FA foi melhorar a ADM das articulações comprometidas, evitar a progressão das deformidades, estimular as reações posturais, simetria corporal e os padrões motores. Após a intervenção com a FA, observou-se melhora na extensibilidade do iliopsoas e isquiostibiais com um ângulo poplíteo de 50ㅜㅡㄹ além do aumento da ADM de abdução do quadril $\left(25^{\circ}\right)$ e dorsiflexão do tornozelo (15) comparado a pré-intervenção. Conclusão: Estes resultados demonstram que a Fisioterapia Aquática Pediátrica pode ser uma terapia eficaz e alternativa para crianças com microcefalia, visto que possibilitou um melhor relaxamento muscular, facilitando 0 aumento na amplitude de movimento das articulações comprometidas, evitando a progressão dos encurtamentos e deformidades, além da estimulação do desenvolvimento sensório-motor, proporcionando uma melhora na funcionalidade.

Palavras-chave: Zika vírus, microcefalia, função motora grossa, fisioterapia aquática. 